Aus der Abteilung Präventive Zahnmedizin, Parodontologie und Kariologie (Komm. Leiter: Prof. Dr. med. dent. M. Hülsmann) im Zentrum Zahn-, Mund- und Kieferheilkunde der Medizinischen Fakultät der Universität Göttingen

\title{
Klinische Studie zur möglichen Assoziation von rheumatoider Arthritis und Parodontitis
}

\author{
INAUGURAL - DISSERTATION \\ zur Erlangung des Doktorgrades \\ für Zahnheilkunde \\ der Medizinischen Fakultät \\ der Georg-August-Universität zu Göttingen
}

\author{
vorgelegt von \\ Sven-Olav Pabel \\ aus
}

Göttingen

Göttingen 2011 
Dekan: Prof. Dr. med. C. Frömmel

I. Berichterstatter: Prof. Dr. med. dent. R. Mausberg

II. Berichterstatter/in: Prof. Dr. med. Dr. med. dent. G. Wiese

III. Berichterstatter/in:

Tag der mündlichen Prüfung: 


\section{Inhaltsverzeichnis}

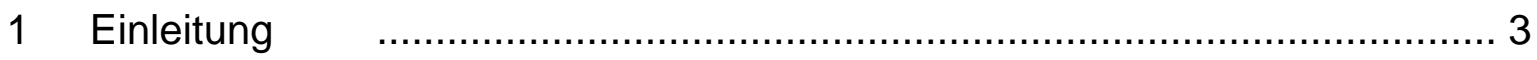

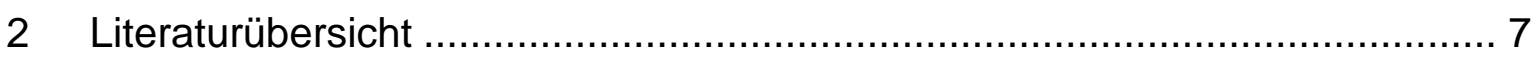

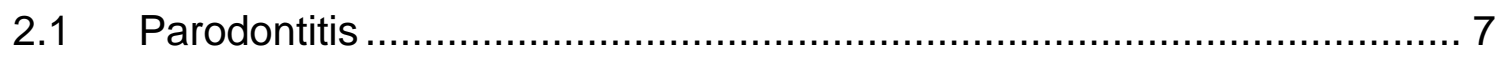

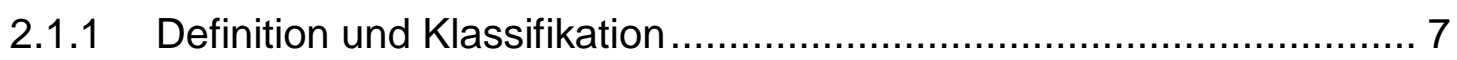

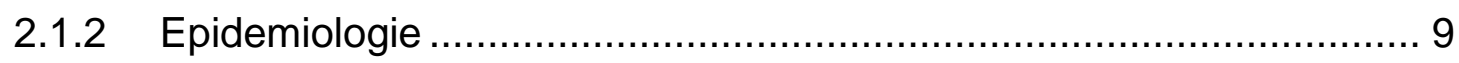

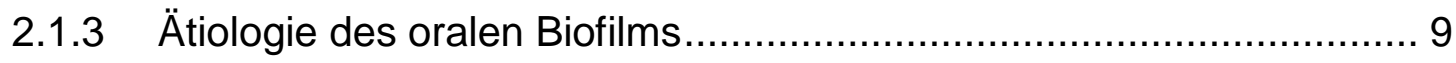

2.1.4 Pathogenese der Parodontitis ................................................. 12

2.1.5 Parodontopathogene Mikroorganismen ....................................... 16

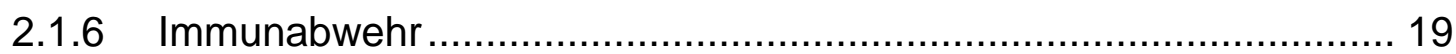

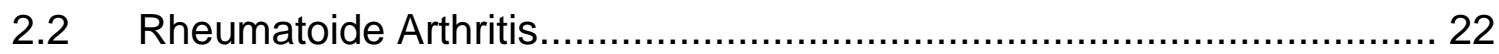

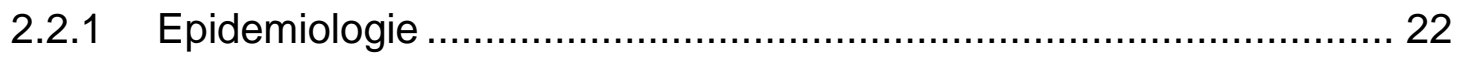

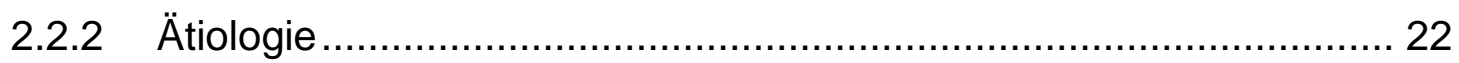

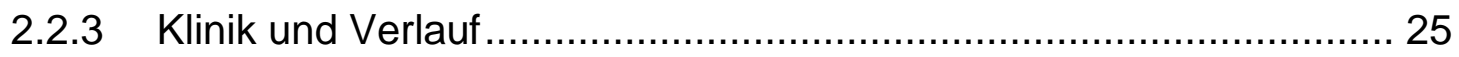

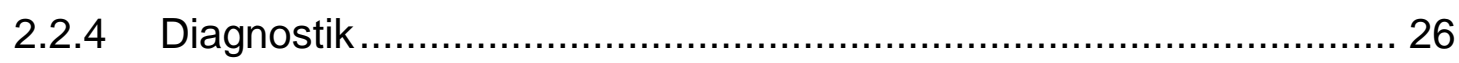

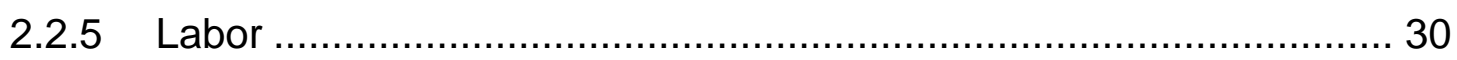

2.2.6 Therapiemöglichkeiten.............................................................. 32

2.3 Parodontitis als Manifestation einer Systemerkrankung......................... 33

2.4 Parodontitis und rheumatoide Arthritis .............................................. 35

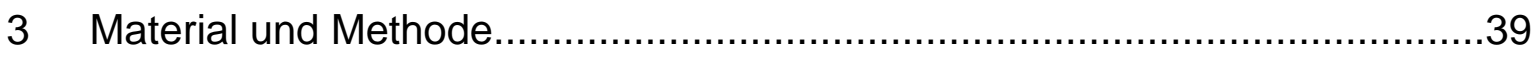

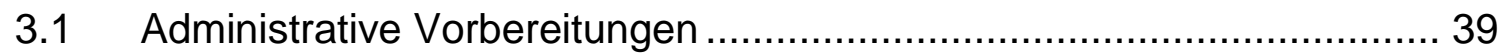

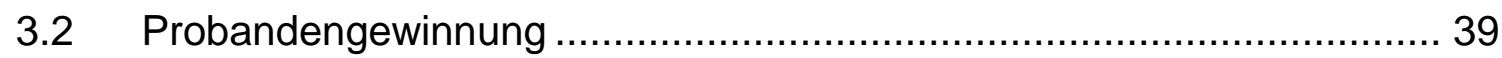

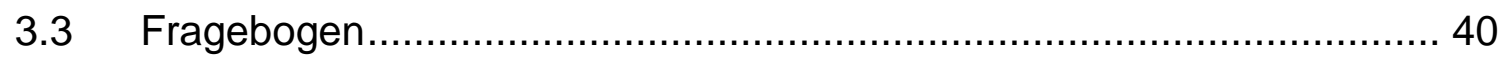

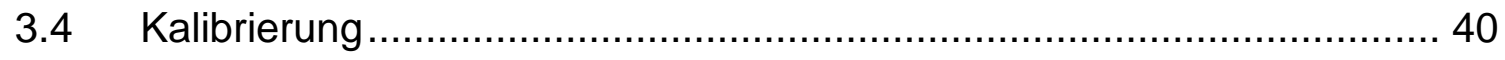

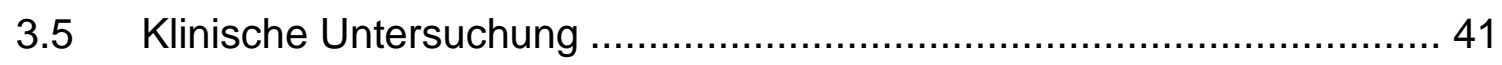

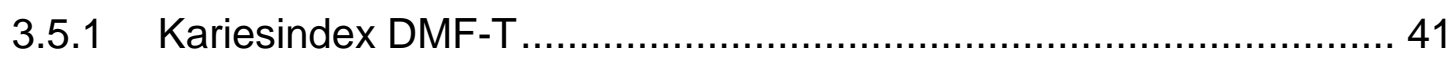

3.5.2 Parodontal-Screening-Index (PSI) ........................................... 41 
3.5.3 Klinische Diagnosefindung …................................................. 43

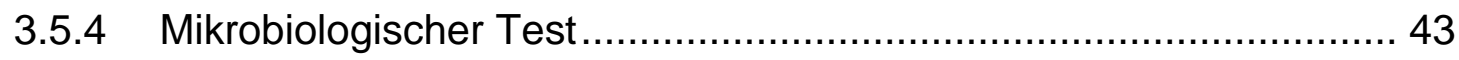

3.5.5 Bestimmung des IL-1-Polymorphismus (Genotypisierung) ............... 44

3.6 Auswertung der Ergebnisse und Statistische Methodik ........................ 45

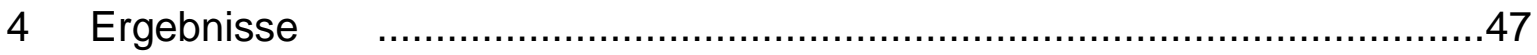

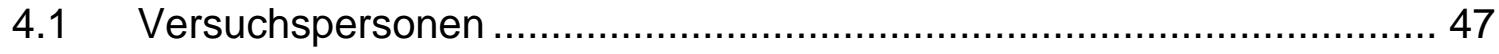

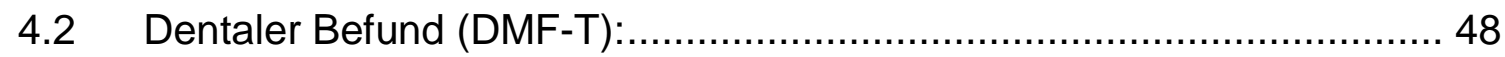

4.3 Parodontaler Screening Index (PSI) .................................................... 49

$4.4 \quad$ IL-1-Polymorphismus ................................................................. 51

4.5 Zusammenhang zwischen parodontalem Zustand und Genotyp (IL-1-

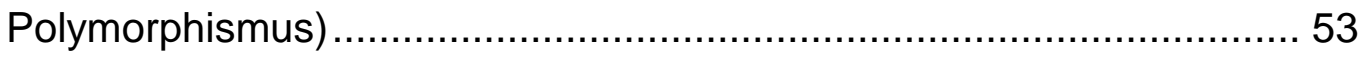

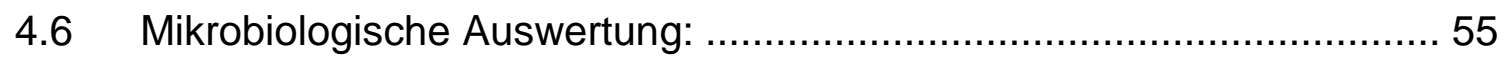

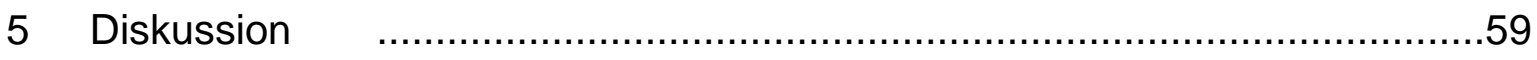

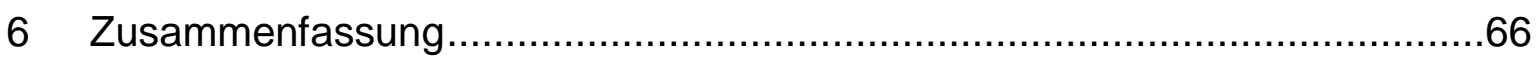

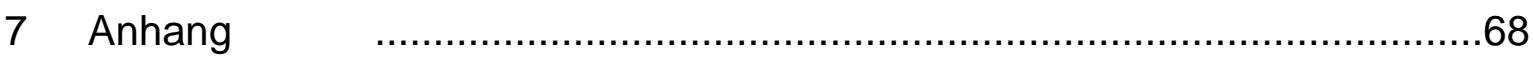

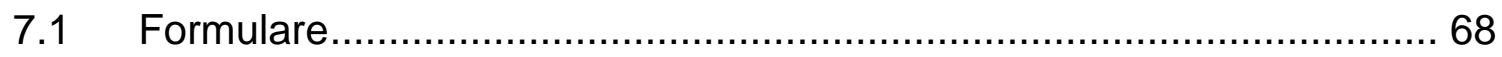

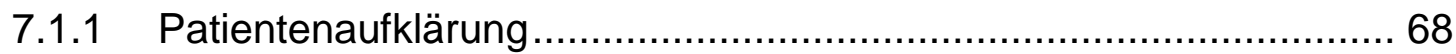

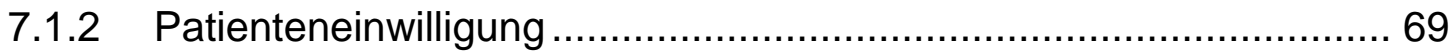

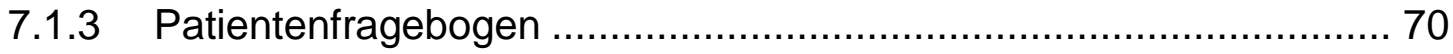

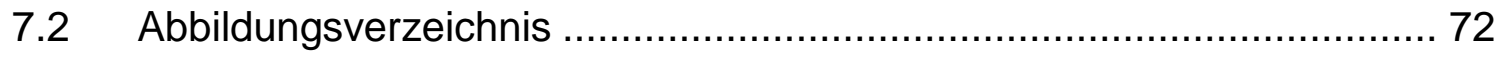

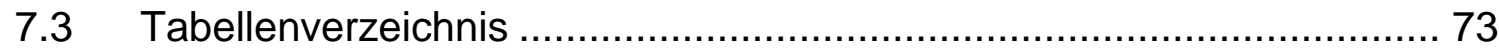

7.4 Bisherige Veröffentlichungen der Ergebnisse ...................................... 74

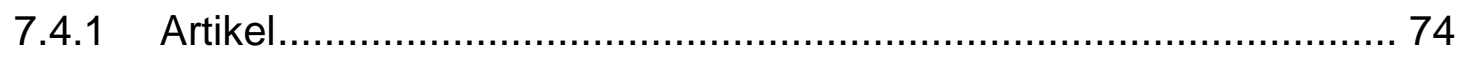

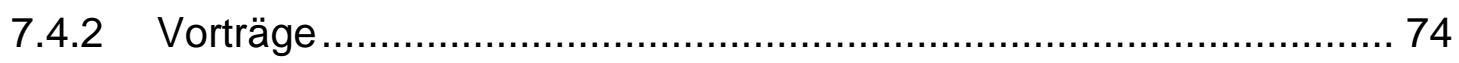

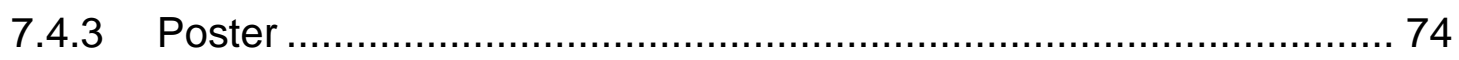

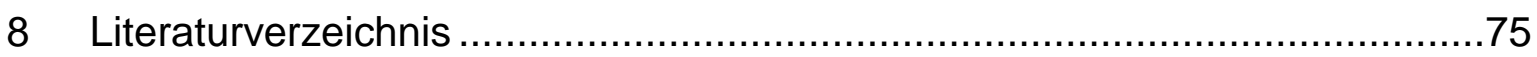




\section{Einleitung}

Entzündliche Erkrankungen des Zahnhalteapparates, d.h. Gingivitis und Parodontitis, gehören mit einer Prävalenz von $80-90 \%$ zu den weltweit am meisten verbreiteten Erkrankungen (Petersen 2003, 2009; Micheelis und Schiffner 2006). Die Parodontitis ist durch den irreversiblen Verlust von Bindegewebe und Knochen des Zahnhalteapparates gekennzeichnet (Page und Kornman 1997). Primäre Ursache dieser Erkrankung ist die mikrobielle Besiedelung der Mundhöhle mit komplexen Biofilmen aus verschiedenen parodontalpathogenen Bakterien (XiménezFyvie et al. 2000; Haffajee und Socransky 2006). Dabei spielen in der subgingivalen Plaque verschiedene überwiegend gram-negative Bakterienspezies eine entscheidende Rolle. Diese sind in einem strukturierten Biofilm aus verschiedenen Bakterien organisiert und können entsprechend ihrer Pathogenität in der Entstehung bzw. der Progression einer Parodontitis verschiedenen Komplexen zugeordnet werden (Socransky und Haffajee 2002); eine besondere Bedeutung bei einer aktiven Parodontitis wird dabei dem roten Komplex mit Porphyromonas gingivalis $(P g)$, Tanerella forsythia $(T f)$ und Treponema denticola $(T d)$ zugeschrieben.

Im Sinne einer opportunistischen Infektion sind zum einen die Menge und Virulenz der Mikroorganismen und zum anderen Resistenzfaktoren des Wirtes für die Progression der parodontalen Destruktion von entscheidender Bedeutung (Listgarten 1986; Page und Kornman 1997). Darüber hinaus sind die Ätiologie und Pathogenese jedoch multifaktoriell und werden durch ein komplexes Zusammenspiel angeborener, erworbener und verhaltensbedingter Risikofaktoren (z.B. Zigarettenkonsum, Stress und Alkoholkonsum) (Page und Kornman 1997; Genco et al. 1999; Dalla Vecchia et al. 2005; Heasman et al. 2006), sowie genetischer Faktoren (Interleukin-1-Polymorphismen) determiniert (Page und Kornman 1997; López et al. 2005; Huynh-Ba et al. 2007). Zum Beispiel zeigen systemische Erkrankungen, wie Diabetes mellitus, orale Symptome und können den Verlauf einer Parodontitis negativ beeinflussen (Cutler et al. 1999; Mealey und Oates 2006).

Auf der anderen Seite stellt die Mundhöhle eine Eintrittspforte für Mikroorganismen in den Blutkreislauf dar. Entzündungen im Bereich der Mundhöhle können im Sinne einer (chronisch-rezidivierenden) Bakteriämie Auswirkungen auf die Allgemeingesundheit haben. Je stärker sich die orale Infektion bzw. Entzündung darstellt, desto höher ist das Risiko einer Bakteriämie (Socransky und Haffajee 2002; 
Dye et al. 2005). Des Weiteren sind Assoziationen mit verschiedenen systemischen Erkrankungen, wie z.B. Herz-Kreislauf-Erkrankungen, Myokardinfarkt, Frühgeburt sowie Arteriosklerose und Schlaganfall beschrieben (Scannapieco 1998; Haraszthy et al. 2000; D'Aiuto et al. 2005; Doĝan et al. 2005; Mealey und Oates 2006; Seymour et al. 2007; Persson und Persson 2008; Pitiphat et al.2008; Lockhart et al. 2009; Tonetti 2009).

So gibt es in den letzten Jahren zunehmend Hinweise für eine Assoziation zwischen Parodontitis und rheumatischen Erkrankungen. Bislang konnte jedoch nicht eindeutig geklärt werden, ob das gemeinsame Auftreten parodontaler und rheumatischer Erkrankungen kausal oder koinzidenziell ist (de Pablo et al. 2009).

Nach vorliegenden Kenntnissen haben Patienten mit rheumatischen Systemerkrankungen ein erhöhtes Risiko, eine Parodontitis zu entwickeln, weisen erhöhten Zahnverlust sowie signifikant mehr Attachmentverlust als Gesunde auf (Mercado et al. 2000; 2001; Kobayashi et al. 2007; Pischon et al. 2008, 2010; de Pablo et al. 2008; Dissick et al. 2010). Darüber hinaus scheint eine Wechselbeziehung zwischen beiden Erkrankungen zu bestehen: So wurde ein positiver Effekt einer nicht-chirurgischen Parodontitistherapie auf die Symptomatik der rheumatoiden Arthritis beschrieben (Ortiz et al. 2009).

Während sich die Ätiologie beider Erkrankungen unterscheidet, sind zugrunde liegende Pathogenitätsmechanismen auffallend ähnlich (Mercado et al. 2003). Somit scheint ein Zusammenhang zwischen beiden Erkrankungen plausibel; vor allem weisen beide Erkrankungen das Vorliegen einer Entzündungsreaktion als wesentliche Gemeinsamkeit auf. Ähnlich wie die Parodontitis am Zahnhalteapparat ist die rheumatoide Arthritis als chronisch-entzündliche Gelenkerkrankung durch einen Verlust von bindegewebigen und mineralisierten Strukturen, der so genannten Synovialmembran, gekennzeichnet (Detert et al. 2010). Die Ätiologie der rheumatoiden Arthritis ist bisher jedoch nicht eindeutig geklärt. Ebenso wie bei der Parodontitis werden neben individuellen Faktoren (Alter, Geschlecht) genetische Faktoren (humanes Leukozyten-Antigen (HLA) -Genotyp) und Umweltfaktoren (Alkoholund Zigarettenkonsum), aber auch bakterielle Infektionen diskutiert (Mercado et al. 2003; Alamanos und Drosos 2005; Costenbader et al. 2006; Detert et al. 2010). Des Weiteren scheint bei beiden Erkrankungen die Reaktion auf den jeweiligen Entzündungsreiz unverhältnismäßig stark zu sein; auch weisen sie ein ähnliches Entzündungsmuster auf. So ist die Entzündungsreaktion beider Krankheitsbilder 
durch den Nachweis entzündungsfördernder Zytokine, wie IL-1, IL-6 und TNF- $\alpha$, gekennzeichnet, die im weiteren Verlauf strukturschädigende Substanzen wie Prostaglandin- $E_{2} \quad\left(P G-E_{2}\right)$ und Matrix-Metallproteinasen (MMP) freisetzen (Greenwald und Kirkwood 1999; Mercado et al. 2003; Havemose-Poulsen et al. 2005). IL-1 gilt daher vor allem bei dem Vorliegen einer rheumatoiden Arthritis als ein wichtiger diagnostischer Parameter (van den Berg 2000). Außerdem wurde der Schweregrad einer Parodontitis mit Varianten eines vorliegenden IL-1-Polymorphismus und einer möglichen Assoziation in Verbindung gebracht. Hierfür konnte jedoch bisher keine gesicherte Evidenz in der Ätiologie der Parodontitis aufgezeigt werden (Huynh-Ba et al. 2007).

Allerdings scheint es möglich, dass Personen, bei denen sowohl eine Parodontitis als auch eine rheumatoide Arthritis vorliegen, an einer systemischen Dysregulation der Entzündungsreaktion leiden könnten (Mercado et al. 2003). Diese Vermutung ist jedoch bis heute nicht verifiziert. Dabei wäre ein Zusammenhang zwischen beiden Erkrankungen auf der Entzündungsebene durch z.B. Vorliegen eines IL-1-Polymorphismus denkbar, der in der Literatur allerdings bisher nicht beschrieben wurde. Jedoch konnte aufgezeigt werden, dass sowohl bei Parodontitis als auch bei rheumatoider Arthritis ähnliche IL-1-Polymorphismen auftreten und ein mögliches Risiko für diese Erkrankungen darstellen (Havemose-Poulsen et al. 2007; Kobayashi et al. 2007). Somit stellt sich die Frage, ob ein IL-1-Polymorphismus bei Patienten mit rheumatoider Arthritis einen Einfluss auf den Parodontalzustand haben könnte. Darüber hinaus wäre denkbar, dass die entsprechende Medikation einen Einfluss auf die parodontale Situation der Rheumatiker hat. Daten hierfür lassen sich bisher nicht finden.

Ziel der Studie war es, den aktuellen Parodontalzustand und die Bakterienlast bei Patienten mit rheumatoider Arthritis zu erfassen sowie verschiedene Einflussfaktoren wie Entzündungsrisiko (IL-1-Polymorphismus), Tabakkonsum, Rheumafaktor und Medikation zu identifizieren und auf mögliche Assoziationen zu untersuchen.

Folgende Hypothesen wurden formuliert:

- Rheumatoide Arthritis-Patienten mit IL-1-Polymorphismus weisen ein erhöhtes Risiko für Parodontitis auf. 
- Rheumatoide Arthritis-Patienten weisen eine erhöhte Prävalenz stark parodontalpathogener Bakterien (Aggregatibacter actinomycetemcomitans (Aa), Porphyromonas gingivalis $(\mathrm{Pg})$, Treponema denticola (Td), Tannerella forsythia (Tf)) auf.

- Bakterienlast und Rheumafaktor stehen in einem engen Zusammenhang. 


\section{Literaturübersicht}

\subsection{Parodontitis}

\subsubsection{Definition und Klassifikation}

Als Parodontitis bezeichnet man eine bakteriell bedingte Entzündung des Zahnhalteapparates, des so genannten Parodontiums. Sie ist in allen Altersstufen und in verschiedenen Formen anzutreffen und kann in irreversiblem Verlust des Parodontiums der betroffenen Zähne und variabel raschem und tief reichendem Knochenabbau resultieren (Schroeder 1997), der bei Ausbleiben therapeutischer Maßnahmen Zahnverlust zur Folge haben kann. Nach Schroeder (1997) sind die wesentlichen Komponenten einer Parodontitis Knochenabbau, Tiefenproliferation und Ulzeration des Saumepithels sowie der progressive bindegewebige Attachmentverlust.

Die primäre Ursache einer Parodontitis besteht in einer lokalen, subgingivalen bakteriellen Infektion, welche oftmals im Zusammenhang mit dem Vorhandensein subgingivaler Plaque, heute als subgingivaler Biofilm benannt, steht (Schroeder 1997). Darüber hinaus sind die Ätiologie und Pathogenese jedoch multifaktoriell und werden durch ein komplexes Zusammenspiel angeborener, erworbener und verhaltensbedingter Faktoren, sog. Risikofaktoren, determiniert. Zudem zeigen viele systemische Erkrankungen orale Symptome und ihre Therapie kann den Verlauf oraler Erkrankungen ebenfalls beeinflussen (Schroeder 1997).

Grundsätzlich unterscheidet man eine apikale (von der Wurzelspitze ausgehende) von einer marginalen (vom Zahnfleischsaum ausgehende) Parodontitis, welche auch ineinander übergehen können (Paro-Endo-Läsionen) (Schroeder 1997, Schroeder 2000).

Veränderungen des Parodontiums werden dahingehend unterteilt, ob sie allein die Gingiva betreffen (Gingivale Erkrankungen), oder ob auch die restlichen Strukturen des Parodonts involviert sind (Parodontale Erkrankungen). Zusätzlich können entzündliche von nicht-entzündlichen Prozessen unterschieden werden. Aufgrund der engen pathophysiologischen Zusammenhänge können die Erkrankungen jedoch auch ineinander übergehen. Da einige parodontale Veränderungen im klinischen Bild auch anderen Mundschleimhauterkrankungen ähneln, muss man auch diese in einer vollständigen Klassifikation berücksichtigen. 
Nach der 1999 von der American Academy of Periodontology (AAP) neu formulierten internationalen Klassifizierung von Parodontalerkrankungen werden die verschiedenen Parodontopathien nach folgenden acht Erkrankungskategorien unterschieden (Deutsche Gesellschaft für Parodontologie 2002):

\section{Gingivale Erkrankung}

2. Chronische Parodontitis

3. Aggressive Parodontitis

4. Parodontitis als Manifestation einer Systemerkrankung

5. Nekrotisierende Parodontalerkrankung

6. Parodontalabszesse

7. Parodontitis im Zusammenhang mit endodontalen Läsionen

8. Entwicklungsbedingte oder erworbene Deformationen und Zustände.

Die chronische Parodontitis ist die häufigste Form aller entzündlichen parodontologischen Erkrankungen (Page und Schroeder 1976). Ein Hauptsymptom ist die Ausbildung parodontaler Taschen als Folge des Stützgewebeverlustes (Knochenabbau). Die chronische Parodontitis kann in jedem Lebensalter entstehen, wobei sie am häufigsten im Erwachsenenalter nach dem 35. Lebensjahr auftritt. In der Regel nehmen Prävalenz und Schwere mit dem Alter zu (Deutsche Gesellschaft für Parodontologie 2002).

Während die bakterielle Plaque als ätiologischer Faktor eine Rolle spielt, ist die Pathogenese (und damit die Progression) durch die Wirtsreaktivität beinflusst. Charakteristisch hierfür ist die langsame Progression, aber es kann auch zu Aktivitätsschüben kommen. Oftmals steht die parodontale Destruktion mit lokalen Reizfaktoren, wie beispielsweise überstehenden Restaurationsrändern, in klarem Zusammenhang (Deutsche Gesellschaft für Parodontologie 2002). Subgingivaler Zahnstein (Konkrement) ist häufig anzutreffen; die Plaquezusammensetzung zeigt sich jedoch variabel. Mögliche Kofaktoren können Systemerkrankungen wie Diabetes mellitus oder HIV-Infektionen, lokale Faktoren (meist iatrogener Art wie z.B. überstehende Füllungsränder), Tabakkonsum und emotionaler Stress sein. Man unterscheidet eine lokalisierte chronische von einer generalisierten Parodontitis 
(Schroeder 1997, Deutsche Gesellschaft für Parodontologie 2002). Die chronische Parodontitis kann nach dem Ausmaß folgendermaßen unterteilt werden:

a) Lokalisiert: bis zu $30 \%$ der Zahnflächen befallen

b) Generalisiert: mehr als 30\% der Zahnflächen befallen.

Zusätzlich wird der Schweregrad der Erkrankung entsprechend dem Attachmentverlust in leicht/mild (1-2 mm), mittel/mäßig (3-4 mm) oder schwer ( $\geq 5 \mathrm{~mm}$ ) eingeteilt (Deutsche Gesellschaft für Parodontologie 2002).

\subsubsection{Epidemiologie}

Über 95\% der Bevölkerung in den zivilisierten Ländern der Erde leiden unter parodontalen Erkrankungen (Schroeder 2000).

Die Vierte Deutsche Mundgesundheitsstudie (DMS IV) ergab eine Verbreitung von Parodontopathien von annähernd 100\% der Bevölkerung (Micheelis und Schiffner 2006). Fortgeschrittene Formen der Parodontitis, die mit drohendem Zahnverlust einhergehen, lagen bei über 20\% der Erwachsenen vor. Dabei steigt der strukturelle Verlust des Zahnhalteapparates mit zunehmendem Lebensalter an. Neueste epidemiologische Daten aus dem Jahr 2006 zeigen weiterhin eine hohe Prävalenz der Parodontitis; so leiden ca. 37 Millionen Erwachsene an einer moderaten (Altersgruppe: 35 - 74 Jahre $\rightarrow$ ca. 24 Mio.) bis schweren (Altersgruppe: 35 - 74 Jahre $\rightarrow$ ca. 13 Mio.) Parodontitis (Micheelis und Schiffner 2006).

Auf der Grundlage epidemiologischer Erhebungen schlussfolgert Kleber (2000), dass die meisten Erwachsenen in unterschiedlichem Ausmaß von gingivalen Erkrankungen oder chronischen Parodontitiden betroffen sind.

\subsection{3 Ätiologie des oralen Biofilms}

Die häufigsten Erkrankungen des Parodontiums sind plaquebedingte entzündliche Veränderungen an Gingiva und Parodont (Rateitschak et al. 1989). Parodontale Veränderungen sind dabei oft die Folge körpereigener Reaktionen auf traumatische und/oder infektiöse Geschehen. Somit muss die Ätiologie pathologischer parodontaler Veränderungen als Resultat der Bakterieneinwirkung des Zahnbela- 
ges und der Wirtsabwehr des betroffenen Menschen gesehen werden (Rateitschak et al. 1989). Zudem stellt die Parodontitis eine Krankheitsform mit überwiegend klar erkennbaren klinischen Merkmalen und speziellen Befunden hinsichtlich der Wirt-Bakterien-Interaktion dar.

Der ätiologisch wichtigste Faktor bei der Entstehung einer Parodontitis ist der Zahnbelag, die so genannte Plaque. Unter Plaque versteht man einen strukturierten, zähen, gelblichen Zahnbelag, welcher aus Bakterien und deren Stoffwechselprodukten sowie Glykoproteinen des Speichels besteht (Rateitschak et al. 1989). Diese Art des Zahnbelages ist nicht abspülbar, sondern muss mechanisch entfernt werden. Es wird zwischen supra- und subgingivaler Plaque unterschieden. Supraund subgingivaler Zahnstein (subgingival: Konkremente) entstehen durch Mineralisierung der Plaque (Rateitschak et al. 1989). Diese beginnt an Kristallisationskernen in der extrazellulären Matrix oder an Strukturen zerfallender oder lebender Bakterienzellen. Zahnstein, bestehend aus Kalziumphosphatkristallen, ist immer von einer Schicht nichtkalzifizierter Plaque bedeckt und stellt deren bedeutsamsten Retentionsfaktor dar (Sanderink et al. 2004).

Man bezeichnet die Feinstruktur der Plaque als Biofilm (Sanderink et al. 2004). Biofilme sind räumlich dreidimensional organisierte Bakterienpopulationen, welche mit einer Oberfläche verbunden und in eine extrazellulären Matrix eingebettet sind (Sanderink et al. 2004). Die extrazelluläre Matrix dient als Gerüst und Schutzstruktur des Biofilms, um die Mikroorganismen zu einer kohärenten Masse zu vereinigen; sie enthält als Hauptbestandteil von den Mikroorganismen gebildete extrazelluläre Polysaccharide und dient als Nahrungsspeicher für die Bakterien (Sanderink et al. 2004). Viele der adhärenten Bakterienarten gehen miteinander Stoffwechselsymbiose ein, kommunizieren untereinander, schaffen und erzeugen Mikrokreisläufe sowie mikroökologische Nischen (Sanderink et al. 2004). Einzelne Nischen interagieren untereinander derart, dass sie sich gegenseitig über Botenstoffe wie Metabolite und Nährstoffe aktiv unterstützen. Biofilme werden als eine geschützte Form des mikrobiellen Wachstums angesehen, welche die Überlebensfähigkeit von Mikroorganismen erhöht (Sanderink et al. 2004). Nach Sanderink et al. (2004) stellt dies einen im Laufe der Evolution gewonnenen Selektionsvorteil dar, welcher kaum überwindbar ist. Dadurch können sich Biofilme erfolgreich der Wirtsabwehr, antimikrobiellen sowie lokalen und systemischen 
antibiotischen Substanzen widersetzen. Eine Entfernung kann nicht allein durch gute Mundhygienemaßnahmen erreicht werden.

Die supragingivale Plaque kann sich bei inadäquater Abwehrleistung der Sulkusflüssigkeit und/oder unzureichender Mundhygiene nach subgingival ausdehnen. Dabei produzieren die Bakterien der supragingivalen Plaque verschiedene Stoffwechselprodukte, durch deren Einwirken das marginale Gewebe zur verstärkten Exsudation und Migration von Leukozyten provoziert wird. Das Saumepithel Iockert sich auf und die Mikroorganismen können in das subgingivale Bindegewebe gelangen (Rateitschak et al. 1989). Bei der Entwicklung der subgingivalen Plaque bereiten Erstbesiedler das Biotop für nachfolgende Mikroorganismen vor. Es liegen von vornherein aber eher anaerobe Bedingungen vor. Unterschieden wird zwischen adhärenter Plaque, die in vielen strukturellen Aspekten der supragingivalen Plaque entspricht, und nichtadhärenter subgingivaler Plaque (schwimmende Plaque). Die zahnadhärente, sich nach apikal ausbreitende Plaque besteht noch weitgehend aus grampositiven aeroben nicht-motilen Kokken und Stäbchen (Schroeder 1997). Es erfolgt durch weitere Vermehrung der Bakterien und Hinzukommen gramnegativer Bakterien die Ausbreitung nach subgingival. Dadurch wird die Bildung einer gingivalen Tasche begonnen. Auf dem Sulkus- bzw. Taschenepithel ist nun die nichtadhärente Plaque anzufinden, die keine definierte intermikrobielle Matrix hat. In ihr sind Leukozyten zwischen Bakterien- und Epithelzellen vorhanden. Diese Plaque führt zu einer Gingivitis (Schroeder 2000). Vor allem bei schnell fortschreitenden parodontalen Entzündungen bzw. aggressiv verlaufenden Parodontitiden kommt es zu einer Dominanz der virulenten nicht-adhärenten Plaque gegenüber der adhärenten.

Kommt es zur Bildung einer parodontalen Tasche, nimmt die anteilige Menge der gramnegativen Bakterien bis auf $90 \% \mathrm{zu}$. Die subgingivale Plaque ist permanent von Sulkusflüssigkeit umgeben. Diese enthält sämtliche humoralen infektionsvermeidenden und kontrollierenden Abwehrstoffe wie Antikörper, vor allem polymorphkernige neutrophile Granulozyten und Komplementproteine (Schroeder 2000).

Von entscheidender Bedeutung für die pathogene Wirkung der Plaque ist die Tatsache, dass es sich hierbei um einen mikrobiellen Biofilm handelt. Durch Proliferation und Reifung entwickelt sich der Biofilm zu einer Kolonie, die in der Lage ist, sich bestimmten Umweltbedingungen anzupassen. 
Der Biofilm gilt als sehr zähe, sessile Lebensform potentiell pathogener Bakterien, die in diesem Verbund ihre negativen Qualitäten potenzieren können (Netuschil 2005). Die Pathogenität der Plaque bzw. des Biofilms variiert mit der Art und der Häufigkeit der vorhandenen Bakterienspezies; dabei ist nicht jeder Biofilm pathogen (Schroeder 1997).

Subgingivale Biofilme, vor allem ihre nichtadhärenten Anteile, sind ätiologisch mit marginalen Parodontitiden assoziiert. Die Biofilmbakterien können sich vervielfältigen und auf der Wurzeloberfläche anlagern. Sie setzen kontinuierlich Antigene (Lipopolysaccharide) frei, welche die Produktion spezifischer Antikörper bewirken. Aufgrund der mangelnden Penetration können Antikörper und Phagozyten nicht durch die extrazelluläre Schleimschicht (Glycocalyx) hindurch, um die Bakterien innerhalb des Biofilms zu bekämpfen. Auch Individuen mit exzellenten zellulären und humoralen Immunreaktionen gelingt es nicht, die Biofilminfektionen mit ihrer körpereigenen Abwehr zu vermeiden. Durch die entzündliche Immunantwort, welche durch die Biofilmbakterien angeregt und unterhalten wird, kommt es zur Zerstörung des Bindegewebes, des parodontalen Ligaments und des alveolären Knochens (Schroeder 1997; Sanderink et al. 2004).

\subsubsection{Pathogenese der Parodontitis}

Die Parodontopathien entstehen durch Wechselwirkungen zwischen äußeren und inneren Umwelteinflüssen sowie dem Ergebnis funktioneller und biologischer Unstimmigkeiten (Kleber 1998). Als primäre Ursache für entzündliche Parodontalerkrankungen gilt die mikrobielle Besiedelung der Mundhöhle. Darüber hinaus sind die Ätiologie und Pathogenese sowie Progression jedoch multifaktoriell und werden durch ein komplexes Zusammenspiel angeborener (genetischer), erworbener und verhaltensbedingter Faktoren determiniert (Rateitschak et al. 1989; Schroeder 1997). Abbildung 1 zeigt die Ätiologie und Pathogenese der Parodontitis unter Berücksichtigung verschiedener Einflussfaktoren (Page und Kornman 1997). 


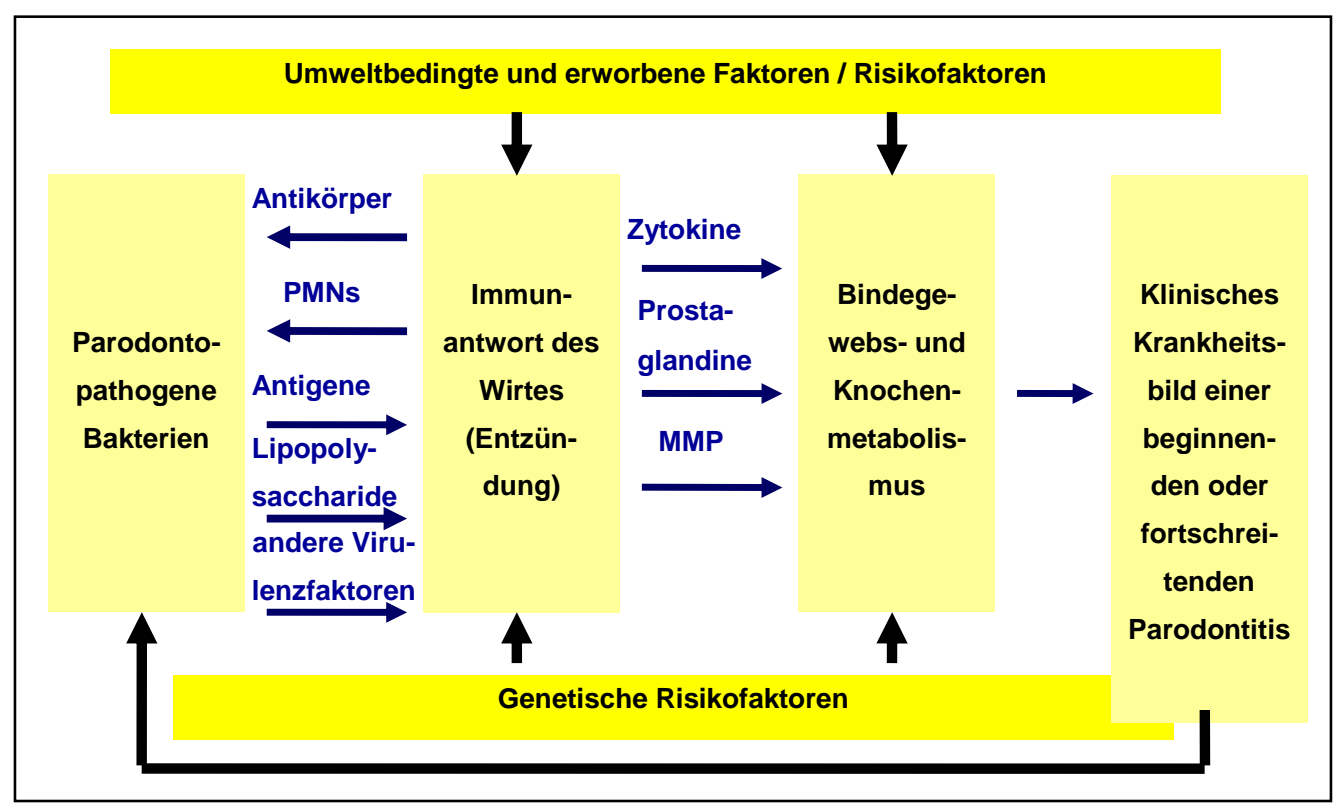

Abb. 1: $\quad$ Ätiologie und Pathogenese der Parodontitis (nach Page \& Kornman 1997, S.11)

Den Verlauf und den Schweregrad einer Parodontitis können psychosomatischer Stress, Rauchen, Ernährungsgewohnheiten, Diabetes mellitus oder HIV und AIDS-Manifestation sowie Bluterkrankungen (z.B. Leukämie), Osteoporose und Behandlung mit immunsuppressiven Medikamenten (wie z.B. bei rheumatoider Arthritis) modifizieren (Kinane und Lappin 2001; Kinane und Hart 2003).

Die Anfälligkeit des Organismus für parodontale Erkrankung scheint dabei durch verschiedene hereditäre Einflüsse wie Funktionsstörungen neutrophiler Granulozyten, Polymorphismen im IL-1- oder Fc-II-Gen oder Mutationen in den Genloci für lgG-2 gesteigert zu werden. Des Weiteren können aber auch mechanische Reinigungshindernisse, z.B. Zahnschief- oder engstände, Zahnstein, Prothesenklammern, überstehende Kronenränder, festsitzende kieferorthopädische Apparaturen, die Speichelmenge und -qualität sowie traumatisierende Okklusion modifizierende Faktoren sein (Salvi et al. 1997; Oliver et al. 1998; Page 1999).

Grundlage hierfür ist eine meist polymikrobielle Infektion mit parodontopathogenen Mikroorganismen des oralen Biofilms (Socransky et al. 2002; Socransky und Haffajee 2002). Jedoch erfolgt dabei die Bakterienwirkung nicht ausschließlich allein bzw. direkt am Wirkungsort. So kann eine Schädigung des Parodontiums vielmehr auch ohne eine bakterielle Invasion in den entsprechenden Kompartimenten des Zahnhalteapparates durch die Immunantwort des Wirts auf den bakteriellen Reiz hervorgerufen werden (Mombelli 2003). 
Aktuelle Erkenntnisse bestätigen eine Korrelation zwischen Plaqueansammlung, Entzündungsgrad der Gingiva und einem damit verbundenen gesteigerten Attachmentverlust (Löe et al. 1992; Schätzle et al. 2003).

$\mathrm{Ob}$ es sich bei Entstehung und Progression parodontaler Erkrankungen um Infektionen durch akkumulierte Plaque in ihrer Gesamtheit (unspezifische Plaquehypothese), um eine Infektion mit spezifischen Bakterien (spezifische Plaquehypothese) oder um eine opportunistische Infektion der vermutlich aus über 700 verschiedenen Arten bestehenden oralen Mikroflora handelt, wird auch heute noch kontrovers diskutiert (Slots 1986; Theilade 1986; Kazor et al. 2003).

Seit den 80er Jahren ist bekannt, dass nicht nur die absolute Menge der Plaque (Quantität), sondern eine kleine Gruppe ganz bestimmter Bakterienarten (Qualität) von besonderer Wichtigkeit für die Entwicklung einer parodontalen Entzündung ist; ebenso ist die Reaktion des Wirtsorganismus auf diese Bakterien maßgeblich von Bedeutung (Rateitschak et al. 1989). Entsprechend beschreibt man die marginale Parodontitis heutzutage als eine chronische lympho-plasmozytäre Entzündung des parodontalen Gewebes mit wechselnd ausgeprägtem Resorptionsvermögen. Sie wird aufgrund einer polymikrobiellen Infektion im Sinne einer opportunistischen Infektion hervorgerufen und ist mit subgingivalen Plaque-Biofilmen bzw. einer insuffizienten Immunabwehr gegen Biofilmantigene assoziiert (Kleber 1998). Dabei handelt es sich um eine komplexe Interaktion zwischen der Wirtsantwort und einer Infektion mit potentiell parodontalpathogenen Keimen (Mutschelknauss 2000).

Auf der Grundlage der opportunistischen Infektionstheorie der Parodontitis formulierte Socransky (1979) neue Postulate für parodontale Erkrankungen indem er die bis dahin bestehenden von Henle und Koch modifizierte (Tab. 1) (Slots und Rams 1992).

Tab. 1: Postulate für Infektionserkrankungen nach Henle \& Koch und Socransky (Slots und Rams 1992)

\begin{tabular}{|l|l|}
\hline Postulate von Henle \& Koch & \multicolumn{1}{|c|}{ Postulate von Socransky } \\
\hline $\begin{array}{l}\text { Der Erreger muss sich bei typischen } \\
\text { Krankheitsformen und nicht bei Gesun- } \\
\text { den nachweisen lassen. }\end{array}$ & $\begin{array}{l}\text { "Sites“ in höherer Zahl als in nichtaktiven } \\
\text { gefunden werden. }\end{array}$ \\
\hline
\end{tabular}




\begin{tabular}{|c|c|}
\hline $\begin{array}{l}\text { Die Züchtung des Erregers in Reinkultur } \\
\text { außerhalb des Organismus muss mög- } \\
\text { lich sein. }\end{array}$ & $\begin{array}{l}\text { Elimination: Die Elimination des Erregers } \\
\text { sollte die Progression der Erkrankung aufhal- } \\
\text { ten. }\end{array}$ \\
\hline $\begin{array}{l}\text { Die pathogenen Eigenschaften des Er- } \\
\text { regers müssen im Tierversuch klinisch } \\
\text { analoge Krankheiten erzeugen, die Er- } \\
\text { reger müssen im kranken Tier nach- } \\
\text { weisbar sein. }\end{array}$ & $\begin{array}{l}\text { Wirtsantwort: Die zelluläre oder humorale } \\
\text { Immunantwort sollte auf die spezifische Rolle } \\
\text { des Erregers bei der Erkrankung hinweisen. }\end{array}$ \\
\hline \multirow[t]{2}{*}{$\begin{array}{l}\text { Zusatz: Über die Postulate von Henle } \\
\text { und Koch hinaus muss es Hinweise auf } \\
\text { die immunologische Erreger-Wirt- } \\
\text { Beziehung Geben. }\end{array}$} & $\begin{array}{l}\text { Virulenzfaktoren: Der Erreger sollte } \\
\text { Virulenzfaktoren besitzen, die für die Initiation } \\
\text { und Progression relevant sind. }\end{array}$ \\
\hline & $\begin{array}{l}\text { Tierversuch: Die Pathogenität des Erregers } \\
\text { im Tierversuch muss darauf schließen las- } \\
\text { sen, dass sie am Menschen eine Parodontitis } \\
\text { auslösen können. }\end{array}$ \\
\hline
\end{tabular}

Durch eine verstärkte Wirtsantwort auf die bakterielle Herausforderung wird die eigentliche parodontale Destruktion hervorgerufen (Kohal und Dennison 2000). Es kommt zu einer Entzündung des Parodonts mit gewöhnlich progressiver und destruktiver Veränderung. Diese führt zum Verlust des Alveolarknochens und parodontalen Ligaments, also zum Stützgewebeverlust. Die lokalen Abwehrreaktionen des von der Infektion betroffenen Wirtes bestimmen die Ausprägung und ihren Verlauf (Sanderink et al. 2004). Dabei spielen opportunistische Erreger/Bakterien, die nur unter bestimmten Bedingungen pathogen wirken, insbesondere Aggregatibacter actinomycetemcomitans (Aa), Porphyromonas gingivalis $(\mathrm{Pg})$ und Tannerella forsythia (Tf) eine herausragende Rolle (Sanderink et al. 2004). Die Symbiose dieser Bakterien/Mikroorganismen und deren Organisation mit weiteren, bislang nicht nachweisbaren Bakterienarten werden in erster Linie für die Destruktivität verantwortlich gemacht. Ob die Bakterien eliminiert, auf nicht-pathogener Ebene stabil bleiben oder eine Parodontitis auslösen, wird durch den Wettbewerb innerhalb der Bakterienflora sowie durch die Interaktionen mit den Wirtsfaktoren entschieden (Sanderink et al. 2004). 
Symptomatisch ist der zyklisch fortschreitende Verlauf je Zahnfläche. Dabei werden kurze aktive Phasen (,burst“) durch längere nicht aktive Phasen (angepasster Zustand, „dormant stage“) abgelöst (Goodson et al. 1982; Kleber 1998). In der aktiven Phase kommt es zu hochakuten Entzündungen mit ulzerierendem Taschengewebe und unverhältnismäßig vielen neutrophilen Granulozyten. Der rasche Knochenabbau geschieht durch die zahlreich vorhandenen Osteoklasten. Die Bakterienquantität ist für den Beginn einer solchen aktiven Phase verantwortlich. In den längeren Ruhephasen findet man ein nicht ulzeriertes Taschenepithel mit einer subakuten Entzündung. Die Bestandteile des Parodontiums, ausgenommen der Knochen, können sich in dieser Phase regenerieren (Saglie et al. 1988).

Die Parodontitis entwickelt sich in verschiedenen Lebensaltern und unter verschiedenen Umständen aus einer Gingivitis (Genco 1992). Die Gründe, warum eine Gingivitis in eine Parodontitis übergeht, konnten bisher noch nicht vollständig geklärt werden. Im Erwachsenenalter sind verschiedene, oftmals schwer zu unterscheidende Verlaufsformen möglich. Nach Schroeder und Attström (1980) breitet sich die subgingivale Plaque apikalwärts aus. Die Entzündungsreaktionen schreiten weiter fort und es resultiert eine nur beschränkt reversible Zerstörung des Zahnhalteapparats. Das knöcherne Stützsystem ist dabei mit betroffen; es entsteht eine parodontale Tasche $(>3 \mathrm{~mm}$ ) und die mikrobielle Flora siedelt sich direkt auf der Wurzeloberfläche an (Rateitschak et al. 1989). Durch komplexe Wechselwirkungen wird körpereigenes Kollagen und Fibrogen zerstört, Osteoklasten werden aktiviert und der Knochenanbau gehemmt. Knochensubstanz und alveoläres Attachment gehen dadurch zunehmend verloren (Rateitschak et al. 1989). Demnach werden die parodontalpathogenen Keime bekämpft und gleichzeitig das parodontale Gewebe durch die körpereigene Abwehr zerstört.

\subsubsection{Parodontopathogene Mikroorganismen}

In subgingivalen Plaqueproben konnten um die 300 Spezies und Subspezies isoliert und charakterisiert werden; nur wenige von innen sind parodontalpathogen. Unter parodontalpathogenen Bakterien versteht man Mikroorganismen, die besondere biochemische Eigenschaften aufweisen, wodurch sie in der Lage sind, die Wurzeloberfläche und die Zahnfleischtasche zu besiedeln (Moore et al. 1982; Slots und Genco 1984). Zudem können sie den Abwehrmechanismus des Wirtes 
ausschalten oder umgehen und das parodontale Gewebe direkt schädigen (Slots und Genco 1984). Mikrobiologische Studien konnten eine Assoziation dieser Parodontopathogene mit unterschiedlichen Formen der marginalen Parodontitis aufzeigen (Ezzo und Cutler 2003). Tabelle 2 stellt die parodontalpathogenen Bakterien mit hoher und sehr hoher klinischer Relevanz dar.

Tab. 2: Parodontalphatogene Bakterien mit hoher bzw. sehr hoher klinischer Relevanz

\begin{tabular}{|l|l|}
\hline Klinische Relevanz & Klinische Relevanz \\
Sehr hoch & hoch \\
\hline $\begin{array}{l}\text { Aggregatibacter actinomycetem- } \\
\text { comitans (Aa) }\end{array}$ & Treponema denticola (Td) \\
Porphyromonas gingivalis (Pg) & Fusobacterium nucleatum (Fn) \\
Prevotella intermedia (Pi) & Prevotella intermedia (Pi) \\
Tannerella forsythia (Tf) & Campylobacter rectus $(\mathrm{Cr})$ \\
nicht klassifizierte Spirochäten & Eubacterium nodatum $(\mathrm{En})$ \\
\hline
\end{tabular}

Nach einer taxonomischen Einteilung können Bakterien in einem hierarchischen System nach ihren Verwandtschaftsbeziehungen, beruhend auf morphologischen, färberischen, physiologischen, biochemischen, antigenetischen und genetischen Merkmalen beschrieben und geordnet werden. Eine genaue Bakterienklassifikation beruht dabei auf der Genauigkeit der Erregeridentifizierung. Socransky et al. (1998) zeigten mittels molekularbiologischer Analysen (Checkerboard DNS-Hybridisierungen), dass bestimmte orale Mikroorganismen häufig gemeinsam vorkommen und so genannte Cluster bzw. Komplexe bilden; dabei wird zwischen einem roten, orangenen, gelben und grünen Komplex unterschieden. Abbildung 2 zeigt, welche Bakterien an der frühen Kolonisation auf der Zahnoberfläche beteiligt sind. Der orangefarbene Komplex wird erst zu einem späteren Zeitpunkt dominant und überbrückt vermutlich die Frühbesiedler mit den Spezies des roten Komplexes, die zu einem noch späteren Zeitpunkt der Plaqueentwicklung an Bedeutung gewinnen. 


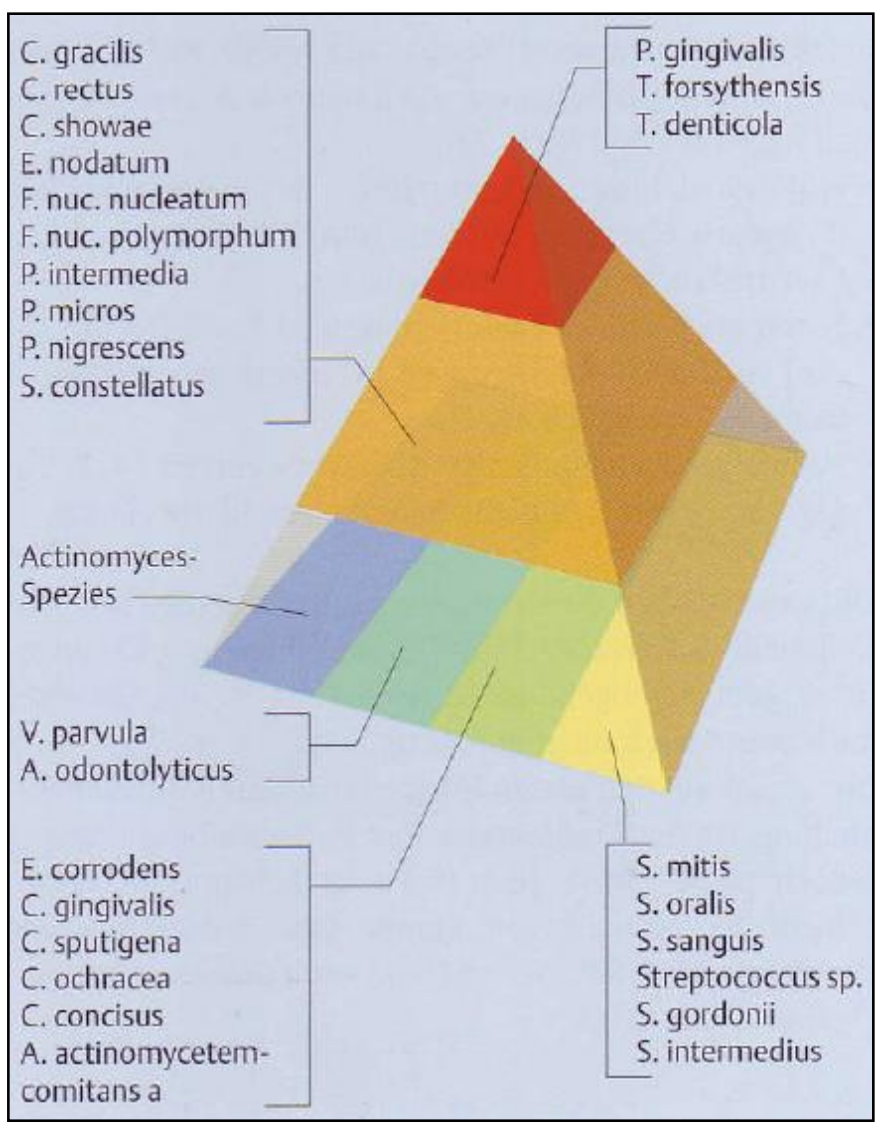

Abb. 2: Darstellung der parodontopathogenen Bakterien nach den SocranskyKomplexen (aus: Gängler und Arnold 2005, S. 262)

Entsprechend den Ausführungen von Socransky et al. (1998) sind einige dieser Komplexe häufig mit parodontalen Erkrankungen vergesellschaftet, andere hingegen vorwiegend mit parodontal gesunden Verhältnissen (Tab. 2) (Socransky et al. 1998). Bei Vorhandensein von Mitgliedern des so genannten roten Komplexes: Tf (früher Bacteroides forsythus), $T d$ und $P g$ besteht ein signifikant erhöhtes Risiko für Blutung auf Sondieren und erhöhte Sondierungstiefen. Aa scheint verstärkt mit aggressiven Formen der Parodontitis (lokalisierte oder chronische Form) assoziiert zu sein (Socransky et al. 1998; Yang et al. 2004). Grundvoraussetzung für den pathogenen Wirkmechanismus ist dabei ein geeignetes pathogenes Mikromilieu für die Bakterien im supra- bzw. subgingivalen Bereich: Das gilt insbesondere hinsichtlich $\mathrm{pH}$, Temperatur, Redoxpotential, Sauerstoffpartialdruck sowie Verfügbarkeit von Supplinen wie Eisen. Diese Bedingungen werden durch andere Mikroorganismen, Wirtszellen oder durch die Nahrungsaufnahme von außen geschaffen (Sanderink et al. 2004). Des Weiteren spielt hinsichtlich der Pathogenität paro- 
dontalpathogener Bakterien auch die weitgehende Abwesenheit bzw. Unterdrückung kommensaler Keime eine entscheidende Rolle (Sanderink et al. 2004).

\subsubsection{Immunabwehr}

Entscheidend für den Verlauf der Parodontitis ist das Gleichgewicht zwischen den pathogenen Bakterien und der Immunabwehr des Wirtsorganismus (Lindhe 1986). Nur einige der schätzungsweise 700 Bakterienspezies der oralen Mundflora werden als bedeutsam für den Krankheitsverlauf eingestuft (Listgarten 1987; Socransky und Haffajee 1992). Es sind überwiegend gramnegative anaerobe Keime, die durch ihre Stoffwechselprodukte das Gewebe schädigen oder direkt in das Gewebe einwandern (van Palenstein Helderman 1981). Vor allem die Kombinationen der subgingivalen Bakterien Porphyromonas gingivalis $(\mathrm{Pg})$ - Tannerella forsythia (Tf) - Treponema denticola (Td) oder Porphyromonas gingivalis (Pg) Treponema denticola $(T d)$ weisen synergistische Effekte in Bezug auf Virulenz und Pathogenität auf und werden mit klinischen Entzündungszeichen am marginalen Parodont assoziiert. Lokale Schutzbarrieren sollen das Eindringen der pathogenen Keime aus der subgingivalen Plaque verhindern, gleichzeitig sind die Abwehrzellen ursächlich an der Destruktion des parodontalen Gewebes beteiligt (Page 1991).

Die parodontalpathogenen Keime (gramnegative Anaerobier) bewirken eine Aktivierung von Monozyten und Makrophagen, die die Produktion und Freisetzung proinflammatorischer Zytokine (IL-1, IL-6, IL-8 IL-10, TNF- $\alpha$ und monozytenchemotaktisches Protein-1 (MCP-1)), gewebeschädigender Enzyme (MatrixMetalloproteinasen (MMP), z.B. Kollagenase) und Mediatoren (z.B. Prostaglandin$E_{2}\left(P G-E_{2}\right)$ ) veranlassen (Sanderink et al. 2004). Des Weiteren wirken Prostaglandine vasodilatierend und erhöhen die Gefäßpermeabilität. PG- $E_{2}$ hat Einfluss auf die Freisetzung von Zytokinen und MMP, wodurch eine entzündliche Parodontolyse herbeigeführt sowie die Immunabwehr umgangen wird. Zytokine und Prostaglandine wirken Osteoklasten aktivierend, veranlassen diese zur Knochenresorption und bewirken somit Knochenabbau (Birkedal-Hansen et al. 1988; van Winkelhoff et al. 1988). Bei der Pathogenese sämtlicher gewebeauflösender Entzündungsprozesse spielen die MMP eine bedeutende Rolle und sind für den 
Um- und Abbau der extrazellulären Matrix und Basalmembranbestandteile verantwortlich.

Betrachtet man eine hinreichende Zahl von Patienten mit einer Parodontitis, fällt eine große Variationsbreite im Verlauf dieser Erkrankung auf. Es wird vermutet, dass der individuelle Verlauf der Parodontitis von der körpereigenen Fähigkeit zur Regulation der immunologischen Abwehrreaktion abhängt (Attström 1972). Seymour (1991) spricht in diesem Zusammenhang von gegenüber Parodontitis „empfindlichen" und "unempfindlichen" Patienten. Damit ist das Vorhandensein parodontopathogener Keime kein alleiniger Indikator für die zukünftige Progression der Parodontitis (Greenstein und Lamster 2000). Somit ist stets zu berücksichtigen, dass die Parodontitis vielmehr eine opportunistische Erkrankung darstellt, bei deren Entstehung auch Einschränkungen der Immunabwehr (Wirtsabwehr) eine bedeutsame ätiologische Rolle spielen. Diese können vererbt oder erworben sein (siehe Kapitel 2.1.4). Kennzeichnend kann in solchen Fällen eine Funktionsstörung oder eine verminderte Anzahl der neutrophilen Granulozyten im Blut sein (Miller et al. 1984; van Dyke 1984).

Aktive Schübe einer Parodontitis sind jedoch durch akute Entzündungen bakteriellen Ursprungs gekennzeichnet. Der Entzündungsreiz kann neben den lokalen Anzeichen wie Rötung, Schwellung, Schmerz und Blutung auch generalisierte Symptome hervorrufen. Dazu gehören neben Fieber und Tachykardie, die bei der akuten nekrotisierenden ulzerösen Gingivitis oder Parodontitis (NUG/NUP) und bei den akuten Schüben der Parodontitis auftreten, auch die Leukozytose im peripheren Blut (Loos 2005). Die funktionellen Aufgaben der Leukozyten sind die spezifische Immunabwehr mit Hilfe von Lymphozyten einerseits und die unspezifische Immunabwehr durch Granulozyten und Monozyten (bzw. Makrophagen) andererseits. Beide Systeme arbeiten jedoch nicht streng voneinander getrennt. In der akuten Phase der Entzündung laufen stets die gleichen pathologischen Prozesse ab: Mikrozirkulationsstörung mit erhöhter Gefäßpermeabilität, Exsudation von Blutplasma und Transmigration von Blutzellen (Leukozytentransmigration). Dabei wird der Ablauf der Entzündungsreaktion durch eine Vielzahl so genannter Entzündungsmediatoren gesteuert, die durch ausschließliches Auftreten am Entzündungsort, antagonistengesteuerte Unterdrückung der Wirkung und den Abbau durch den Organismus charakterisiert sind. Man unterscheidet die Entzündungs- 
mediatoren nach zellvermittelten und plasmavermittelten Mediatoren (Riede 1989).

Zellvermittelte Mediatoren werden in unmittelbarer Umgebung ihres Syntheseortes aktiv. Entweder liegen sie in gespeicherter Form in bestimmten Zellen vor und werden bei Bedarf freigesetzt, oder sie werden von den Zellen im Bedarfsfall sofort synthetisiert. Sie sind in erster Linie für die frühe Entzündungsreaktion verantwortlich. Vertreter dieser Mediatoren sind unter anderem Makrophagenprodukte. Diese wiederum aktivieren unter anderem das Akute-Phase-Protein und den Tumornekrosefaktor- $\alpha$ (TNF- $\alpha$ ). TNF- $\alpha$ wird von neutrophilen Granulozyten produziert und aktiviert die T- und B-Lymphozyten, d.h. die zelluläre Immunantwort (Vilcek und Lee 1991; Ruddle 1992). Es ist für die Permeabilitätssteigerung des Gewebes verantwortlich und neben IL-1 und IL-6 gehört es zu den wichtigsten Immunmediatoren (van Snick 1990).

Plasmavermittelte Mediatoren müssen enzymatisch aktiviert werden, da nur inaktive Vorstufen synthetisiert werden, unter anderem das Akute-Phase-Protein Creaktives-Protein (CRP). Es gehört zu der unspezifisch wirkenden Immunantwort des Organismus auf Entzündungsprozesse im Körper. Aktiviert wird die CRPSynthese durch Makrophagenprodukte und Prostaglandin E und F. CRP aktiviert das Komplementsystem und die Zytolyse, beseitigt Gewebsgifte, aktiviert die Killer-Lymphozyten und stimuliert die Thromboxan- $\mathrm{A}_{2}$-Bildung (Thomas und Abdelhamid 1988).

Normale CRP-Werte sprechen zwar nicht eindeutig gegen ein entzündliches Geschehen, aber insbesondere generalisierte bakterielle Infektionen können ausgeschlossen werden (Thomas und Abdelhamid 1988). Verschiedene Untersuchungen konnten zeigen, dass eine Parodontitis mit einem erhöhten Aufkommen von Entzündungsmediatoren im peripheren Blut, wie zum Beispiel CRP, Leukozytenzahl und TNF- $\alpha$, verbunden sein kann (Loos 2005; D'Aiuto et al. 2006; Tonetti et al. 2007). Durch eine systematische Parodontaltherapie und damit verbundene Beseitigung bzw. Reduktion der parodontalen Entzündung kann das Vorhandensein dieser Mediatoren systemisch beeinflusst und minimiert werden (D'Aiuto et al. 2006; Tonetti et al. 2007). 


\subsection{Rheumatoide Arthritis}

\subsubsection{Epidemiologie}

Die rheumatoide Arthritis stellt eine Erkrankung des rheumatischen Formenkreises dar. Es handelt sich dabei um eine entzündliche, systemische Autoimmunerkrankung des Bindegewebes mit typischer polyartikulärer Entzündung. Sie ist durch synoviale Hyperplasie und progrediente Gelenkdestruktion gekennzeichnet. Es treten systemisch pathologische Immunphänomene auf, wie die Produktion von Autoantikörpern und extraartikulären Manifestationen. Dazu gehören Beteiligungen der Lunge, des Herzens, der Augen sowie der Speichel- und Tränendrüsen. Unter rheumatoider Arthritis, früher auch chronische Polyarthritis oder im Volksmund Gelenkrheuma genannt, leiden etwa 1-2\% der erwachsenen Bevölkerung (Gross 2004). Frauen sind bis zu viermal häufiger betroffen, wobei sich die Erkrankung meistens zwischen dem 35. und 50. Lebensjahr manifestiert. Nach der Diagnosestellung rechnet man mit einer Verkürzung der Lebenserwartung um 15$20 \%$.

Die juvenile ideopatische Arthritis stellt eine Sonderform dar, die bereits bei Kindern und Jugendlichen auftritt.

\subsection{2 Ätiologie}

Die Ursachen für die Entstehung der rheumatoiden Arthritis sind noch nicht endgültig geklärt. Heute geht man von einer genetischen Disposition und einer möglicherweise bakteriellen Infektion aus, die eine Autoimmunreaktion auslöst. Zusätzlich spielen Alter, Geschlecht, Umweltfaktoren sowie Lebensgewohnheiten, insbesondere Rauchen, eine Rolle.

Es gibt Anzeichen für eine Punktmutation, einen sogenannten „Single Nucleotid Polymorphism" (SNP). Zum einen konnte ein SNP auf einem Gen-Locus auf Chromosom 9 nachgewiesen werden, der für den Tumor-Nekrose-Faktor-Rezeptorassoziierten-Faktor 1 (TRAF 1-Gen) und den Komplement-Faktor 5 (C5-Gen) codiert. Außerdem wurde auf dem „PTPP22“-Gen eine Variante gefunden, die eine T-Lymphozyten-ständige Protein-Tyrosin-Phosphatase codiert. Dieses Enzym spielt in der intrazellulären Signaltransduktionskaskade eine große Rolle bei der Abschwächung von Signalen für die Regulation der Immunreaktion (Yamamoto und Yamada 2007). 
Hormonelle Einflüsse lassen sich anhand der geschlechtspezifischen Inzidenzen ableiten. Frauen vor der Menopause erkranken dreimal häufiger als Männer und postmenopausale Frauen (Villinger und Brühlmann 1999).

Die entzündlich veränderte, verdickte, hyperämische und von T-Zellen (CD4+-TZellen), B-Zellen und Makrophagen infiltrierte Synovialis (Gelenkinnenhaut) zeigt den typischen Gelenkbefall der rheumatoiden Arthritis, man spricht von der chronischen Synovialitis. Die Synovialis zeigt dabei eine pathogene Vielschichtigkeit, da sie normalerweise nur ein- bis zweischichtig ist. Es kommt zu einer lymphfollikelähnlichen Infiltration, bei der es sich dabei fast ausschließlich um T-Zellen handelt. Zusätzlich besteht eine starke Vaskularisation, so dass die verdickte Synovialmembran (Pannus) den Knorpel überwächst und schließlich zerstört. Der Knorpel wird unterminiert und es kommt zum Knochensubstanzverlust, der im Röntgenbild als Usur sichtbar ist. Bei diesem chronisch-progredienten Verlauf kommt es zu Schüben mit hoher entzündlicher Aktivität. Die Folge sind Gelenkdestruktion und -funktionsverlust (Gromnica-Ihle 2005).

Bei der Entwicklung des entstehenden Gelenkschadens sind CD4+-T-Zellen wichtige und zentrale Akteure. Antigen-aktivierte CD4+-T-Zellen stimulieren Monozyten, Makrophagen und synoviale Fibroblasten zur Zytokinproduktion (IL-1, IL-6 und TNF- $\alpha$ ) sowie zur Sekretion von MMPs (Abb. 3).

IL-1, IL-6 und TNF- $\alpha$ sind die Schlüssel-Zytokine, die die Eskalation des entzündlichen Prozesses vermitteln und chronifizieren. Des Weiteren regen die aktivierten CD4+-Zellen B-Lymphozyten zur Produktion von Immunglobulinen an, wie z.B. den Rheumafaktor, und stimulieren die Osteoklasten-Aktivierung (Choy und Panayi 2001). 


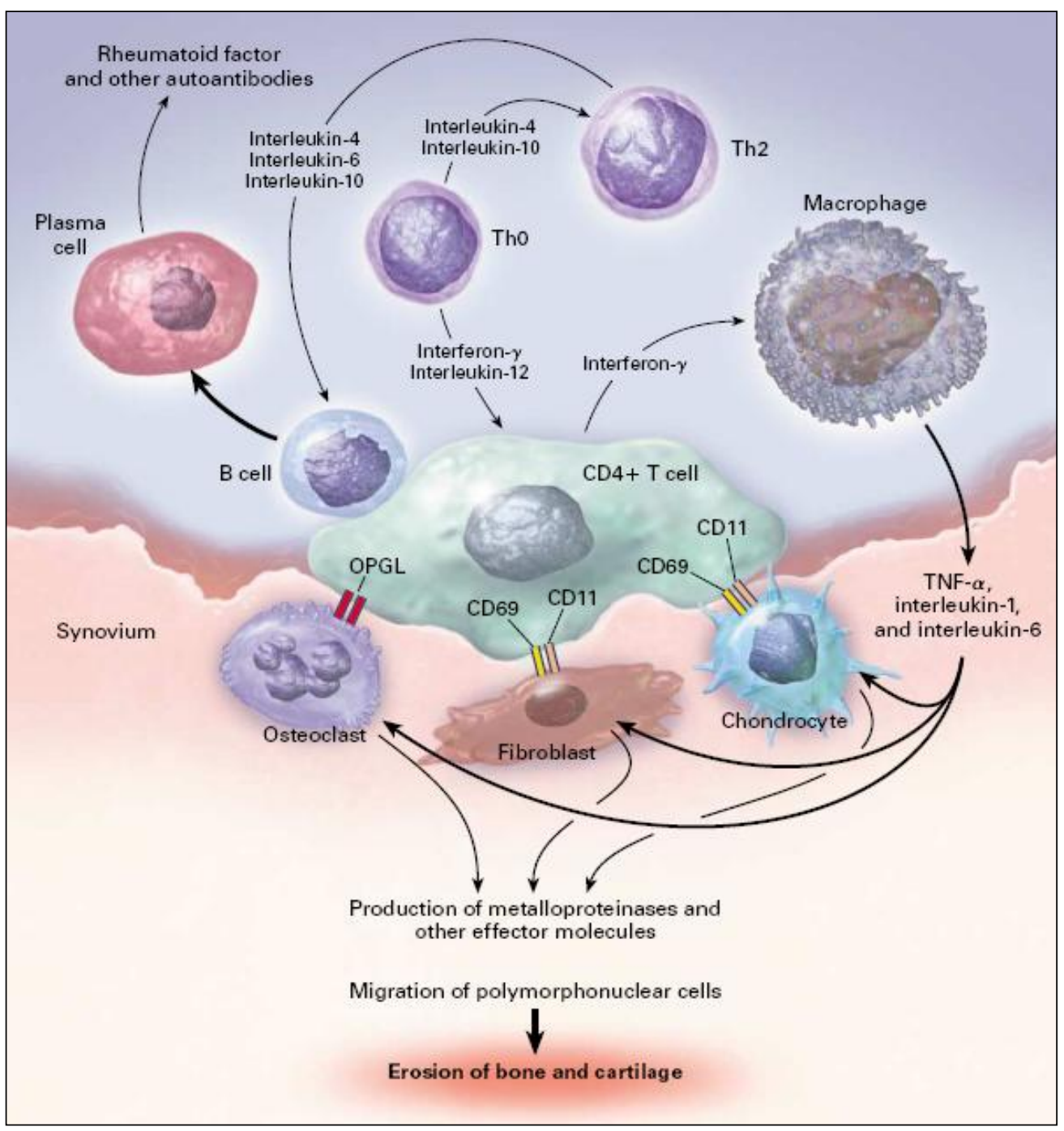

Abb. 3: Schematische Darstellung der Reaktionswege bei rheumatoider Arthritis. (aus: Choy und Panayi 2001, S. 908)

In einem gesunden Gelenk besteht die Synovialmembran aus ein bis zwei Zellschichten und dem darunterliegenden lockeren Bindegewebe (Abb. 4) .Die Synovialisdeckzellen lassen sich in Typ-A (Makrophagen-ähnlich) und Typ-B (Fibroblasten-ähnlich) differenzieren. Zu Beginn des entzündlichen Prozesses wird die Membran hyperplastisch, hyperämisch und es kommt zu einer Vaskularisierung. T- und B-Zellen infiltrieren die Membran und kommen neben einer hohen Konzentration von neutrophilen Granulozyten (>20000/ $\mu$ l) vermehrt in der Synovialflüssigkeit vor. Bereits in diesem Stadium kommt es zu einem tumorösen Einwachsen der Synovia in den Gelenkknorpel. Im weiteren Verlauf werden der Knorpel und der subchondrale Knochen durch das entzündliche Gewebe, welches als Pannus bezeichnet wird, zerstört. Dieses Gewebe besteht aus Typ-A- und 
Typ-B-Deckzellen und Plasmazellen. Des Weiteren kann es aufgrund hoher Zytokin-Konzentrationen auch zu extra-artikulären Symptomen kommen, z.B. gelenknaher Osteoporose durch Osteoklastenaktivierung (Choy und Panayi 2001).

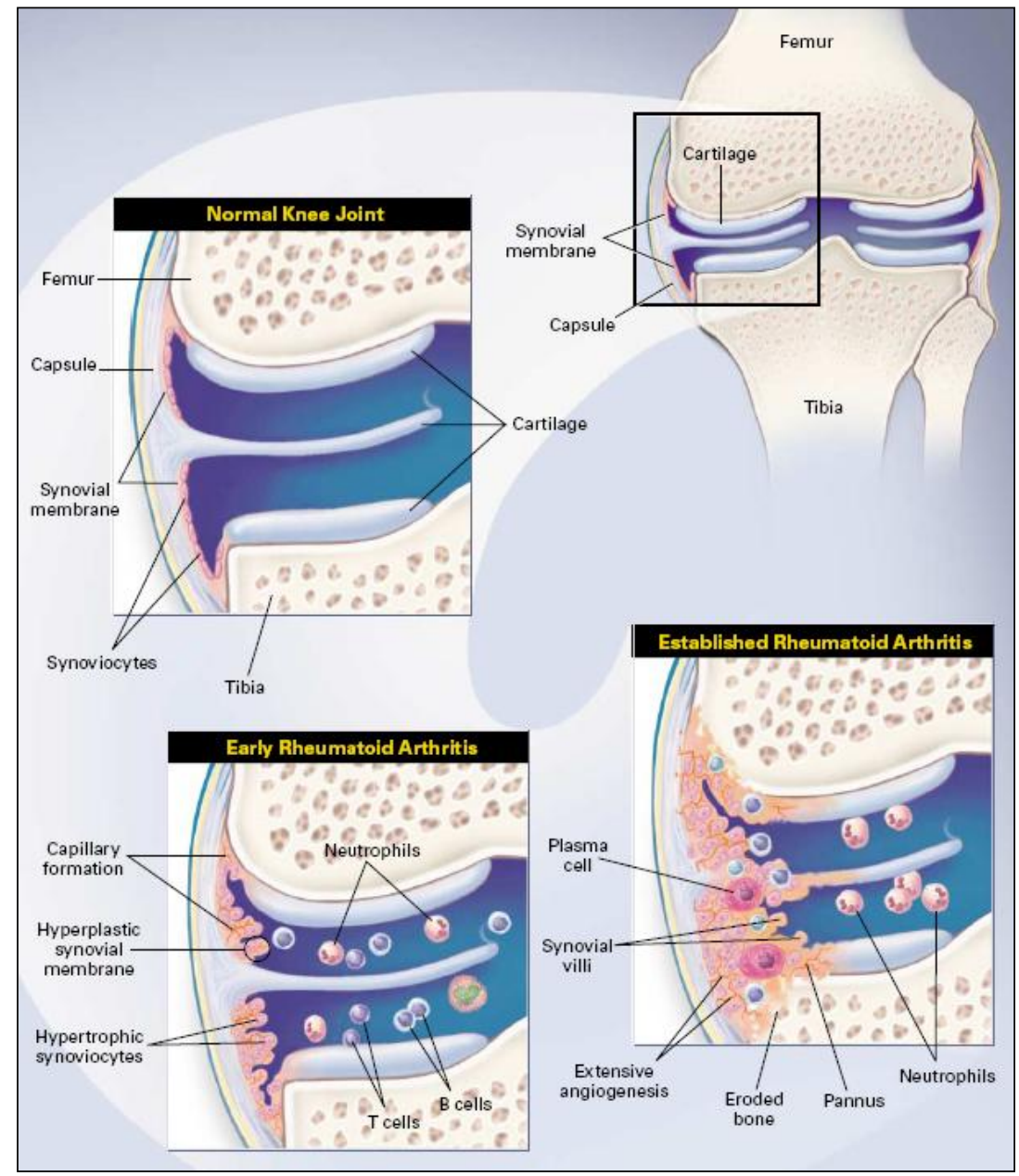

Abb. 4: Schematischer Querschnitt durch ein Kniegelenk (aus: Choy und Panayi 2001, S. 911)

\subsubsection{Klinik und Verlauf}

Die Erkrankung beginnt meist schleichend und kann mit grippeähnlichen Allgemeinsymptomen wie nächtlichem Schwitzen, Leistungsknick mit Müdigkeit, Abgeschlagenheit, subfebrilen Temperaturen, Anorexie und Myalgien einhergehen.

Die Symptome der rheumatoiden Arthritis erklären sich durch die Entzündungsreaktion, die sich mit schmerzhafter Steife der betroffenen Gelenke am Morgen (Morgensteifigkeit) äußert. In der initialen Phase der Erkrankung zeigen sich weitgehend symmetrische Schwellungen und schmerzhafte Bewegungseinschränkungen der Metakarpophalangeal- und/oder proximalen Interphalangealgelenke, nicht 
jedoch der distalen Interphalangealgelenke. Anhand des Zustands der Fingergelenke kann eine Prognose bezüglich des Krankheitsverlaufs gegeben werden. Im weiteren Verlauf der Erkrankung kommt es auch zu Gelenkentzündungen der unteren (Knie-, Sprung- und Zehengelenke) und oberen Extremitäten (Schulter, Ellenbogen). Ebenso kann das Kiefergelenk betroffen sein. An der Wirbelsäule äuBern sich die Symptome, wenn überhaupt, meistens im Bereich des Atlantoaxialgelenkes (Bukhari et al. 2002).

Als typische Zeichen der irreversiblen Gelenkzerstörung im fortgeschrittenen Stadium gelten die Ulnardeviationen der Hand sowie Knopfloch- und Schwanenhalsdeformitäten. Der chronisch-progressive Verlauf der Krankheit erfolgt meist in Schüben.

In schweren Krankheitsverläufen und in Abhängigkeit vom Rheumafaktor-Titer kommt es in $30-50 \%$ der Fälle zu extraartikulären Manifestationen (EAM) (Chandrasekaran und Radhakrishna 1995; Carmona et al. 2003; Turesson und Jacobsson 2004; Calgüneri et al. 2006). Hierzu zählen Muskelatrophie, Rheumaknoten, Tendovaginitis, Pleuritis, Lungenfibrose, Perimyokarditis, Polyneuropathie, Keratokonjunktivitis sicca und generalisierte Vaskulitis. Als Ausdruck dieser systemischen Beteiligung weisen Patienten mit rheumatoider Arthritis ein signifikant höheres Risiko für kardiovaskuläre Ereignisse auf (Goodson et al. 2005; MaraditKremers et al. 2005)

\subsubsection{Diagnostik}

Zur Diagnosestellung orientiert man sich an der Anamnese und den klinischen Befunden. Weitere diagnostische Hilfsmittel stellen die Labor- und Röntgendiagnostik dar, welche Rückschlüsse auf die Krankheitsaktivität und den Verlauf zulassen. Da es jedoch für das Krankheitsbild „rheumatoide Arthritis“ keine spezifischen diagnostischen Kriterien und Tests gibt, entwickelte das American College of Rheumatologie (ACR) einen spezifischen Katalog von Klassifikations-Kriterien (Arnett et al. 1988) (Tab. 3). Dieser stützt sich auf Aussagen von Studienpopulationen und dient besonders der Abgrenzung der rheumatoiden Arthritis von anderen Formen der entzündlich-rheumatischen Gelenkerkrankungen. Die Erfüllung der Kriterien darf jedoch nicht alleine ausschlaggebend für die Diagnosestellung sein, 
sondern dient lediglich der Diagnosefindung. Bei Vorliegen von vier der sieben Kriterien gilt die Diagnose einer rheumatoiden Arthritis als gesichert.

Tab. 3: Klassifikationskriterien der rheumatoiden Arthritis (nach Arnett et al.1988)

\begin{tabular}{|l|l|}
\hline 1. & Morgensteifigkeit (mind. eine Stunde Dauer) $>6$ Wochen \\
\hline 2. & Arthritis in 3 oder mehr Gelenkregionen $>6$ Wochen \\
\hline 3. & Arthritis an Hand- und Fingergelenken $>6$ Wochen \\
\hline 4. & Symmetrische Arthritis $>6$ Wochen \\
\hline 5. & Rheumaknoten \\
\hline 6. & Positiver Rheumafaktor \\
\hline 7. & Charakteristische Veränderungen im Röntgenbild \\
\hline
\end{tabular}

Bei der Erstuntersuchung und zur Verlaufskontrolle wird die dorso-volare Röntgenaufnahme der Hände und Füße eingesetzt (Brower 1990) (Abb. 5). Hier können z.B. Gelenkspaltverschmälerungen, Erosionen, Zysten und gelenknahe Osteoporosen dargestellt werden (Østergaard et al. 2005). Aufgrund ihrer hohen Bedeutsamkeit für das Krankheitsbild der rheumatoiden Arthritis stellen röntgenologisch darstellbare Veränderungen auch ein Kriterium der ACR-Klassifikation dar (Arnett et al. 1988). 


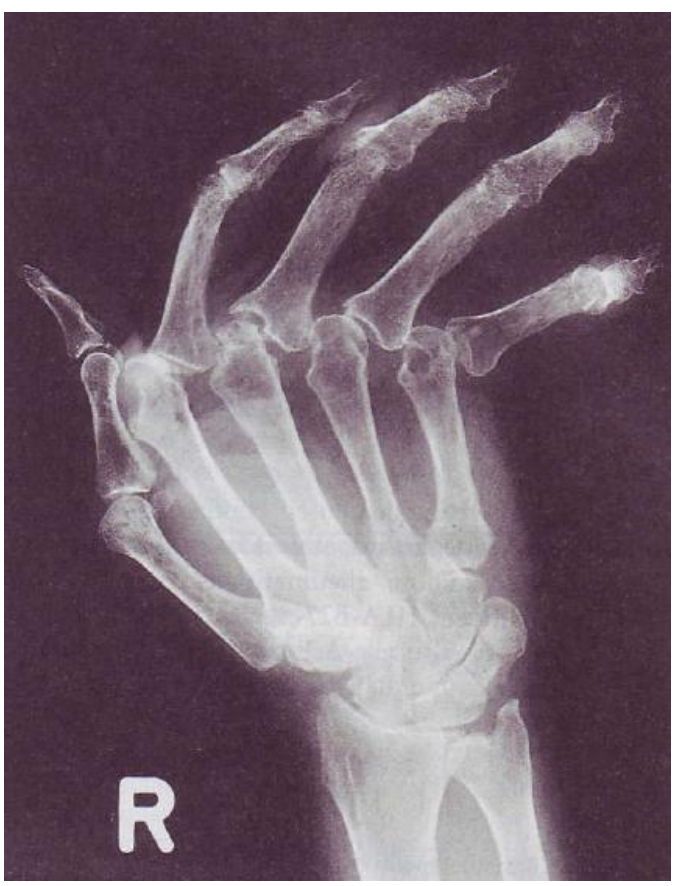

Abb. 5: Rheumatoide Arthritis im Handskelettbereich mit Ulnardeviation und Subluxationsstellung (aus: Gross 2004, S. 1057)

Zur Stadieneinteilung der radiologischen Befunde wurden verschiedene Systeme vorgeschlagen. In Tabelle 4 ist die Stadieneinteilung nach Larsen (1973) dargestellt.

Tab. 4: Larsen-Stadien der radiologischen Befunde (nach Larsen 1973, S.137)

\begin{tabular}{|l|l|}
\hline Stadium & Befund im Röntgenbild \\
\hline Grad 0 & Normal \\
\hline Grad 1 & $\begin{array}{l}\text { Weichteilschwellung, gelenknahe Osteoporose oder geringe } \\
\text { Gelenkspaltverschmälerung }\end{array}$ \\
\hline Grad 2 & Eine oder mehrere kleine Erosionen, Gelenkspaltverschmälerung nicht obligat \\
\hline Grad 3 & Ausgeprägte Erosionen und Gelenkspaltverschmälerung \\
\hline Grad 4 & Große Erosionen, Gelenkfläche nur teilweise erhalten \\
\hline Grad 5 & Mutilierende Veränderungen: Gelenkfläche zerstört, schwere Deformität möglich \\
\hline
\end{tabular}

Seit 2010 haben der ACR und der EULAR (European League Against Rheumatism) eine neue Basis für eine internationale Standardisierung der Krank- 
heitsklassifikation veröffentlicht. Die „2010 ACR/EULAR-Kriterien zur Klassifikation der rheumatoiden Arthritis“ bilden einen Wert von Null bis Zehn und sind in vier Befunde unterteilt:

1. Gelenkbeteiligung $\Rightarrow$ maximal 5 Punkte

2. Serologische Parameter (Rheumafaktor (RF) und Antikörper gegen zyklisch-citrullinierte Peptide (CCP-AK)) $\Rightarrow$ maximal 3 Punkte

3. Akutphasereaktion (C-reaktives Protein (CRP)) $\Rightarrow$ maximal 1 Punkt

4. Dauer der Beschwerden $>6$ Wochen $\Rightarrow$ maximal 1 Punkt.

Ab einem Punktwert von mindestens 6 gilt die Diagnose „rheumatoide Arthritis“ als gesichert (Aletaha et al. 2010).

Als Ergänzung zu den ACR-Kriterien gibt es den „Disease Activity Score 28“ (DAS28). Dieser Score dient der Messung der Krankheitsaktivität zu einem beliebigen Zeitpunkt des Krankheitsverlaufes. Es handelt sich hierbei um ein validiertes System, welches von der EULAR entwickelt wurde.

Folgende Parameter werden für die Ermittlung des DAS28 benötigt:

- Anzahl der druckdolenten Gelenke (0-28 von der EULAR definiert)

- Anzahl der tumorösen Gelenke (0-28)

- Blutkörperchensenkungsgeschwindigkeit (BSG [mm/h])

- Einschätzung des Krankheitszustandes bzw. der Krankheitsaktivität durch den Patienten (0-100 Visuelle Analogskala (VAS)).

Durch die Berechnung mittels folgender Formel:

DAS28 =

$0,56 x \sqrt{\text { druckschmerzhafte Gelenke }}+0,28 x \sqrt{\text { geschwollene Gelenke }}+0,7 x \ln (B S G)+0,014 x$ Krankheitszustand

erhält man einen DAS28-Wert zwischen Null und Zehn. Tabelle 5 gibt eine Übersicht, welche Krankheitsaktivität den Zahlenwerten zugeordnet werden kann (Fransen und van Riel 2005). 
Tab. 5: Einteilung der Krankheitsaktivität nach DAS28

\begin{tabular}{|l|l|l|}
\hline Grüner Bereich & Werte zwischen 0 und 3,2 & fehlende/ geringeKrankheitsaktivität \\
\hline Gelber Bereich & Werte zwischen 3,2 und 5,1 & mittlere Krankheitsaktivität \\
\hline Roter Bereich & Werte $>5,1$ & hohe Krankheitsaktivität \\
\hline
\end{tabular}

\subsubsection{Labor}

Anhand laborchemischer Untersuchungen des Blutes können sowohl unspezifische als auch spezifische Hinweise auf das Vorliegen einer rheumatoiden Arthritis gegeben werden. Die Erhebung erhöhter Werte für C-reaktives Protein (CRP) und die Blut-Senkungs-Geschwindigkeit (BSG) ist keinesfalls ausreichend für die Diagnostik des Vorliegens einer rheumatoiden Arthritis, da sie auch als Reaktion auf eine Verletzung, Infektion oder andere inflammatorische Ereignisse erhöht sein können. Erhöhte Werte geben jedoch erste Hinweise auf eine aktuelle Krankheitsaktivität. In Ausnahmefällen können schwere, hoch entzündliche Verläufe einer rheumatoiden Arthritis auch ohne BSG-Beschleunigung und CRP-Erhöhung auftreten (Strunk et al. 2005).

Als spezifische diagnostische Marker haben sich in der Praxis vor allem der Rheumafaktor (RF) und Antikörper gegen zyklische citrullinierte Peptide (CCP-AK) durchgesetzt. Heute definiert man den RF als eine heterogene Gruppe von Immunglobulinen (Ig), die sich gegen Antigene des Fc-Fragments von IgG richten. Ein relativ spezifischer Marker der rheumatoiden Arthritis ist der Rheumafaktor der Klasse M (IgM). Dieser ist bei $65-80 \%$ der rheumatoiden Arthritis-Patienten, aber auch bei anderen rheumatischen Erkrankungen nachweisbar. Verschiedene Bestimmungsmethoden können allerdings sehr variable Werte für Sensitivität und Spezifität aufweisen (Saraux et al. 2002).

Das Vorhandensein des RFs ist jedoch nicht pathognomonisch für rheumatoide Arthritis, auch bei einigen Gesunden und bei Patienten mit infektiösen und chronisch-inflammatorischen Krankheiten lässt sich der RF nachweisen. Leicht erhöhte RF-Werte finden sich $u$. a. bei viralen Infektionen wie Hepatitis B und C, bei chronisch-bakteriellen Erkrankungen wie Tuberkulose und Syphilis und bei lymphproliferativen Erkrankungen wie dem Morbus Waldenström (Newkirk 2002). Ist bei ge- 
sicherter Diagnose der Rheumafaktor-Nachweis im Serum positiv, spricht man von seropositiver rheumatoider Arthritis.

Ein sehr spezifischer Marker der rheumatoiden Arthritis sind die CCP-AK, die schon in der Frühphase der Erkrankung bei über $50 \%$ der Patienten nachweisbar sind. Die Spezifität dieses Nachweisverfahrens liegt bei $96 \%$, die Sensitivität bei $68 \%$. Insbesondere für die Diagnose einer seronegativen rheumatoiden Arthritis, bei der kein Rheumafaktor-Nachweis gelingt, sind sie für die Frühdiagnose von großer Bedeutung (Bas et al. 2002). Ihr Auftreten scheint mit aggressiveren Verläufen und einer schlechteren Prognose assoziiert. Teilweise kann schon Jahre vor Krankheitsbeginn (bei $25-40 \%$ der Betroffenen) im Serum späterer Rheumatoider Arthritis-Patienten CCP-AK nachgewiesen werden (Rantapää-Dahlqvist et al. 2003). Rheumafaktoren und CCP-Antikörper sind voneinander unabhängige Risikofaktoren für die Ausprägung radiologischer Erosionen, es besteht für beide eine positive Korrelation zur Titerhöhe (Berglin et al. 2006; Mewar et al. 2006; Inanc et al. 2007). Viele Daten lassen vermuten, dass Rauchen bei Vorliegen einer rheumatoiden-Arthritis-spezifischen Human-Leukocyte-Antigen (HLA)-Konstellation die Bildung von CCP-AK induzieren kann (Klareskog et al. 2006; Lee et al. 2007). Nachweisbar ist, dass Nikotinkonsum mit und ohne Vorliegen bestimmter „shared-epitope“-Allele zu höheren Serumkonzentrationen und einer größeren Diversifikation der CCP-AK führt (van der Helm-van Mil et al. 2007; Verpoort et al. 2007). Aus theoretischer Sicht würde dies die oben gemachten Annahmen einer genetischen Prädisposition bestätigen, die unter verschiedenen Einflüssen, wie beispielsweise Rauchen, zur Ausbildung einer spezifischen Autoimmunreaktion führt.

Die für einen aggressiven Verlauf typischen Serummarker RF und CCP-AK gelten ebenso wie weibliches Geschlecht, frühes Auftreten von Knochenerosionen, extraartikuläre Manifestationen sowie initial hohe Werte für zirkulierende Immunkomplexe als negative Prädiktoren (Kaarela 1985). 


\subsubsection{Therapiemöglichkeiten}

Das Ziel der Behandlung der rheumatoiden Arthritis ist zum einen die Linderung der akuten Beschwerden, zum anderen soll es zu einer nachhaltigen Eindämmung der Entzündung kommen und somit das Fortschreiten der rheumatoiden Arthritis aufgehalten werden.

Die vielschichtige Therapie der rheumatoiden Arthritis umfasst neben der symptomatischen Schmerzbehandlung und der Basistherapie mit krankheitsmodifizierenden Wirkstoffen auch Physiotherapie und in Einzelfällen operative Maßnahmen.

Durch Basismedikamente, die wegen ihres Einflusses auf die Krankheit auch "disease modifying antirheumatic drugs" (DMARD) genannt werden, kommt es zu einer Verlangsamung oder Vermeidung von Strukturschäden. Sie wirken aber erst mit einer Verzögerung von etwa 4 bis 6 Wochen. Es handelt sich dabei um die Antirheumatika Methotrexat (MTX), Sulfasalazin, Chloroquin, Gold, Azathioprin, Cyclosporin A und Leflunomid. Nach ACR-Guidelines (2002) wird MTX als Goldstandard empfohlen.

Die nichtsteroidalen Antirheumatika (NSAR), insbesondere Diclofenac, wirken gegen die Gelenkschmerzen, sind aber aufgrund der Nebenwirkungen langfristig nicht für die Therapie geeignet (Brooks und Day 1991; Furst 1994). Es kommt dabei häufig zu gastrointestinalen Nebenwirkungen (Magenschleimhauterosionen, Dyspepsie etc.). Auch Glukokortikoide zeigen einen sehr schnell einsetzenden Effekt und werden meist direkt in die betroffenen Gelenke injiziert. Heutzutage wird zunehmend mit „Biologicals“ therapiert. Dies sind gentechnisch hergestellten Medikamenten, die sich gezielt gegen die fehlgesteuerten Immunzellen und die von innen gebildeten Zytokine richten. Zum Einsatz kommen hierbei unter anderem Infliximab, ein Anti-TNF- $\alpha$-Antikörper, sowie Etanercept, ein TNF-RezeptorFusionsprotein (Klareskog et al. 2004; van der Heijde et al. 2005).

Vor allem durch den initialen, frühzeitigen Einsatz von Kombinationstherapien ist eine effektivere Verlangsamung beziehungsweise Verhinderung der Erkrankung erreichbar. Man kombiniert hierbei MTX mit Infliximab bzw. Etanercept (GoekoopRuiterman et al. 2007). 


\subsection{Parodontitis als Manifestation einer Systemerkrankung}

In den letzten Jahren wurden in der Fachliteratur die Zusammenhänge zwischen unterschiedlichen allgemeinen Erkrankungen und dentalen bzw. parondontalen Entzündungen heftig diskutiert. Zahlreiche Autoren stellten in verschiedenen Studien dar, dass orale Entzündungen Einfluss auf den allgemeinen Gesundheitszustand haben (Slots 2003). Sie befassten sich unter anderem mit dem Zusammenhang von Erkrankungen wie z.B. Schlaganfall (Syrjänen et al. 1989; Demmer und Desvarieux 2006) oder Arteriosklerose mit Parodontalerkrankungen.

Viele Arbeitsgruppen beschäftigten sich in diesem Zusammenhang mit Herz- und Gefäßkrankheiten, insbesondere dem Herzinfarkt und den plötzlichen Herztod. Sie versuchten das Risiko zu beschreiben, dass ein schlechter Mundgesundheitszustand zu Problemen mit dem Herz führen könnte. Die Ergebnisse der einzelnen Untersuchungen zeigten insgesamt eine ähnliche Richtung. Von den einzelnen Autoren wurden sie aber unterschiedlich bewertet. DeStefano et al. (1993), Beck et al. (1996), Jansson et al. (2001), Janket et al. (2003), Elter et al. (2004), Mattila et al. (1995) und Pussinen et al. (2004) erkannten einen Zusammenhang zwischen den beiden Erkrankungen. Anderer Meinung waren Hujoel et al. (2000), Howell et al. (2001), Müller (2002) und Hung et al. (2004).

Beck et al. (1996) beschrieben ein um 50\% höheres koronares HerzkrankheitsRisiko (KHK-Risiko) bei entzündungsbedingtem Verlust des Alveolarknochens mit einer Taschentiefe von über $3 \mathrm{~mm}$. Auch DeStefano et al. (1993) und Elter et al. (2004) kamen zu solchen Ergebnissen. Jansson et al. (2001) beschrieben eine deutlich erhöhte Todesrate durch KHK bei schlechter Mundgesundheit.

Krankhafte Veränderungen in der Umgebung des Zahnes werden mit einem statistisch ermittelten KHK-Risikofaktor von 2,1 bewertet. Rauchen und höheres Alter zeigen denselben Risikofaktor. Im Vergleich zu einer mundgesunden Gruppe beschrieb er einen erhöhten „low density lipoprotein“ (LDL)-Spiegel, aber geringere „high density lipoprotein“ (HDL)-Spiegel und Triglyceridwerte bei Parodontitispatienten. Das Blutserum betreffend lieferten Pussinen et al. (2004) den Nachweis, dass eine Entzündung, die durch $P g$ ausgelöst wurde, das Risiko für einen Herzinfarkt ansteigen lässt. Janket et al. (2003) ermittelten in einer Zwischenuntersuchung ein um 19\% höheres Risiko für spätere Herz- und Gefäßerkrankungen bei Vorliegen einer Parodontitis. 
Persson und Persson (2008) empfahlen, dass Personen, die regelmäßig den Zahnarzt besuchen und bei denen ein erhöhter Attachmentverlust festgestellt wird, sich aufgrund eines erhöhten Herzinfarktrisikos einer gezielten medizinischen als auch zahnmedizinischen Betreuung unterziehen sollten.

Desvarieux et al. (2003) untersuchten den Zusammenhang von Zahnverlusten als Folge einer Parodontopathie und Ablagerungen in den Carotitiden. Unter den Teilnehmern mit mindestens zehn fehlenden Zähnen befanden sich auffallend mehr Personen mit atheromatösen Plaques (einer Ansammlung von Bindegewebe, Fett, Calcium u. a. in der Gefäßwand).

Müller (2002) fasste in einer Meta-Analyse die Untersuchungen von Beck et al. (1996) und Joshipura et al. (1996) zusammen. Er ermittelte ein verhältnismäßiges Risiko von 1,12 und schloss sich den Meinungen von Hujoel et al. (2000) und Howell et al. (2001) an. Er sieht keine statistisch auffallenden Zusammenhänge zwischen den Erkrankungen. Viele Forschungsgruppen befassten sich mit der Frage, ob bei bereits bestehenden Erkrankungen der Mundgesundheitszustand im Vergleich zu nicht erkrankten Gruppen verändert ist. Die Studien von Offenbacher et al. (1996) und Dörtbudak et al. (2005) zeigten Zusammenhänge zwischen Parodontopathien bei der Mutter und Frühgeburten, bzw. untergewichtigen Neugeborenen. Pinson et al. (1995) und Campus et al. (2005) beschrieben vermehrte Parodontalerkrankungen bei Diabetikern.

Den Mundgesundheitszustand von Herzinfarkt-Patienten in Finnland prüften Mattila et al. $(1989,2000)$. Beide Arbeiten dokumentieren schlechtere dentale und parodontale Zustände der KHK-Patienten gegenüber gesunden Testpersonen. Die Arbeitsgruppen Malthaner et al. (2002) und Tuominen et al. (2003) konnten dies nicht bestätigen.

Der Mundgesundheitszustand von zehn eineiigen schwedischen Zwillingen, von denen jeweils ein Zwilling an koronarer Herzkrankheit litt, der andere dagegen gesund war, wurde klinisch und radiologisch verglichen (Tabrizi et al. 2007). Deutlich schlechtere orale Gesundheit wurde bei den erkrankten Zwillingen festgestellt. Außerdem wurden schlechtere parodontale Parameter ermittelt.

Ein ursächlicher Zusammenhang konnte jedoch in keiner der Untersuchungen dargestellt werden. Dennoch häuften sich für Desvarieux et al. (2003) und Demmer und Desvarieux (2006) die Hinweise, die einen Zusammenhang zwischen KHK und dem Gesundheitszustand des Mundes belegen. 


\subsection{Parodontitis und rheumatoide Arthritis}

In den letzten Jahren gibt es zunehmend Hinweise für eine Assoziation zwischen Parodontitis und rheumatoider Arthritis. Nach vorliegenden Kenntnissen weisen Patienten mit rheumatischen Erkrankungen ein erhöhtes Risiko auf eine Parodontitis zu entwickeln und weisen erhöhten Zahnverlust sowie signifikant mehr Attachmentverlust als Gesunde auf. Bislang ist jedoch das gemeinsame Auftreten parodontaler Erkrankungen und rheumatoider Arthritis nicht eindeutig geklärt, und somit sind mögliche Kausalzusammenhänge weiterhin unklar.

Wie die Parodontitis ist auch die rheumatoide Arthritis durch den typischen Verlust bindegewebiger und mineralisierter Strukturen gekennzeichnet. Trotz intensivster Forschungsbemühungen ist die Ätiologie der rheumatoiden Arthritis, ähnlich wie bei der Parodontitis, noch unklar. Neben individuellen- (Geschlecht, Alter), genetischen- (HLA-Genotyp) und Umweltfaktoren (Alkohol- und Zigarettenkonsum) stehen Infektionen immer wieder im Mittelpunkt der Diskussion (Alamanos und Drosos 2005; Turesson et al. 2005; Costenbader et al. 2006).

Es wird immer wieder diskutiert, dass in der Pathogenese der rheumatoiden Arthritis insbesondere orale Infektionen eine zentrale Rolle spielen (Hara et al. 1996; Rosenstein et al. 2004; Weissmann 2004). Es wurden bakterielle DNA von Anaerobiern und hohe Antikörpertiter gegen diese Spezies sowohl im Serum als auch in der Synovialflüssigkeit nachgewiesen (Yoshida et al. 2001; Moen et al. 2003; Ogrendik et al. 2005; Moen et al. 2006; Mikuls et al. 2009). Diese hochpathogenen oralen Bakterien können eine chronische Bakteriämie unterhalten und zu einer potenziellen Schädigung am Endokard sowie an Gelenken führen (Lockhart et al. 2009; Lu et al. 2009). Hierbei weisen Parodontitis-Patienten ein höheres Risiko für eine Bakteriämie auf (Forner et al. 2006).

Einen hohen Vorhersagewert für die Entstehung einer rheumatoiden Arthritis haben vor allem als diagnostische Marker eingesetzte Antikörper gegen zyklischcitrullinierte Peptide (CCP-AK) in Kombination mit dem Rheumafaktor. Diese weisen eine Spezifität von 95-98\% für eine rheumatoide Arthritis auf (van der Helmvan Mil et al. 2005).

Bis heute ist $P$. gingivalis das einzige bekannte Bakterium, welches das Enzym Peptidyl-Arginin-Deaminase (PAD) exprimieren kann. Somit stellt es einen wichti- 
gen Pathogenitätsfaktor der rheumatoiden Arthritis dar (Schellekens et al. 1998; McGraw et al. 1999; Schellekens et al. 2000; Rosenstein et al. 2004). PAD bewirkt eine irreversible posttranslationale Umwandlung von Arginin (Peptylarginin LArginin) zu Citrullin. Aber es besteht keine vollständige Homologie zwischen humanem PAD und der PAD von Porphyromonas gingivalis (McGraw et al. 1999). Als Nebenprodukt der Arginindeaminaseaktivität entsteht Ammoniak. Das Bakterium $P$. gingivalis benutzt dieses Ammoniak zur Neutralisation des sauren Milieus und dient somit der eigenen Wachstumssicherung (McGraw et al. 1999). Die PAD steht in einer engen Wechselbeziehung mit dem Wachstum des $P$. gingivalis. Auffällig ist, dass bei Parodontitis-Patienten eine hohe Ammoniak-Konzentration in der Sulcus-Flüssigkeit festgestellt werden kann (Niederman et al. 1990). Es ist möglich, dass durch $P$. gingivalis erzeugte parodontale Infektionen in enger Verknüpfung mit einer genetischen Prädisposition, entzündliche Erkrankungen wie die rheumatoide Arthritis auslösen, beziehungsweise immunregulierend auf den Krankheitsverlauf der rheumatoiden Arthritis einwirken (Liao et al. 2009; Mikuls et al. 2009). Hierbei spielt die gesteigerte Autoantikörperbildung gegen citrullinierte Proteine eine wesentliche Rolle. Dabei korreliert bei rheumatoide ArthritisPatienten der $P$. gingivalis-Titer mit der CCP-AK-Konzentration (Mikuls et al. 2009), jedoch ist bisher unklar, ob der Anstieg der Protein-Citrullinierung ein generelles und damit unspezifisches Phänomen darstellt, oder ob dieses kennzeichnend für parodontale Bakterien ist.

Bei Parodontitis-Patienten konnte sowohl in der Gingiva, der subgingivalen Plaque, als auch im Serum der Rheumafaktor nachgewiesen werden (Rosenstein et al. 2004). Dieser lässt sich bei rheumatoider Arthritis und anderen rheumatischen Erkrankungen nachweisen. Bei seropositiven Parodontitis-Patienten konnten im Vergleich zu seronegativen Parodontitis-Patienten auch erhöhte Titer von IgG- und IgM-Antikörpern gegen orale Mikroorganismen nachgewiesen werden (Hirsch und Clarke 1989). Die oralen bakteriellen Epitope zeigten eine Kreuzreaktion mit dem Rheumafaktor der seropositiven Parodontitis-Patienten (Thé und Ebersole 1996). Für die Epitopentwicklung in der RF-Fc-Region ist die $P$. gingivalis-Proteinase zuständig. Diese Proteinasen sind wichtige Virulenzfaktoren, die zum einen das Wachstum von $P$. gingivalis ermöglichen, zum anderen zur Zerstörung des Wirtsgewebes führen (Potempa et al. 2000). Die Identifikation der 
Lysin- und Arginin-Aminosäuresequenz für diese Fc-Region des IgG-Moleküls wurde von Bonagura et al. (1993) experimentell erarbeitet. Eine Schlüsselfunktion in der Rheumafaktorproduktion durch rheumatoide Zellen übernimmt $P g$, der speziell Lysin und Arginin zersetzt und die $\operatorname{lgG}_{3}-\mathrm{CH}_{2}$ - und $-\mathrm{CH}_{3}$ - Domänen durch $P$. gingivalis-Proteinase verarbeitet wird (Martin et al. 1994). Ungeklärt ist derzeit, ob und inwieweit der Rheumafaktor die chronische Parodontitis beeinflusst.

Auffällig ist, dass bei Patienten mit rheumatoider Arthritis das IgG anders glykolysiert ist. So fehlt bei ca. $60 \%$ der Patienten in den Kohlehydratketten des Fc-Teils die terminale Galaktose. Dieses Vorkommen ist mit einer schlechten Verlaufsprognose der rheumatoiden Arthritis assoziiert (Gran et al. 1983). Das Bakterium Prevotella melaninogenica kann an der Fc-Region des IgG-Moleküls binden und mit seinem Enzym die Galaktose katabolisieren (Haraldsson et al. 2005). Durch Galaktose oder N-Acetylgalaktosamine (u.a. Kohlenhydrate) können Bakterien gehemmt werden (Eshdat und Sharon 1984).

Die als Bindungsstelle für Superantigen-identifizierte-Region V-beta $(\mathrm{V} \beta)$ befindet sich am variablen Teil der Beta-Kette des T-Zell-Rezeptors (TCR). Superantigene sind hitzestabile, hydrophile Moleküle, die die Fähigkeit besitzen, TCR- und MHC(Major Histocompatibility Complex)-II-Moleküle miteinander zu verkleben (Gascoigne und Ames 1991) und somit ein Dauersignal bei den T-Zellen auszulösen (Dellabona et al. 1990). Aufgrund der mangelnden Variabilität der V $\beta$-Region werden jeweils mehrere Prozent des T-Zell-Pools aktiviert (Choi et al. 1989). Bei rheumatoide Arthritis-Patienten finden sich mehr TCR des V $\beta$-Gens (V $\beta$ 6, 8, 14, 17) als in der Kontrollgruppe (Cuesta et al. 1997; Hall et al. 1998), wobei $P$. gingivalis und $P$. intermedia die Expression von $V \beta-6$ und $V \beta-8$ (Superantigene) bei rheumatoider Arthritis steigern (Mathur et al. 1995).

Von den parodontalpathogenen Bakterien werden Enzyme gebildet, die das kollagene Stützgerüst sowie die Interzellularsubstanz auflösen und somit das Eindringen von weiteren Mikroorganismen erleichtern (Renggli 1977).

Die Hauptkomponente des hyalinen Knorpels ist Kollagen II. Es wurde bei rheumatoide Arthritis-Patienten ein erhöhtes Vorkommen von Autoantikörpern gegen Kollagen II nachgewiesen, welches die Destruktion forcieren kann (Clague et al. 1983; Rönnelid et al. 1994). 
Des Weiteren spielen Th17 und IL-17 eine große Rolle in der Pathogenese der rheumatoiden Arthritis sowie bei Parodontalerkrankungen (Tesmer et al. 2008; Cardoso et al. 2009).

Insgesamt bleibt festzuhalten, dass Zusammenhänge möglich und zum Teil erklärbar, aber bisher nicht eindeutig auf kausaler Ebene erklärt sind. 


\section{Material und Methode}

\subsection{Administrative Vorbereitungen}

Die Erlaubnis zur Durchführung der Studie wurde bei der Ethik-Kommission der Georg-August-Universität Göttingen beantragt und unter der Antragsnummer 8/9/05 genehmigt.

Da für die Untersuchung Patienten mit der Diagnose „rheumatoide Arthritis“ benötigt wurden, wurde in der Rheumaklinik Bad Wildungen, unter der Leitung von Chefarzt Dr. med. B. Krohn-Grimberghe, um Teilnahme an der Studie und Untersuchungsmöglichkeiten gebeten.

\subsection{Probandengewinnung}

Jeder Proband wurde schriftlich aufgeklärt und erklärte mit seiner Unterschrift die freiwillige Teilnahme an der geplanten Studie (s. 7.1.1 und 7.1.2).

Die Teilnehmer der Untersuchung rekrutierten sich aus Patienten der Rheumaklinik Bad Wildungen. Zu den Einschlusskriterien gehörten:

- Alter zwischen 18 und 70 Jahren

- Abgesicherte Diagnose: rheumatoide Arthritis (DAS28).

Die Einsicht in die Krankenakte der Patienten gab Aufschluss über eventuelle Vorerkrankungen. Somit konnten Probanden bereits vor Beginn der Untersuchungen aus anamnestischen Gründen von der Studie ausgeschlossen werden. Ausschlusskriterien waren:

- Immunsupprimierung

- Organtransplantation

- Patienten, bei denen eine Endokarditisprophylaxe erforderlich ist

- Vorliegen von Hepatitis A, B, C, Tuberkulose, HIV

- Patienten mit Niereninsuffizienz

- Patienten mit Anfalls- oder Nervenleiden

- suchtkranke Patienten

- bekannte Unverträglichkeit/ Überempfindlichkeit

- Schwangere

- Diabetiker. 
Zudem wurden aktuelle Blutparameter, wie z.B. C-reaktive Protein (CRP), Anzahl der weißen Blutkörperchen, Thrombozyten, Lymphozyten- und neutrophile Granulozytenzahlen sowie der Rheumafaktor (RF) erfasst.

\subsection{Fragebogen}

Für die Untersuchung wurde ein Fragebogen entworfen. Es wurden anamnestische Fragen u. a. zum Gesundheitszustand, Fragen zu Lebensgewohnheiten sowie Mundhygienegewohnheiten gestellt (s. 7.1.3). Bei der Auswertung der Ergebnisse sollten die gewonnenen Informationen dazu dienen, den einzelnen Patienten näher zu charakterisieren und ggf. Rückschlüsse auf seinen Parodontalzustand zu ziehen.

Die Probanden füllten den Fragebogen vor der klinischen Untersuchung selbstständig aus. Im Vorfeld wurde auf die Wichtigkeit der wahrheitsgemäßen und exakten Beantwortung der 30 Fragen hingewiesen. Bei Nichtverständnis oder Missverständnis einzelner Fragen stand der Zahnarzt zur Klärung zur Verfügung. Die Angaben der Probanden wurden vertraulich behandelt, anonym ausgewertet und anschließend vernichtet.

\subsection{Kalibrierung}

Die klinische Diagnose des Parodontalzustandes sollte mit Hilfe des ParodontalScreening-Index (PSI) standardisiert erhoben werden. Um eine exakte Reproduzierbarkeit der Messergebnisse zu gewährleisten, erfolgte im Vorfeld der Untersuchungsreihe eine individuelle Kalibrierung des klinischen Untersuchers. Ziel war es, eine einheitliche und reproduzierbare Erhebung der Messwerte zu garantieren. Der klinische Untersucher erhob bei vier Freiwilligen den PSI. Die Messungen wurden im Abstand von jeweils sieben Tagen so lange wiederholt, bis die Einzelwerte jedes Patienten, bei aufeinander folgenden Messungen, identisch waren. Auf diesem Wege sollte der Untersucher sich potenzieller Fehlerquellen bewusst werden, diese an der eigenen Messmethode erkennen und entsprechend abstellen. Folgende Fehlerquellen kamen in Betracht:

- ein falscher Anstellwinkel der Sonde bei der Messung

- ein zu großer oder zu geringer Kraftaufwand bei der Sondierung

- abweichender Kraftaufwand an den verschiedenen Messpunkten

- unzureichende Sicht 
- zu schnelle Bewertung eines Messpunktes hinsichtlich des Kriteriums „Blutung auf Sondierung“

- falsche Abfolge der Messpunkte.

\subsection{Klinische Untersuchung}

In der Zeit vom 16. April 2007 bis 21. Oktober 2008 wurden die Probanden in der Rheumaklinik Bad Wildungen klinisch untersucht. Im Rahmen der klinischen Untersuchung wurden der DMF-T-Index als Kariesindex und der ParodontalScreening-Index (PSI) erhoben. Zusätzlich wurden für die mikrobiologische Analyse (micro-IDent ${ }^{\circledR}$ plus- Test, Hain Lifesience $\mathrm{GmbH}$, Nehren, Deutschland) eine Poolprobe aus den tiefsten parodontalen Taschen und Abstriche von der Wangenschleimhaut zur Bestimmung des genetischen Risikos anhand des IL-1Polymorphismus (GenoType ${ }^{\circledR}$ PST plus-Test, Hain Lifesience $\mathrm{GmbH}$, Nehren, Deutschland). Alle Untersuchungen wurden unter standardisierten Umgebungsbedingungen durchgeführt.

\subsubsection{Kariesindex DMF-T}

Als erster klinischer Untersuchungsschritt wurde der DMF-T-Index erhoben. Der Untersucher zählte dazu die Zähne mit konservierender Versorgung (Füllungen) und prothetischer Kronenversorgung ( $F=$ filled), sowie fehlende $(M=$ missed) und zerstörte Zähne ( $D=$ decayed). Die drei resultierenden Werte wurden addiert und repräsentieren den DMF-T-Wert des Patienten. Ein hoher DMF-T steht für ein in höherem Maße vorgeschädigtes Gebiss z.B. durch Karies (hieraus resultieren ggf. Füllungen, Kronen und fehlende Zähne) oder durch Parodontitis (es resultieren u. U. fehlende Zähne). Ein niedriger DMF-T-Index steht für ein weniger vorgeschädigtes Gebiss (WHO 1997).

\subsubsection{Parodontal-Screening-Index (PSI)}

Um eine klinische Diagnose hinsichtlich des Parodontalzustandes zu ermitteln, wurde der Parodontal-Screening-Index (PSI) erhoben. Der PSI wurde von der American Academy of Periodontology (AAP) und der American Dental Association (ADA) entwickelt und beruht auf einem modifizierten CPITN (Community 
Periodontal Index of Treatment Needs) (Ainamo et al. 1982). Ziel dieser Untersuchung ist eine erste orientierende Beurteilung des Parodontalzustandes, um Anhaltspunkte für den individuellen Behandlungsbedarf zu erlangen. Hierbei wurden die Probanden auf die Kriterien „Blutung auf Sondierung“, „Zahnstein“, „überstehende Restaurationsränder" und „pathologische Taschen“ untersucht. Das zu untersuchende Gebiss wurde sextantenweise bewertet. Innerhalb jedes Sextanten wurden alle funktionsfähigen Zähne an sechs Messpunkten (mesio-vestibulär, vestibulär, disto-vestibulär, mesio-oral, oral, disto-oral) sondiert (Abb. 6 und 7).

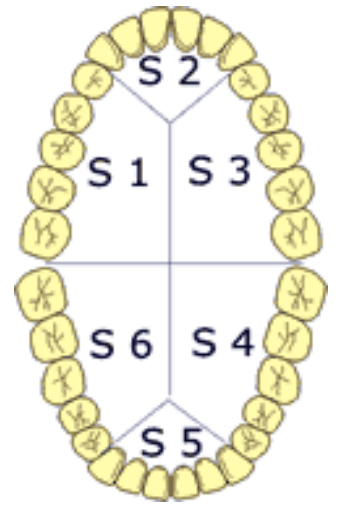

Abb. 6: Schematische Darstellung der Gebissunterteilung in Sextanten (www.zahnwissen.de)

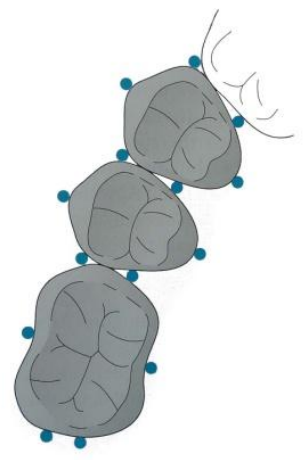

Abb. 7: Schematische Darstellung der Sondierungspunkte bei der Erhebung des PSI (Heidemann 1997, S. 103)

Zur Erhebung dieses Index wurden WHO-Sonden der Firma Morita ${ }^{\circledR}$ (Kyoto, Japan) (Abb. 8) und zahnärztliche Mundspiegel benutzt. Zur Messung der Taschentiefe führte der Untersucher die Sonde leicht zwischen Zahn und Zahnfleisch ein, wobei die aufzuwendende Kraft zwischen 15 und $26 \mathrm{~g}$ liegen sollte. Das Austasten sollte dem Patienten keinen Schmerz bereiten. Die Sondierungstiefe wurde an der Markierung der Sonde abgelesen. Durch das kugelförmige Ende der Sonde erfolgte gleichzeitig ein Ertasten von ggf. vorhandenem Zahnstein, Konkrementen oder überstehenden Restaurationsrändern. Nach Abwarten einer Zeitspanne von etwa 10 Sekunden wurde der sondierte Sextant auf das Kriterium „Blutung auf Sondierung" untersucht. Die ermittelten Informationen und erhobenen Daten wurden nach dem PSI-Schema bewertet. Jeder einzelne Messpunkt wurde mit einem Wert zwischen 0 und 4 bewertet. Der jeweils schlechteste Einzelwert stellt dabei den Referenzwert des Sextanten dar. Nicht in Betracht gezogen wurden die Werte PSI 3 bzw. 4 distal der zweiten Molaren. In dieser Region handelt es sich meistens um 
Pseudotaschen, die das Ergebnis verfälschen würden. Zahnlose Sextanten wurden mit einem X gekennzeichnet. Mit dem Kürzel „ * " (In Worten: Sternchen) hatte der Untersucher die Möglichkeit, klinische Auffälligkeiten zu dokumentieren, wie z.B. Furkationsbefall, Lockerungsgrad, Rezessionen oder muko-gingivale Veränderungen.

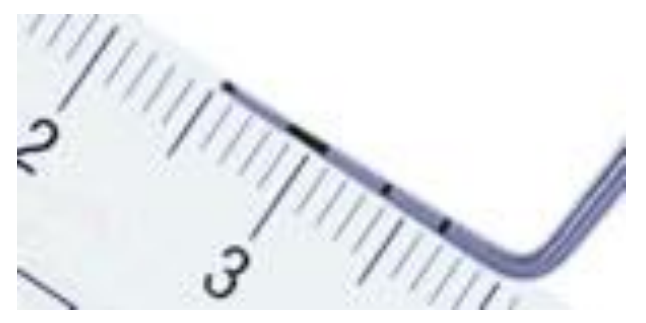

Abb. 8: Markierung der WHO-Sonde (www.zahnwissen.de)

Die auf diesem Wege ermittelten Werte wurden diktiert und notiert, im Anschluss vertraulich ausgewertet und vernichtet.

\subsubsection{Klinische Diagnosefindung}

Anhand der Graduierung des Parodontal-Screening-Index (PSI) wurde in Anlehnung an die von Tonetti und Claffey (2005) eine modifizierte Definition für Parodontitis zur klinischen Diagnose formuliert:

- Gesund/Gingivitis: PSI-Grad 0-2, max. ein Sextant PSI-Grad 3

- Moderate Parodontitis: PSI-Grad 3, max. ein Sextant PSI-Grad 4

- Starke Parodontitis: mehr als ein Sextant PSI-Grad 4.

\subsubsection{Mikrobiologischer Test}

Nach supragingivaler Plaqueentfernung wurden mit sterilen Papierspitzen der Größe ISO 50 (Hain Lifesience $\mathrm{GmbH}$, Nehren, Deutschland) PlaqueBiofilmproben von mindestens 2 (Ober- und Unterkiefer) bis max. 4 (1.- 4 . Quadrant) Zähnen aus der jeweils tiefsten Zahntasche entnommen und anschließend gepoolt. Mit einem kommerziell erhältlichen semiquantitativen Nachweis von 11 
verschiedenen Bakterien wurde die bakterielle Besiedelung der Patienten bestimmt (micro-IDent ${ }^{\oplus}$ plus- Test, Hain Lifesience $\mathrm{GmbH}$, Nehren, Deutschland). Die Bestimmung beschränkte sich hierbei auf folgende Komplexe (Nachweisgrenze: $\left.>10^{2}\right)$ :

- Violetter-Komplex: Aggregatibacter actinomycetemcomitans (Aa)

- Roter Komplex: Porphyromonas gingivalis (Pg), Tanerella forsythia (Tf), Treponema denticola $(\mathrm{Td})$

- Oranger Komplex: Prevotella intermedia (Pi), Peptostreptococcus micros (Pm), Fusobacterium nucleatum (Fn)

- Gelber Komplex: Campylobacter rectus (Cr), Eubacterium nodatum (En)

- Grüner Komplex: Eikanella corrodens (Ec),Capnocytophaga species (Cs).

\subsubsection{Bestimmung des IL-1-Polymorphismus (Genotypisierung)}

Anhand der mit dem Wangenschleimhautabstrich entnommenen menschlichen Mundschleimhautzellen wurde die molekulargenetische Charakterisierung des Interleukin-1-Polymorphismus (Genotypisierung) vorgenommen. Dieser Nachweis erfolgte mit einem kommerziell erhältlichen Test (GenoType ${ }^{\circledR}$ PST plus-Test; Hain Lifesience $\mathrm{GmbH}$, Nehren, Deutschland) und dessen IL-1-Polymorphismusspezifischen Gensonden: IL-1A -889 (Allel 1 (C): -C889, Allel 2 (T): -889T), IL-1B +3953 (Allel 1 (C): +C3953, Allel 2(T): +3953T) und IL-1RN (IL-1-Rezeptorantagonist) +2018 (Allel 1 (T): +T2018, Allel 2 (C): +2018C) des menschlichen Interleukin-Genklusters.

Entsprechend der Genotypen der IL-1-Polymorphismen (homozygot negativ, homozygot positiv oder heterozygot) erfolgte eine Ableitung in vier verschiedene Risikogruppen für Entzündung, z.B. Parodontitis, nach einer vom Hersteller standardisierten Auswertung entsprechend der Bandenmuster der IL-1-Polymorphismen: 
- Genotype 1: normale Entzündungsreaktion, kein erhöhtes genetisches Risiko

- Genotype 2: erhöhte Entzündungsreaktion, erhöhtes genetisches Risiko

- Genotype 3: stark erhöhte Entzündungsreaktion, stark erhöhtes genetisches Risiko für progressive Parodontitis

- Genotype 4: verminderte genetische Entzündungshemmung.

\subsection{Auswertung der Ergebnisse und Statistische Methodik}

Die erhobenen Befunde, formulierten Diagnosen und Ergebnisse des Fragebogens wurden in codierter Form mit Hilfe des Tabellenkalkulationsprogrammes Microsoft EXCEL 2003 archiviert. Die Auswertung erfolgte ebenfalls computergestützt. Es wurden Mittelwerte, Standardabweichungen, Minima und Maxima errechnet.

Als Auswertungsmethode wurde eine nichtparametrische Varianzanalyse mit den Kovariablen Alter, Geschlecht, Rauchen und den verabreichten Medikamenten (Methotrexat, Leflunomid (Arava ${ }^{\circledR}$ ), Calciumcarbonat + Colecalciferol (Ideos ${ }^{\circledR}$ ), Prednisolon, Folsäure) verwendet. Dabei wurden Genotyp Grad 2 und Genotyp Grad 3 zu einer Gruppe zusammengefasst.

Die Charakteristika der einzelnen Probanden, welche zur Zuordnung in eine Klientel dienten, waren folgende:

- Diagnose Rheuma Ja/ Nein

- Alter des Patienten

- Datum der Erstdiagnose

- Kariesindex DMF-T

- Raucher/ Nichtraucher

- Dauer des Nikotinkonsums in Jahren.

Die statistische Überprüfung erfolgte durch die Abteilung Medizinische Statistik der Universität Göttingen. 
Ziel der Untersuchung war es, den Parodontalzustand bei Patienten mit rheumatischen Erkrankungen zu charakterisieren. Im Fokus stand dabei die Frage, ob bei Rheumatikern die Ausprägung des der IL-1-Polymorphismus (Genotyp-Grad 1-4) Einfluss auf den Parodontalzustand nimmt und ob der Schweregrad der rheumatischen Erkrankung (klassifiziert nach Rheumafaktor erhöht: ja/nein) mit dem Parodontalzustand assoziiert ist. 


\section{Ergebnisse}

\subsection{Versuchspersonen}

Insgesamt konnten 66 Patienten $(w=29 ; m=37)$ in die Untersuchung einbezogen werden. Das durchschnittliche Alter der Patienten betrug 49.5 \pm 8.4 Jahre. Unter den Probanden befanden sich 46 Raucher (69,7\%) und 20 Nichtraucher (30,3\%). Einen seropositiven Rheumafaktor (RF) wiesen 25 Patienten (37,9\%) auf. Tabelle 6 und 7 geben einen Überblick über die Patientencharakteristik: Geschlecht, Alter, Krankheitsbeginn, Raucherverhalten und Medikamenteneinnahme sowie die erfassten Blutparameter.

Tab. 6: Patientencharakteristik der Teilnehmer nach Geschlecht, Alter (in Jahren), Dauer der Erkrankung nach Erstdiagnose (in Jahren) und Rauchverhalten

\begin{tabular}{|c|c|c|c|c|c|c|}
\hline & \multicolumn{2}{|c|}{$\begin{array}{c}\text { Dauer der Erkran- } \\
\text { kung } \\
\text { [in Jahren] }\end{array}$} & \multicolumn{2}{|c|}{$\begin{array}{c}\text { Alter } \\
\text { [in Jahren] }\end{array}$} & \multicolumn{2}{|c|}{ Rauchgewohnheiten } \\
\hline & $\min$. & $\max$. & $\min$. & $\max$. & Raucher & Nichtraucher \\
\hline $\begin{array}{l}\text { männlich } \\
\qquad(\mathrm{n}=37)\end{array}$ & 0.5 & 46 & 28 & 59 & $\mathrm{n}=27$ & $n=10$ \\
\hline $\begin{array}{l}\text { weiblich } \\
(n=29)\end{array}$ & 1 & 28 & 37 & 69 & $\mathrm{n}=19$ & $n=10$ \\
\hline $\begin{array}{c}\text { total } \\
(n=66)\end{array}$ & \multicolumn{2}{|c|}{$\begin{array}{c}\text { Mittelwert } \pm S A: \\
7.6 \pm 8.6\end{array}$} & \multicolumn{2}{|c|}{$\begin{array}{c}\text { Mittelwert } \pm S A \text { : } \\
49.5 \pm 8.4 \\
\text { (median: } 50 \text { ) }\end{array}$} & $\begin{array}{c}n=46 \\
(69,7 \%)\end{array}$ & $\begin{array}{c}n=20 \\
(30,3 \%)\end{array}$ \\
\hline
\end{tabular}

(SA: Standardabweichung) 
Tab. 7: Eingenommene Medikamente und Blutparameter der Studienteilnehmer

\begin{tabular}{|c|c|}
\hline Eingenommene Medikamente & $\begin{array}{c}\text { Anzahl der Pa- } \\
\text { tienten (\%) }\end{array}$ \\
\hline Methotrexat (MTX) & $\mathrm{n}=34(51,5)$ \\
\hline Folsäure & $\mathrm{n}=40(60,6)$ \\
\hline Prednisolon & $\mathrm{n}=35(53,0)$ \\
\hline $\begin{array}{c}\text { Calciumcarbonat }+ \text { Colecalciferol } \\
\left(\operatorname{Ideos}^{\circledR}\right)\end{array}$ & $\mathrm{n}=26(39,4)$ \\
\hline Leflunomid $\left(\right.$ Arava $\left.^{\circledR}\right)$ & $\mathrm{n}=15(22,7)$ \\
\hline $\begin{array}{l}\text { Serum / Blutparameter } \\
\text { (Mittelwert } \pm S A)\end{array}$ & \\
\hline $\operatorname{CRP}(\mathrm{mg} / \mathrm{dl})$ & $1.43 \pm 1.65$ \\
\hline WBC (tsd/ul) & $7.40 \pm 2.48$ \\
\hline PLT (tsd/ul) & $307.42 \pm 76.96$ \\
\hline Lymphozyten (\%) & $31.68 \pm 11.28$ \\
\hline Neutrophile Granulozyten (\%) & $56.25 \pm 12.30$ \\
\hline
\end{tabular}

(SA: Standardabweichung, CRP: C-reactives Protein, WBC: weiße Blutkörperchen; PLT: Thrombozyten im Plasma)

\subsection{Dentaler Befund (DMF-T):}

Der mittlere DMF-T der Probanden lag bei 16.8 \pm 6.3 . Durchschnittlich waren

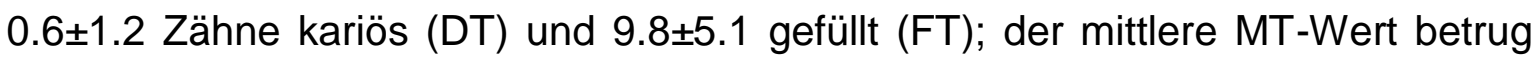
6.4 46.6 . (Tab. 8). Insgesamt hatten 61 Patienten mehr als 7 Zähne; ein Patient war zahnlos. In der nichtparametrischen Varianzanalyse zeigte lediglich die Kovariable Alter einen signifikanten Einfluss auf den DMF-T $(p=0.026)$. 
Tab. 8: Mittelwerte der erhobenen dentalen Befunde (DMF-T)

\begin{tabular}{|c|c|c|c|}
\hline DMF-T & D-T & M-T & F-T \\
\hline $16,8 \pm 6,3$ & $0,6 \pm 1,2$ & $6,4 \pm 6,6$ & $9,8 \pm 5,1$ \\
\hline
\end{tabular}

\subsection{Parodontaler Screening Index (PSI)}

Kein Proband war in Bezug auf Parodontalerkrankungen gesund (PSI score 0). 16 Probanden (24,6\%) wiesen einen höchsten PSI-Wert von 1 oder 2 und 18 Probanden (27,7\%) einen PSI-Wert von 3 auf, während 31 Probanden $(47,7 \%)$ einen PSI-Wert von 4 hatten (Tab. 9). Der zahnlose Patient wurde hierbei nicht berücksichtigt. Dementsprechend wiesen 75,4\% ( $n=49)$ einen parodontalen Behandlungsbedarf auf. Die absoluten PSI-Werte der einzelnen Sextanten sind in Abbildung 9 (inklusive zahnloser Patient) graphisch dargestellt.

Tab. 9: Absolute Häufigkeit der PSI-Werte

\begin{tabular}{|c|c|c|c|}
\hline PSI 0 & PSI 1 \& 2 & PSI 3 & PSI 4 \\
\hline $\mathrm{n}=0$ & $\mathrm{n}=16$ & $\mathrm{n}=18$ & $\mathrm{n}=31$ \\
$(0 \%)$ & $(24,6 \%)$ & $(27,7 \%)$ & $(47,7 \%)$ \\
\hline
\end{tabular}




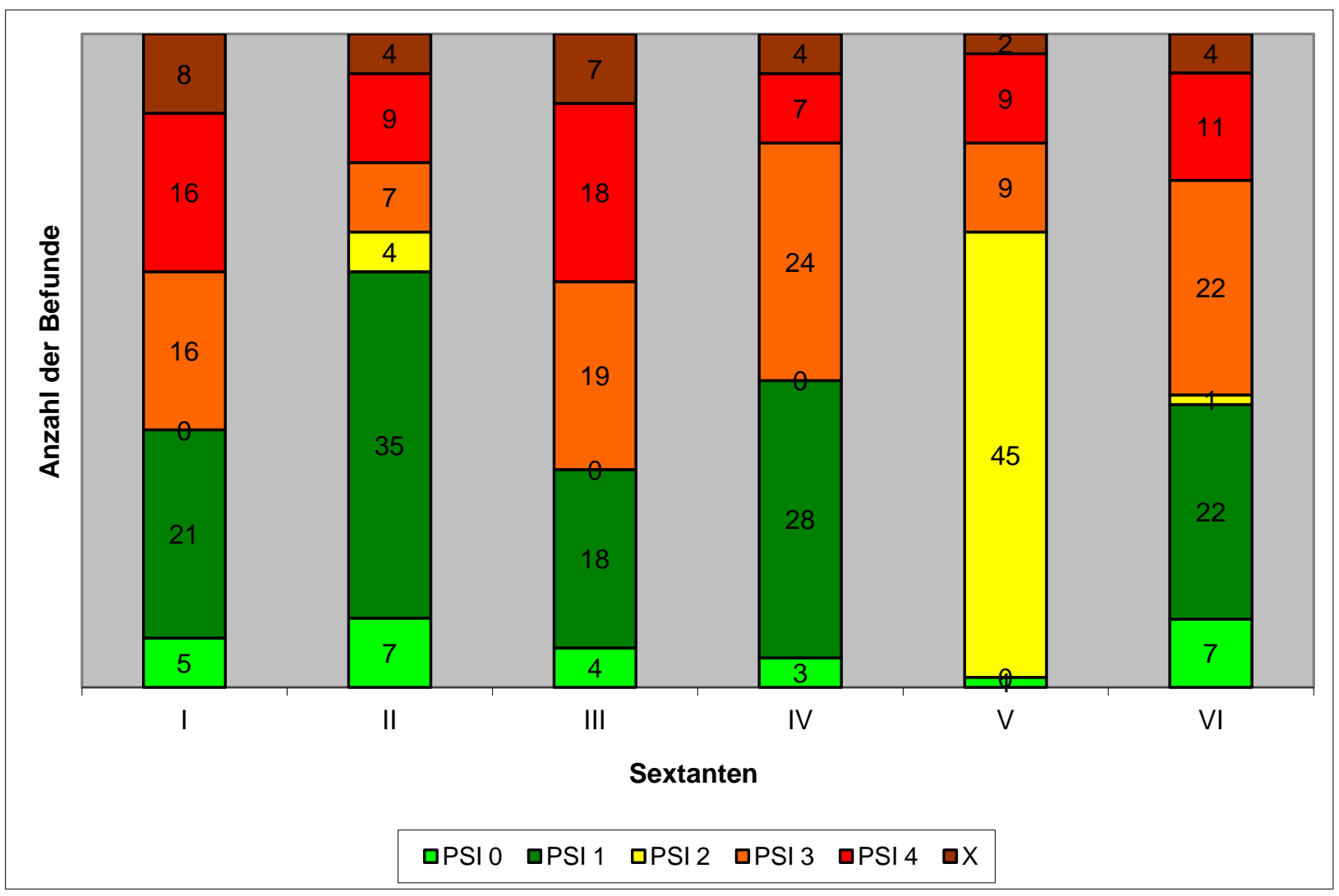

Abb. 9: Übersicht der PSI-Werte der einzelnen Sextanten graphisch dargestellt.

In Übereinstimmung mit der in dieser Studie angewendeten Definition können folgende Diagnosen anhand des PSI gestellt werden: 24 Patienten (36,9\%) hatten die Diagnose „gesund/Gingivitis“, 18 Patienten (27,7\%) zeigten eine „moderate Parodontitis” und bei 23 Patienten (35,4\%) konnte eine „starke Parodontitis“ festgestellt werden. Der zahnlosen Patienten wurde nicht mit einbezogen.

Der Rheumafaktor wies keinen signifikanten Einfluss auf den Paradontalzustand auf $(p=0.33)$. Für die Kovariablen Alter $(p=0,22)$, Geschlecht $(p=0,74)$ und Medikation $(p=0,09)$ war kein signifikanter Einfluss auf den Parodontalzustand festzustellen. Einzig die Kovariable Rauchen zeigt einen signifikanten Einfluss $(p=0,0004)$ (Abb.10). 


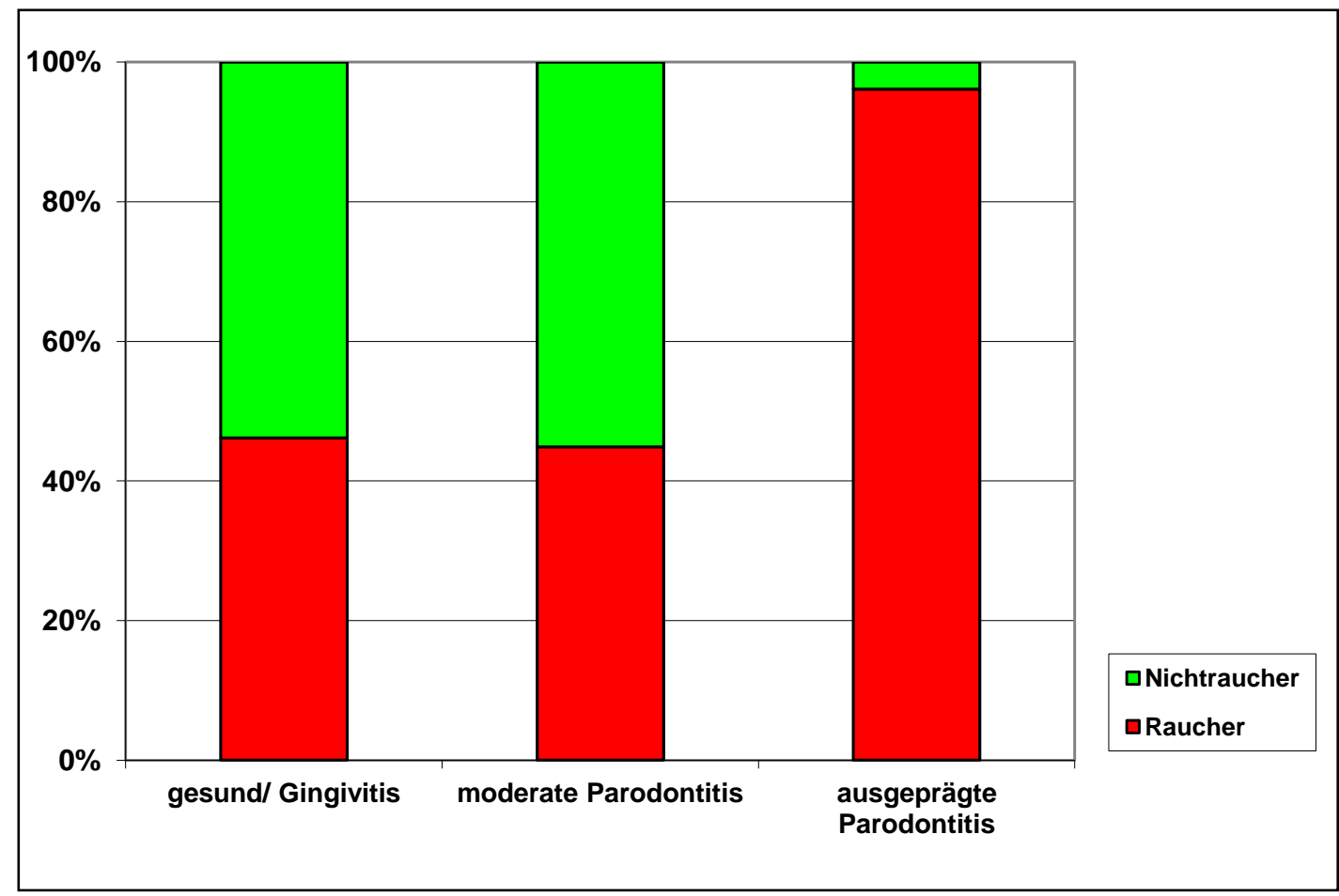

Abb. 10: Verteilung des Rauchverhaltens der Patienten (Raucher/Nichtraucher) nach dem Parodontalzustand (gesund/Gingivitis, moderate Parodontitis, ausgeprägte Parodontitis)

\subsection{IL-1-Polymorphismus}

Die Verteilung der IL-1-Polymorphismen entsprechend dem vorliegenden Genotyp sind in Tabelle 10 aufgeführt. Lediglich 19 Patienten (28,8\%) wiesen ausschließlich homozygot negative Befunde ohne IL-1-Polymorphism bei allen drei untersuchten Genarealen auf; alle anderen $(71,2 \%)$ zeigten entsprechende auffällige Genotypen (heterozygot oder homozygot positiv). 
Tab. 10: Verteilung der IL-1-Polymorphismen (IL-1A -889, IL-1B +3953, IL-1RN +2018) nach Genotyp (homozygot negativ, homozygot positiv und heterozygot)

\begin{tabular}{|c|c|c|}
\hline IL-1-Polymorphismus & Allele & $\begin{array}{l}\text { Anzahl der Patienten } \\
\qquad(\mathrm{n}=66)\end{array}$ \\
\hline \multirow{3}{*}{ IL-1A -889 } & $\begin{array}{l}\text { homozygot negativ } \\
\quad(\text { kein C / T) }\end{array}$ & $n=33$ \\
\hline & heterozygot ( $\mathrm{C}$ oder $\mathrm{T})$ & $n=31$ \\
\hline & $\begin{array}{l}\text { homozygot postiv } \\
\text { (C und } T)\end{array}$ & $n=2$ \\
\hline \multirow{3}{*}{ IL-1B +3953 } & $\begin{array}{l}\text { homozygot negativ } \\
\quad(\text { kein C / T) }\end{array}$ & $n=42$ \\
\hline & heterozygot ( $\mathrm{C}$ oder $\mathbf{T})$ & $n=23$ \\
\hline & $\begin{array}{l}\text { homozygot postiv } \\
\text { (C und T) }\end{array}$ & $n=1$ \\
\hline \multirow{3}{*}{ IL-1RN +2018 } & $\begin{array}{l}\text { homozygot negativ } \\
\quad(\text { kein C / T) }\end{array}$ & $n=38$ \\
\hline & heterozygot ( $\mathrm{C}$ oder $\mathrm{T})$ & $n=25$ \\
\hline & $\begin{array}{l}\text { homozygot postiv } \\
\qquad(\mathrm{C} \text { und } \mathrm{T})\end{array}$ & $n=3$ \\
\hline
\end{tabular}

Anhand der IL-1-Polymorphismen/Genotypen erfolgte die Einteilung in die Risikogruppen. Bei 24 Patienten lag Genotyp 1 (kein erhöhtes genetisches Risiko), bei 14 bzw. sechs Patienten Genotyp 2 (erhöhtes genetisches Risiko) bzw. 3 (stark erhöhtes genetisches Risiko) vor. Zweiundzwanzig Patienten zeigten eine verminderte genetische Entzündungshemmung (Genotyp 4) (Abb.11). Ein erhöhtes genetisches Risiko für entzündliche Reaktionen (IL-1-Genotyp Gruppe 2-4) wurde bei $63,6 \%$ der Rheumapatienten $(n=42)$ festgestellt. 


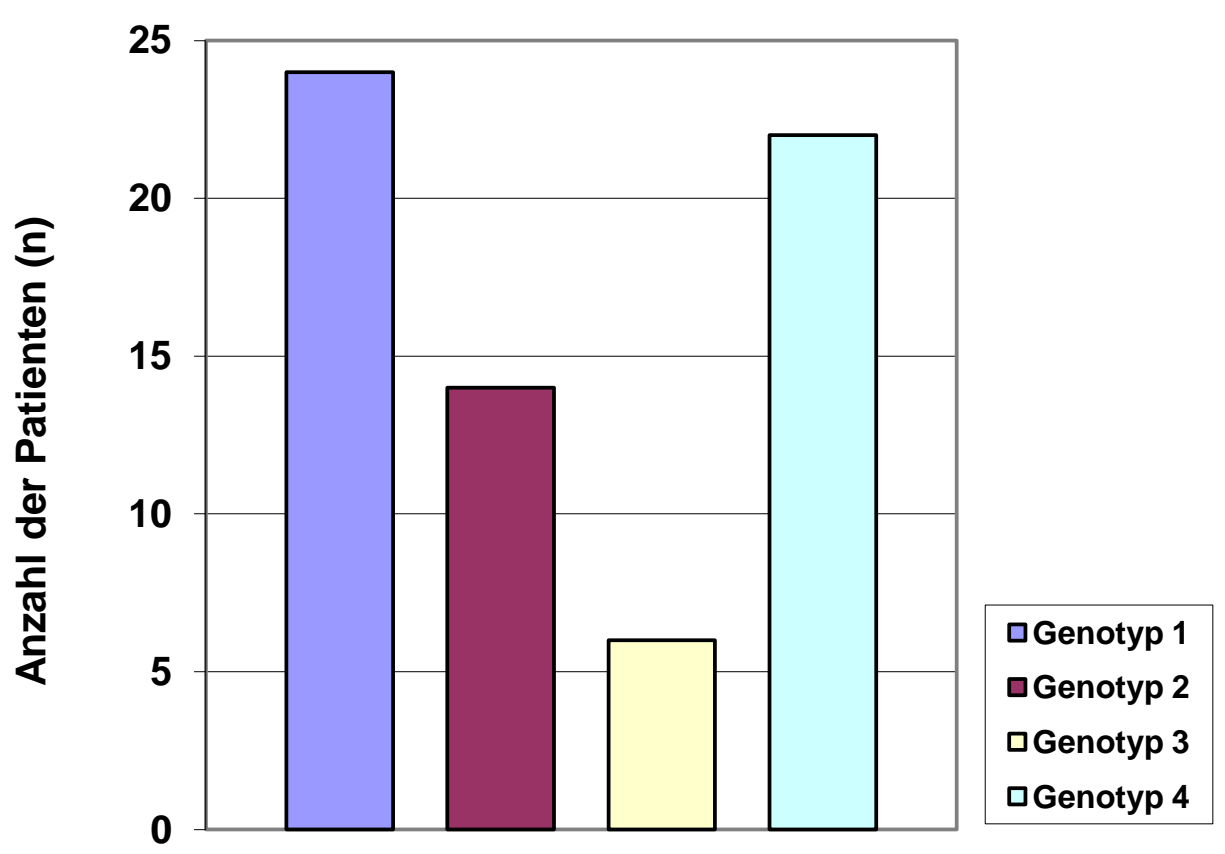

Abb. 11 Anzahl der Patienten in den jeweiligen Genotypgruppen

\subsection{Zusammenhang zwischen parodontalem Zustand und Geno- typ (IL-1- Polymorphismus)}

Betrachtet man den Parodontalzustand (gesund/Gingivitis, moderate Parodontitis, starke Parodontitis), wiesen von den parodontal gesunden Patienten neun Patienten Genotyp 1, sieben Patienten Genotyp 2 oder 3 und acht Patienten Genotyp 4 auf. Patienten mit moderater Parodontitis zeigten folgende Risikogenotypen: Genotyp 1: $n=4$, Genotyp 2 oder 3: $n=8$, Genotyp 4: $n=6$. Bei Patienten mit ausgeprägter Parodontitis wurde folgende Verteilung festgestellt: Genotyp1: n=11, Genotyp 2 oder 3: n=5, Genotyp 4: n=7 (Tab. 11 und Abb.12). Der zahnlose Patient wurde hierbei nicht berücksichtigt.

In der nichtparametrischen Varianzanalyse war kein signifikanter Einfluss des Risikogenotyps auf den Parodontalzustand festzustellen $(p=0.76)$. 
Tab. 11: Verteilung des Risikogenotyps (1-4) nach dem Parodontalzustand

\begin{tabular}{|l|c|c|c|}
\hline & gesund/Gingivitis & $\begin{array}{c}\text { moderate } \\
\text { Parodontitis }\end{array}$ & $\begin{array}{c}\text { ausgeprägte } \\
\text { Parodontitis }\end{array}$ \\
\hline Genotyp 1 & 9 & 4 & 11 \\
\hline Genotyp 2-3 & 7 & 8 & 5 \\
\hline Genotyp 4 & 8 & 6 & 7 \\
\hline Gesamt & 24 & 18 & 23 \\
\hline
\end{tabular}

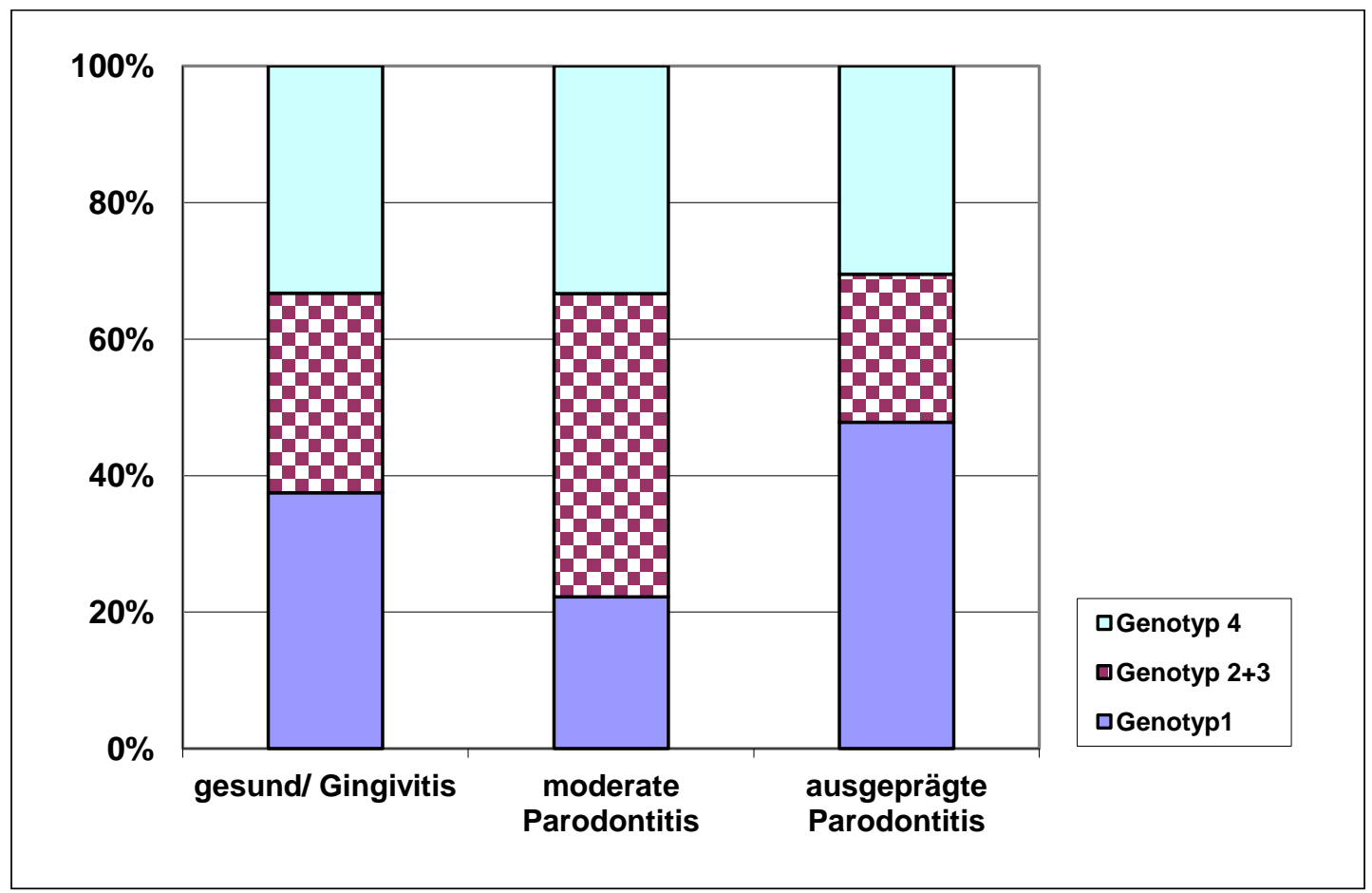

Abb. 12: Verteilung der ermittelten IL-1-Polymorphismen (Risikogenotyp 1-4) nach dem Parodontalzustand

Wie oben bereits aufgeführt zeigte lediglich die Kovariable Rauchen einen signifikanten Einfluss auf den Parodontalzustand ( $p=0.0004)$ (Abb. 10); wobei eine Gleich-verteilung der Raucher in den Risikogenotypgruppen vorlag (Abb. 13). 


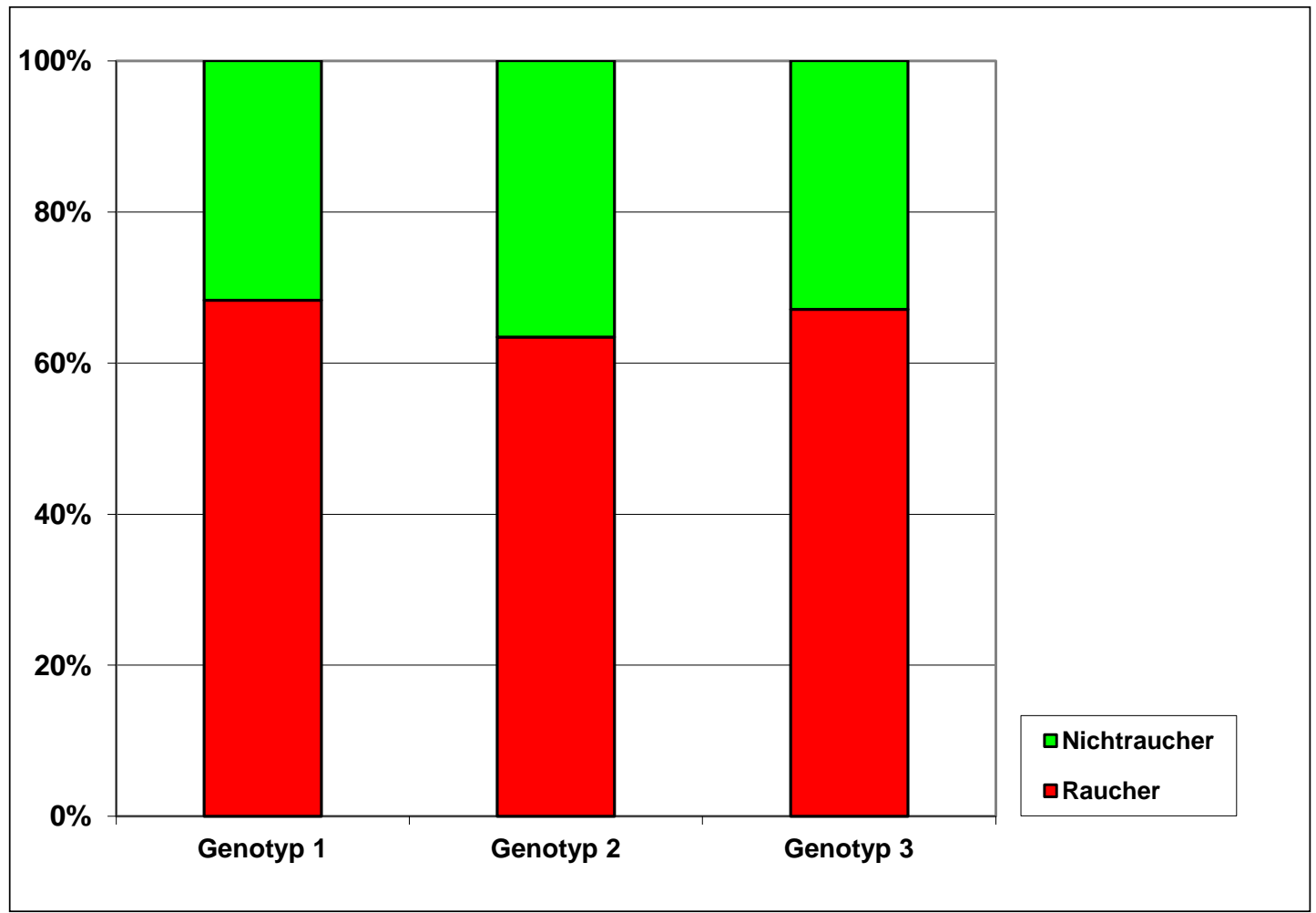

Abb. 13: Verteilung des Rauchverhaltens (Raucher/Nichtraucher) nach dem ermittelten IL-1-Polymorphismus (Risikogenotyp 1-4)

\subsection{Mikrobiologische Auswertung:}

Bei allen rheumatoide Arthritis-Patienten konnten die 11 parodontalpathogenen Bakterien in unterschiedlicher Verteilung und Konzentration nachgewiesen werden (Nachweisgrenze $10^{2}$ ). Dabei waren überwiegend Bakterien des orangenen und gelben Komplexes aufzufinden (Fn (98\%), Ec (91\%) und Pm (88\%)). Stark parodontalpathogene Bakterien des roten und violetten Komplexes (Aa-Komplex) wurden bei weniger Patienten gefunden. Aus dem roten Komplex waren $\mathrm{Td}(66 \%)$ und $\operatorname{Tf}(78 \%)$ am häufigsten vertreten (Tab. 12). 
Tab. 12: Prävalenz der einzelnen Bakterien nach Komplexen in der Patientengruppe sowie mediane Bakterienkonzentration oberhalb der Nachweisgrenze über die gesamte Patientengruppe und für die ausschließlich positiven Befunde ( $n=65)$.

\begin{tabular}{|c|c|c|c|c|}
\hline \multicolumn{2}{|c|}{ Komplexe / Bakterien } & $\begin{array}{c}\text { Prävalenz der einzel- } \\
\text { nen Bakterien (Anzahl } \\
\text { der Patienten \%) }\end{array}$ & $\begin{array}{c}\text { Mittlere Bakterienkon- } \\
\text { zentration aller } \\
\text { Patienten }\end{array}$ & $\begin{array}{l}\text { Mittlere Bakterienkonzent- } \\
\text { ration von Patienten über } \\
\text { der Nachweisgrenze }\left(>10^{2}\right)\end{array}$ \\
\hline Violetter Komplex & $\mathrm{Aa}$ & $16 \%$ & $<10^{3}$ & $>10^{6}$ \\
\hline \multirow{3}{*}{ Roter Komplex } & $\mathrm{Pg}$ & $58 \%$ & $10^{5}-10^{6}$ & $>10^{7}$ \\
\hline & Tf & $78 \%$ & $10^{6}-10^{7}$ & $10^{6}-10^{7}$ \\
\hline & $\mathrm{Td}$ & $66 \%$ & $10^{5}-10^{6}$ & $10^{6}-10^{7}$ \\
\hline \multirow{3}{*}{ Oranger Komplex } & $\mathrm{Pi}$ & $41 \%$ & $<10^{4}$ & $>10^{7}$ \\
\hline & $\mathrm{Pm}$ & $88 \%$ & $10^{5}-10^{6}$ & $10^{6}-10^{7}$ \\
\hline & $\mathrm{Fn}$ & $98 \%$ & $>10^{7}$ & $>10^{7}$ \\
\hline \multirow{2}{*}{ Gelber Komplex } & $\mathrm{Cr}$ & $67 \%$ & $10^{5}-10^{6}$ & $10^{6}-10^{7}$ \\
\hline & En & $47 \%$ & $<10^{4}$ & $10^{5}-10^{6}$ \\
\hline \multirow{2}{*}{ Grüner Komplex } & Ec & $91 \%$ & $10^{6}-10^{7}$ & $10^{6}-10^{7}$ \\
\hline & Cs & $81 \%$ & $10^{5}-10^{6}$ & $10^{5}-10^{6}$ \\
\hline
\end{tabular}

(Aa: Aggregatibacter actinomycetemcomitans, Pg: Porphyromonas gingivalis, Tf: Tanerella forsythia, Td: Treponema denticola, Pi: Prevotella intermedia, Pm: Peptostreptococcus micros, Fn: Fusobacterium nucleatum, Cr: Campylobacter rectus, En: Eubacterium nodatum, Ec: Eikanella corrodens and Cs: Capnocytophaga species; Nachweisgrenze: $>10^{2}$ )

Ein Einfluss des Rheumafaktors auf die Bakterienlast konnte in keinem Fall ermittelt werden ( $p>0.05)$. Nur bei En ließen sich Tabakkonsum ( $E n: p=0.02)$ und bei $E c$ und $C s$ die Medikation als auffällige Einflussfaktoren erkennen ( $E c: p=0.04 ; C s$ : $p=0.01)$. Bei den übrigen Bakterien zeigten die Kovariablen Alter, Geschlecht, Tabakkonsum und Medikation keinen signifikanten Einfluss ( $p>0.05)$. Im Fall von Ec und $C s$ zeigte der IL-1-Genotyp einen signifikanten Einfluss ( $E c$ : $\mathrm{p}=0.04 ; C s: 0.03$ ) (Tab. 13). 
Tab. 13: Statistischer Vergleich ( $p$-Werte adjustiert) des Einflusses der Faktoren Rheumafaktor und Genotyp sowohl der Kovariablen (Alter, Geschlecht, Raucher und Medikation) auf die untersuchten parodontalpathogenen Bakterien.

\begin{tabular}{|c|c|c|c|c|c|c|}
\hline \multirow{2}{*}{$\begin{array}{l}\text { Parodontal- } \\
\text { pathogene } \\
\text { Bakterien }\end{array}$} & \multicolumn{2}{|c|}{ Faktor } & \multicolumn{4}{|c|}{ Kovariablen } \\
\hline & Rheumafaktor & IL-1-Genotyp & Alter & Geschlecht & Raucher & $\begin{array}{c}\text { Rheuma- } \\
\text { Medikamente }\end{array}$ \\
\hline $\mathrm{Aa}$ & $p=0.29$ & $p=0.76$ & $p=0.59$ & $p=0.98$ & $p=0.91$ & $p=0.71$ \\
\hline $\mathbf{P g}$ & $p=0.94$ & $p=0.46$ & $p=0.16$ & $p=0.05$ & $p=0.40$ & $p=0.82$ \\
\hline Tf & $p=0.50$ & $p=0.83$ & $p=0.06$ & $p=0.99$ & $p=0.37$ & $p=0.23$ \\
\hline Td & $p=0.81$ & $p=0.68$ & $p=0.15$ & $p=0.37$ & $p=0.48$ & $p=0.43$ \\
\hline $\mathbf{P i}$ & $p=0.09$ & $p=0.75$ & $p=0.13$ & $p=0.17$ & $p=0.08$ & $p=0.62$ \\
\hline Pm & $p=0.24$ & $p=0.98$ & $\mathrm{p}=0.52$ & $p=0.52$ & $p=0.05$ & $p=0.39$ \\
\hline Fn & $p=0.24$ & $p=0.08$ & $\mathrm{p}=0.17$ & $p=0.54$ & $\mathrm{p}=0.61$ & $p=0.65$ \\
\hline $\mathrm{Cr}$ & $p=0.48$ & $p=0.84$ & $p=0.85$ & $p=0.49$ & $p=0.19$ & $\mathrm{p}=0.72$ \\
\hline En & $p=0.15$ & $p=0.60$ & $\mathrm{p}=0.99$ & $p=0.83$ & $\mathrm{p}=0.02^{*}$ & $p=0.21$ \\
\hline Ec & $p=0.27$ & $p=0.04^{\star}$ & $p=0.21$ & $p=0.68$ & $p=0.16$ & $p=0.04^{\star}$ \\
\hline Cs & $\mathrm{p}=0.28$ & $\mathrm{p}=0.03^{\star}$ & $\mathrm{p}=0.46$ & $\mathrm{p}=0.42$ & $\mathrm{p}=0.34$ & $p=0.01^{*}$ \\
\hline
\end{tabular}

(Aa: Aggregatibacter actinomycetemcomitans, Pg: Porphyromonas gingivalis, Tf: Tanerella forsythia, Td: Treponema denticola, Pi: Prevotella intermedia, Pm: Peptostreptococcus micros, Fn: Fusobacterium nucleatum, Cr: Campylobacter rectus, En: Eubacterium nodatum, Ec: Eikanella corrodens und Cs: Capnocytophaga species; Nachweisgrenze: $>10^{2} ;{ }^{*}=$ signifikanter Einfluss)

Die parodontale Situation (Gingivitis oder moderate/starke Parodontitis) zeigt einen signifikanten Einfluss auf die Prävalenz der oralen Bakterien Pg, Tf, Td, Pi, En und $\mathrm{Aa}$. Bei den anderen nachgewiesenen Bakterien ( $\mathrm{Pm}, \mathrm{Fn}, \mathrm{Cr}, \mathrm{Ec}, \mathrm{Cs}$ ) ist kein signifikanter Einfluss erkennbar ( $p>0.05)$ (Tab. 14). 
Tab. 14: Prävalenz der einzelnen Bakterien in Abhängigkeit von Gingivitis oder Parodontitis

\begin{tabular}{|c|c|c|c|c|}
\hline \multicolumn{2}{|c|}{ Komplexe / Bakterien } & $\begin{array}{l}\text { Prävalenz der } \\
\text { zahl }\end{array}$ & $\begin{array}{l}\text { en Bakterien (An- } \\
\text { ienten \%) } \\
\text { moderate oder } \\
\text { starke Parodontitis } \\
\qquad(\mathrm{n}=41)\end{array}$ & $\begin{array}{c}\text { Signifikanzniveau } \\
\left(p-\text { Wert }^{\star}\right)\end{array}$ \\
\hline Violetter Komplex & $\mathrm{Aa}$ & $25 \%$ & $10 \%$ & $0.05^{\star}$ \\
\hline \multirow{3}{*}{ Roter Komplex } & $\mathrm{Pg}$ & $38 \%$ & $68 \%$ & $0.002^{\star}$ \\
\hline & Tf & $50 \%$ & $93 \%$ & $0.001^{*}$ \\
\hline & $\mathrm{Td}$ & $42 \%$ & $78 \%$ & $0.006^{\star}$ \\
\hline \multirow{3}{*}{ Oranger komplex } & $\mathrm{Pi}$ & $17 \%$ & $54 \%$ & $0.01^{*}$ \\
\hline & $\mathrm{Pm}$ & $67 \%$ & $98 \%$ & 0.45 \\
\hline & $\mathrm{Fn}$ & $88 \%$ & $100 \%$ & 0.13 \\
\hline \multirow{2}{*}{ Gelber Komplex } & $\mathrm{Cr}$ & $46 \%$ & $78 \%$ & 0.16 \\
\hline & En & $17 \%$ & $68 \%$ & $0.03^{*}$ \\
\hline \multirow{2}{*}{ Grüner Komplex } & Ec & $79 \%$ & $95 \%$ & 0.38 \\
\hline & Cs & $71 \%$ & $85 \%$ & 0.60 \\
\hline
\end{tabular}

(Aa: Aggregatibacter actinomycetemcomitans, Pg: Porphyromonas gingivalis, Tf: Tanerella forsythia, Td: Treponema denticola, Pi: Prevotella intermedia, Pm: Peptostreptococcus micros, Fn: Fusobacterium nucleatum, Cr: Campylobacter rectus, En: Eubacterium nodatum, Ec: Eikanella corrodens and Cs: Capnocytophaga species; Nachweisgrenze: $>10^{2},{ }^{*}=$ signifikanter Einfluss) 


\section{Diskussion}

Die Ergebnisse der untersuchten rheumatoide Arthritis-Patienten zeigten nach der vorab festgelegten Definition eine verhältnismäßig hohe Prävalenz der moderaten bis ausgeprägten Parodontitis ( $n=41 / 63,1 \%$ ). Ebenfalls konnte bei $75,4 \%$ ein paro-dontaler Behandlungsbedarf (PSI-Score 3 und 4) festgestellt werden.

Zudem lag in der untersuchten Patientengruppe mit durchschnittlich $6.4 \pm 6.6$ eine relativ hohe Anzahl fehlender Zähne (MT) vor. Diesbezüglich ist jedoch zu bemerken, dass die Ursachen für Zahnverlust vielfältig sein können. Primär ist von einer kariösen Zerstörung der Zahnhartsubstanz auszugehen. Des Weiteren kommt, vor allem im höheren Lebensalter, die Destruktion des Zahnhalteapparats (Parodontitis) in Betracht, was wiederum für eine Assoziation beider Erkrankungen (rheumatoider Arthritis, Parodontitis) sprechen könnte. Diese Assoziation bleibt jedoch für die vorliegende Untersuchung spekulativ.

Andere klinische und epidemiologische Studien mit Rheumapatienten stellten ebenfalls eine hohe Prävalenz von Zahnverlust fest (Mercado et al. 2001; Kobayashi et al. 2007; Pischon et al. 2008; de Pablo et al. 2008). Während Kobayashi et al. (2007) und Pischon et al. (2008) eine ähnliche Anzahl fehlender Zähne bei ihren Patienten fanden, stellten Mercado et al. (2001) und de Pablo et al. (2008) durchschnittlich 11.6 bzw. 20 fehlende Zähne in ihren rheumatoide ArthritisPatientengruppen fest. Darüber hinaus wiesen rheumatoide Arthritis-Patienten ein erhöhtes Risiko für „Zahnlosigkeit“ auf (Odds Ration (OR): 2.27) (de Pablo et al. 2008).

Die hohe Prävalenz der Parodontitis bzw. parodontalen Behandlungsbedürftigkeit in der untersuchten Patientengruppe ist sicherlich bemerkenswert, war aber auf Grundlage vorangegangener Studien zu erwarten. Anhand epidemiologischer Erhebungen und klinischer Fall-Kontroll-Studien scheint eine Assoziation zwischen rheumatoider Arthritis und dem Vorliegen einer Parodontitis sowie erhöhtem Zahnverlust gesichert (de Pablo et al. 2009). So zeigten Patienten mit rheumatoider Arthritis auffällig gehäuft klinische Zeichen einer Parodontitis mit erhöhten Taschentiefen ( $O R=2.47)$ und Attachmentverlust (Mercado et al. 2001; Kobayashi et al. 2007; Pischon et al. 2008). Die Odds Ratio für eine positive Assoziation wird mit 8.05 angegeben (Pischon et al. 2008). Die vorliegende Untersuchung bestätigt damit ein gehäuftes Auftreten von Parodontitis bei rheumatoide Arthritis-Patienten. Dabei konnte lediglich das Rauchen als signifikanter Einflussfaktor identifiziert 
werden. Dass Zigarettenkonsum ein Risikofaktor für Parodontitis darstellt, ist jedoch, unabhängig vom rheumatoide Arthritis-Status, hinlänglich beschrieben (Heasman et al. 2006).

Zudem scheint bei Vorliegen einer mittelschweren bis schweren Parodontitis bei Nichtrauchern das Risiko für eine rheumatoide Arthritis um das 2,6fache erhöht und bei Rauchern mit einer gesteigerten rheumatoide Arthritis-Inzidenz assoziiert zu sein (Molitor et al. 2009). Dieser Sachverhalt wurde in dieser Untersuchung nicht festgestellt, auffällig war jedoch die große Anzahl an Rauchern bei den untersuchten rheumatoide Arthritis-Patienten ( $n=46$ / 69,7\%).

Der Großteil der untersuchten rheumatoide Arthritis-Patienten $(71,2 \%)$ wies einen heterozygoten oder homozygot positiven Genotyp eines IL-1-Polymorphismus (IL1A -889, IL-1B +3953 oder IL-1RN +2018) auf. Darüber hinaus wurde auf Grundlage der IL1-Polymorphismen bei der Mehrzahl der rheumatoide Arthritis-Patienten ( $n=42$ / 63,6\%) ein erhöhtes genetisches Risiko für Entzündungsreaktionen (Genotyp 2-4) gefunden. Jedoch zeigten die Ergebnisse, dass ein IL-1-Polymorphismus bei rheumatoide Arthritis-Patienten nicht mit einem erhöhten ParodontitisRisiko in Verbindung zu stehen scheint. Damit konnte die vorab gestellte Hypothese, dass rheumatoide Arthritis-Patienten mit IL-1-Polymorphismus ein erhöhtes Risiko für Parodontitis aufweisen, nicht bestätigt werden.

Bezüglich der IL-1-Polymorphismen (IL-1A -889, IL-1B +3953 oder IL-1RN +2018) ist das gehäufte Auftreten der heterozygoten und homozygot positiven Genotypen sowie der abgeleiteten Risikogenotypen 2, 3 und 4 auffallend. Die Ergebnisse bestätigen damit andere Studien, die eine Assoziation von IL-1-Polymorphismen, u.a. IL-1A+4845 und IL-1B+3954, mit Parodontitis bzw. Risiko für Parodontitis zeigten (Kornman et al. 1997; McDevitt et al. 2000; Greenstein und Hart 2002; Kobayashi et al. 2007). Jedoch gibt es bis heute keine gesicherte Evidenz für einen Zusammenhang zwischen IL-1-Polymorphismus und Parodontitis (Huynh-Ba et al. 2007). Darüber hinaus scheint eine Assoziation zwischen IL-1-Polymorphismen und rheumatoider Arthritis vorzuliegen (Kobayashi et al. 2007; Marinou et al. 2009). So wurde eine Assoziation von IL-1A+4845 und IL-1B+3954 Genkombination mit rheumatoider Arthritis bei einer japanischen Patientengruppe festgestellt (Kobayashi et al. 2007). Dies führte dazu, dass IL-1-Polymorphismen als Risikofaktoren für rheumatoide Arthritis und Parodontitis angenommen wurden. Auf Grundlage inrer Ergebnisse folgerten die Autoren, dass ein IL-1-Polymorphismus 
bei Patienten mit Vorliegen beider Krankheitsbilder (rheumatoide Arthritis und $\mathrm{Pa}$ rodontitis) vorstellbar sei (Kobayashi et al. 2007). Ob ein Zusammenhang zwischen IL-1-Polymorphismus und Parodontitis vorlag, wurde jedoch nicht untersucht. Hingegen zeigten Ergebnisse einer repräsentativen Studie an über 3000 rheumatoide Arthritis-Patienten und entsprechender Kontrolle keine Assoziation zwischen IL-1-Polymorphismen und einer rheumatoiden Arthritis-Symptomatik (Johnsen et al. 2008). Bei Betrachtung der vorliegenden Ergebnisse auf eine mögliche Assoziation des IL-1-Polymorphismus/Genotyp und abgeleitetem genetischem Entzündungsrisiko mit dem Parodontalzustand konnten lediglich der Zigarettenkonsum als Risikofaktor identifiziert werden. Sowohl der Risikogenotyp (IL-1Polymorphismus/Genotyp-Kombination) als auch der Rheumafaktor scheinen keinen Einfluss auf Parodontitis zu haben. Dagegen stellte eine andere Untersuchung ein OR von 4.5 für Zahnlosigkeit bei Patienten mit positivem Rheumafaktor fest (de Pablo et al. 2008).

Bei allen Patienten (100\%) konnten die 11 untersuchten parodontalpathogenen Bakterien in unterschiedlicher Verteilung und Konzentration nachgewiesen werden.

Hinsichtlich der bakteriellen Flora wurden überwiegend Parodontalpathogene des moderat pathogenen orangenen und gelben Komplexes festgestellt. Die stark parodontalpathogenen Bakterien, wie $\mathrm{Aa}(16 \%)$ und $\mathrm{Pg}(58 \%)$ waren hingegen seltener nachzuweisen. Dabei zeigten die Ergebnisse, dass sowohl der Risikogenotyp als auch der vorliegende Rheumafaktor bei den untersuchten rheumatoide Arthritis-Patienten keinen Einfluss auf die Bakterienlast hat. Einflussfaktoren bezüglich der Parodontalsituation sind vornehmlich der Faktor Rauchen und bei einigen Bakterien der moderat pathogenen Komplexe neben dem Rauchen die Medikation.

Damit konnte die vorab gestellte Hypothese, dass bei rheumatoide ArthritisPatienten überwiegend stark parodontalpathogene Bakterien nachgewiesen werden können, nicht bestätigt werden. Eine mögliche Erklärung für den Zusammenhang zwischen Schweregrad der rheumatoiden Arthritis (Rheumafaktor) und Bakterienlast sowie dem Einfluss der Medikation auf die bakterielle Zusammensetzung bei Patienten mit rheumatoider Arthritis konnte somit in dieser Untersuchung nicht gefunden werden. 
Eine Assoziation zwischen parodontalpathogenen Bakterien und rheumatoider Arthritis ist in der Literatur bisher nur vereinzelt beschrieben. Dabei standen Untersuchung zum Antikörpernnachweis gegen Parodontalpathogene im Serum und der Synovialflüssigkeit im Mittelpunkt der Betrachtungen (Moen et al. 2003; Ogrendik et al. 2005; Moen et al. 2006; Mikuls et al. 2009; Martinez-Martinez et al. 2009). So wurden bei rheumatoide Arthritis-Patienten (mit Parodontitis) vermehrt Serumantikörper gegen Parodontalpathogene festgestellt (Ogrendik et al. 2005). Darüber hinaus konnten in der Synovialflüssigkeit von rheumatoide ArthritisPatienten häufig $P i$ sowie $P g$ und $T d$, letztere zwei hochpathogene Bakterien des roten Komplexes, identifiziert werden (Moen et al. 2006). Hingegen finden sich bisher nur wenige Angaben über die Bakterienzusammensetzung subgingivaler Biofilme bei rheumatoide Arthritis-Patienten. So wurde in einer Untersuchung an 19 rheumatoide Arthritis-Patienten bei allen untersuchten Patienten ein positiver Nachweis der Bakterien $P i, T f, P n, A a, P g$ und $T d$ in subgingivalen Plaqueproben festgestellt (Martinez-Martinez et al. 2009). Dabei wurden die höchsten Prävalenzen für Prevotella intermedia (100\%), Porphyromonas gingivalis $(79 \%)$ und Treponema denticola (84\%) in den subgingivalen Plaqueproben gefunden. Zudem wurde in der Synovialflüssigkeit eine gleiche Prävalenz der untersuchten Bakterien (100\%) festgestellt; im Serum war die Prävalenz etwas geringer (84\%) (MartinezMartinez et al. 2009). Mögliche Einflussfaktoren auf die Bakterienzusammensetzung wurden dabei jedoch nicht untersucht. Auch in der vorliegenden Untersuchung zeigt sich eine auffällig hohe Prävalenz positiver Bakterienbefunde (100\%) in den subgingivalen Plaqueproben bei den untersuchten rheumatoide ArthritisPatienten. Ein einheitliches Bild der Biofilmzusammensetzung konnte jedoch auch hier nicht detektiert werden; so unterschieden sich die Bakterienzusammensetzung der Patienten in der Art bzw. Verteilung der Bakterien und der Konzentration. Während Treponema denticola ebenfalls eine erhöhte Prävalenz (66\%) aufwies, wurden weitere hochpathogene Bakterien wie Porphyromonas gingivalis (58\%) und Aggregatibacter Actinomycetemcommitans (16\%) selten festgestellt. Dagegen wurde Tanerella forsythia als Vertreter des roten Komplexes mit $78 \%$ am häufigsten nachgewiesen. Zudem wurden weniger stark pathogene Bakterien häufiger beobachtet.

Die Vermutung, dass der rheumatoide Arthritis-Verlauf vor allem von parodontalen Infektionen mit Porphyromonas gingivalis negativ beeinflusst wird, legen einige 
Studien nahe (Liao et al. 2009; Mikuls et al. 2009). Hintergrund für diese Annahme war, dass das Enzym Peptidyl-Arginin-Deiminase (PAD), ein wichtiger Pathogenitätsfaktor für rheumatoide Arthritis, von Porphyromonas gingivalis exprimiert werden kann (Schellekens et al. 1998; McGraw et al. 1999; Schellekens et al. 2000; Rosenstein et al. 2004). Dabei kommt der erhöhten Antikörperbildung gegen zyklisch-citrullinierte Peptide (CCP) eine wesentliche Bedeutung zu, zumal der PgTiter bei rheumatoide Arthritis-Patienten auffällig mit der CCP-AK-Konzentration verknüpft war (Mikuls et al. 2009). Ob es sich allerdings bei dem Anstieg von CCP-AK tatsächlich um eine spezifische Infektion mit parodontalpathogenen Bakterien (wie Porphyromonas gingivalis) oder um ein generelles, also unspezifisches Phänomen handelt, ist weiterhin unklar. Darüber hinaus schreiben MartinezMartinez et al. (2009) neben Porphyromonas gingivalis auch den Bakterien Treponema denticola und Prevotella intermedia eine bedeutende Rolle in der rheumatoide Arthritis-Pathogenese zu. In der vorliegenden Untersuchung zeigten hingegen die hochpathogenen Bakterien Treponema denticola und Tanerella forsythia des roten Komplexes eine hohe Prävalenz. Auf der Grundlage dieser und der vorliegenden Arbeit könnte Treponema denticola ebenfalls eine Schlüsselrolle in der Pathogenese der rheumatoiden Arthritis zugesprochen werden. Darüber hinaus scheinen bei der untersuchten Patientengruppe die Faktoren Rauchen, Rheumafaktor und Medikation nur einen geringfügigen Einfluss auf die Bakterienzusammensetzung zu haben. Vergleichsstudien hierzu finden sich bisher nicht.

Weder der Risikogenotyp noch der Rheumafaktor zeigten einen signifikanten Einfluss auf den Parodontalzustand. Lediglich die Kovariable Rauchen konnte als Einflussfaktor identifiziert werden. Bei der Bakterienlast wurde ausschließlich bei Campylobacter species ein auffälliger Einfluss des Genotyps festgestellt, für den Rheumafaktor war dies bei keiner der untersuchten Bakterien der Fall. Lediglich bei Prevotella intermedia, Peptostreptococcus micros und Eubacterium nodatum ließen sich der Tabakkonsum und bei Eikanella corrodens und Campylobacter species die Medikation als auffällige Einflussfaktoren erkennen.

Die Ergebnisse zeigten eine verhältnismäßig hohe Prävalenz der Parodontitis und eine hohe Anzahl fehlender Zähne bei den untersuchten Patienten mit rheumatoider Arthritis. 
Aufgrund des Missverhältnisses zwischen der Anzahl an Rauchern in der Kontrollgruppe und der rheumatoide Arthritis-Patienten wurde die Kontrollgruppe bei der statistischen Analyse nicht berücksichtigt.

Zur Beurteilung des Parodontalzustandes wurde der PSI verwendet. Dieser liefert umfangreiche Informationen über den Zustand des Zahnhalteapparates und erlaubt eine umfassende Beurteilung der parodontalen Situation (Ainamo et al. 1982; Diamanti-Kipioti et al. 1993). Dagegen gibt er keine Auskunft über den tatsächlichen Zustand der parodontalen Destruktion, da der klinische Attachmentverlust (CAL) nicht mit erfasst wird. Aus diesem Grund wäre zur Beurteilung der parodontalen Situation neben der Erhebung des PSI die Erhebung des Parodontalstatus mit Erfassung des CAL für eine bessere Aussagekraft vorteilhaft gewesen. Es ist jedoch davon auszugehen, dass bei entsprechendem PSI-Befund (Score 3 und 4) auch ein Attachmentverlust vorliegt. Daher erfolgte die Bestimmung der parodontalen Situation anhand des Periodontal Screening Index (PSI) mit Ableitung des Parodontalzustands (gesund/Gingivitis, moderate und starke Parodontitis) in Modifikation der von Tonetti und Claffey (2005) empfohlenen Definition. Die Neuanfertigung und Auswertung von Orthopantomogrammen oder Zahnfilmen (Status) wurde aus ethischen Gründen nicht in die Studie mit eingeschlossen, hätte die Beurteilung der parodontalen Situation jedoch komplettiert.

Ein Großteil der rheumatisch erkrankten Patienten wies eine moderate bis ausgeprägte Parodontitis, ein Vorkommen der untersuchten parodontalpathogenen Bakterien, sowie ein erhöhtes genetisches Risiko für Entzündung auf. IL-1Polymorphismen (IL-1A -889, IL-1B +3953 oder IL-1RN +2018) mit homozygotem positivem und heterozygotem Genotyp wurden bei der Mehrzahl der untersuchten rheumatoide Arthritis-Patienten festgestellt. Eine Assoziation zwischen IL-1-Polymorphismus/Genotyp sowie genetischem Risiko und Parodontalbefund war nicht festzustellen. Rheumatoide-Arthritis-Patienten mit IL-1-Polymorphismus weisen demnach kein erhöhtes Risiko für Parodontitis auf. Auch eine Assoziation zwischen Rheumafaktor und Genotyp auf Parodontalzustand und Bakterienlast war nicht festzustellen. Die Untersuchung konnte nicht eindeutig verifizieren, ob Parodontalpathogene einen wichtigen Faktor in der Aktivität der rheumatoiden Arthritis darstellen. 
Auf Grundlage bekannter Studien und der hier festgestellten Ergebnisse bleibt der Zusammenhang zwischen Parodontitis und rheumatoider Arthritis weiterhin ungeklärt.

Nachfolgende Studien sollten einen ganzheitlichen medizinischen Ansatz zur Klärung einer möglichen Assoziation oder pathogener Zusammenhänge beider Erkrankungen wählen. Dabei sollte zum Einen geklärt werden, ob eine genetische Disposition im Entzündungsmechanismus eine Wechselwirkung beider Erkrankungen begünstigen kann und zum Anderen, ob eine orale bakterielle Infektion eine rheumatische Erkrankung negativ beeinflussen kann.

Zur Klärung einer möglichen Assoziation bzw. pathogener Zusammenhänge beider Erkrankungen sind weitere Studien notwendig. 


\section{Zusammenfassung}

Ziel der Studie war es, den Parodontalzustand und spezifische IL-1-Polymorphismen bei Patienten mit rheumatischen Erkrankungen zu erfassen und auf mögliche Assoziationen zu untersuchen.

66 Patienten (29 Frauen, 37 Männer) mit einer rheumatoiden Arthritis: im Alter von 49.5 \pm 8.4 Jahren nahmen teil. Die zahnärztliche Untersuchung umfasste den DMFT und den PSI sowie die Dokumentation der Rauchgewohnheiten. Anhand der PSI-Grade erfolgte die Einteilung in gesund/Gingivitis, moderate Parodontitis und ausgeprägte Parodontitis. Zur Bestimmung der IL-1-Polymorphismen (IL-1A-889, IL-1B+3953, IL-1RN+2018) wurden Wangenschleimhautabstriche entnommen, analysiert und einem Genotyp für Entzündungsrisiko (Grad 1-4) zugeordnet (GenoType PST ${ }^{\circledR}$ plus; Hain Lifescience). Zur mikrobiologischen Analyse wurde eine Poolprobe entnommen und auf 11 parodontalpathogene Mikroorganismen untersucht (micro-IDent ${ }^{\circledR}$ plus, Hain Lifescience).

Der mittlere DMF-T betrug 16.8 \pm 6.3 . 24 Patienten waren gesund/Gingivitis; 18 Patienten zeigten eine moderate und 23 eine ausgeprägte Parodontitis. 19 Patienten $(28,8 \%)$ wiesen homozygot negative Befunde auf den untersuchten Genarealen auf. Genotyp 1 (kein erhöhtes genetisches Risiko) lag bei 24 Patienten vor, Genotyp 2 (erhöhtes genetisches Risiko) oder 3 (stark erhöhtes genetisches Risiko) bei 14 bzw. sechs Patienten und eine verminderte genetische Entzündungshemmung (Grad 4) lag bei 22 Patienten vor. Die Verteilung war wie folgt: Parodontal gesund - Genotyp 1: $n=9$, Genotyp 2 oder $3 n=7$, Genotyp: 4 n=8; Moderate Parodontitis - Genotyp 1: $n=4$, Genotyp 2 oder 3: $n=8$, Genotyp 4: $n=6$; Ausgeprägter Parodontitis - Genotyp1: $n=11$, Genotyp 2 oder 3: n=5, Genotyp 4: $\mathrm{n}=7$. Bei allen Patienten konnten Parodontalpathogene in unterschiedlicher Verteilung und Konzentration nachgewiesen werden. Bei den meisten Patienten lagen Fn (98\%), Ec (91\%) und Pm (88\%) oberhalb der Nachweisgrenze; starke Parodontalpathogene waren seltener nachzuweisen: Aa (16\%) und Pg (58\%). Die statistische Auswertung mittels einer nichtparametrischen Varianzanalyse zeigte keinen signifikanten Einfluss des Risikogenotyps auf den Parodontalzustand $(p=0.76)$. Für die Kovariablen Alter $(p=0.22)$, Geschlecht $(p=0.74)$ und Medikation $(p=0.09)$ war kein signifikanter Einfluss auf den Parodontalzustand festzustellen. Einzig die Kovariable Rauchen zeigte einen signifikanten Einfluss ( $p=0.0004)$. 
Ein Großteil der untersuchten Patienten wies eine moderate bis ausgeprägte $\mathrm{Pa}$ rodontitis, die Anwesenheit der untersuchten parodontalpathogenen Bakterien sowie ein erhöhtes genetisches Entzündungsrisiko auf. Eine Assoziation zwischen IL-1-Polymorphismus und Parodontalbefund ergab sich nicht.

Auch eine Assoziation zwischen Rheuma-Faktor und Genotyp auf Parodontalzustand und Bakterienlast war nicht festzustellen.

Auf Grundlage dieser Ergebnisse bleibt der Zusammenhang zwischen Parodontitis und rheumatoider Arthritis weiterhin ungeklärt. 


\section{Anhang}

\subsection{Formulare}

\subsubsection{Patientenaufklärung}

Prof. Dr. med. dent. R. Mausberg; Georg-August-Universität Göttingen, Zentrum Zahn-,

Mund- und Kieferheilkunde; Abteilung Zahnerhaltung, Präventive Zahnheilkunde und Parodontologie; Robert-Koch-Str. 40, 37075 Göttingen; Tel. 0551/ 392878

\section{Patientenaufklärung}

Klinische Studie zur möglichen Assoziation von rheumatoider Arthritis und Parodontitis

SEHR GEEHRTE PATIENTin, sehr geehrter Patient!

Parodontitis ist eine Zahnfleischerkrankung mit Verlust der Verankerungsstrukturen des Zahnes im Kieferknochen bis hin zum Abbau des Kieferknochens. Als Folge können betroffene Zähne verloren gehen. Die Entzündung der Verankerungsstrukturen entwickelt sich aus einer Entzündung des Zahnfleisches. Dabei spielen viele verschiedene Faktoren eine Rolle: Zahnbelag, bestimmte Bakterien, körpereigene Abwehr, aber auch systemische Erkrankungen wie Rheuma (rheumatoide Arthritis) und der Zuckerkrankheit (Diabetis Mellitus). Gentechnologische und mikrobiologische Untersuchungen können eine genauere Auskunft über Krankheitszustand und Risikofaktoren geben. Mittels einer Speichelanalyse kann man zudem Rückschlüsse auf den Schweregrad der Entzündung ziehen.

Um bei Innen Aussagen über mikrobielle Zusammenhänge, genetische Konstellationen und der Höhe zweier Entzündungsparameter treffen zu können, werden bei Innen eine Speichelprobe und eine Zahntaschenprobe entnommen, sowie ein Mundschleimhautabstrich gemacht. Mit Ihren Proben werden dann spezielle Tests durchgeführt. Diese erfassen zum einen Ähnlichkeiten und/oder Unterschiede in der bakteriellen Zusammensetzung Ihrer Mundflora, zum anderen genetische Defekte in einer bestimmten Komponente Ihres Immunsystems. Parallel dazu wird die Konzentration eines bestimmten Antikörpers Ihres Speichels ermittelt um Rückschlüsse auf die Ursache von Entzündungen ziehen zu können.

Ziel dieser rein wissenschaftlichen Untersuchung soll es sein, Patienten die an rheumatoider Arthritis und chronischer Parodontitis erkrankt sind, auf mögliche Zusammenhänge zwischen den beiden Krankheitsbildern im Vergleich zu parodontal Gesunden zu untersuchen.

Die Probenentnahme und Untersuchungen Ihrer Proben führt der Doktorand (Studentin der Zahnmedizin) unter Aufsicht eines fachkundigen Arztes durch.

Des Weiteren bitten wir Sie, einige Fragen zu Ihrem Allgemeinzustand, Lebensgewohnheiten und Zahnpflegegewohnheiten zu beantworten. Bitte versuchen Sie diese Fragen wahrheitsgemäß und möglichst genau zu beantworten.

Grund dieser Studie ist die Überprüfung des klinischen Zusammenhangs einer systemischen Erkrankung, in diesem Fall der rheumatoiden Arthritis, mit einer Erkrankung des Zahnhalteapparates. Dies dient dem Ziel, sicher und frühest möglich derartige Zusammenhänge zu erkennen, um einen möglichen Zahnverlust zu verhindern bzw. zu verzögern.

Risiken und Nebenwirkungen bei der Durchführung der Studie sind nicht zu erwarten, da keine Medikamente oder Röntgenaufnahmen notwendig sind. Ihre Patientendaten und Angaben werden pseudonymisiert behandelt, nur zu Forschungszwecken verwendet und nach Auswertung vernichtet.

Wir bitten um die freiwillige Teilnahme an der Studie. Sie können jederzeit die Teilnahme widerrufen, ohne Angabe von Gründen und ohne Nachteile erwarten zu müssen. 


\subsubsection{Patienteneinwilligung}

Prof. Dr. med. dent. R. Mausberg; Georg-August-Universität Göttingen, Zentrum Zahn-,

Mund- und Kieferheilkunde; Abteilung Zahnerhaltung, Präventive Zahnheilkunde und

Parodontologie; Robert-Koch-Str. 40, 37075 Göttingen; Tel. 0551/ 392878

\section{Patienteneinwilligung}

Klinische Studie zur möglichen Assoziation von rheumatoider Arthritis und Parodontitis

Ich, wurde von meinem Arzt vollständig über Wesen, Bedeutung

und Tragweite der klinischen Prüfung mit dem Titel:

\section{Klinische Studie zur möglichen Assoziation von rheumatoider Arthritis und Parodontitis}

aufgeklärt.

Mir ist bekannt, dass bei dieser Untersuchung personenbezogene Daten, insbesondere medizinische Befunde über mich erhoben, gespeichert und ausgewertet werden sollen.Dies schließt die Einsicht in meine Krankenakte ein. Die Verwendung der Angaben über meine Gesundheit erfolgt nach gesetzlichen Bestimmungen und setzt vor der Teilnahme an der klinischen Prüfung die folgende freiwillig abgegebene Einwilligungserklärung voraus.

Ich habe den Aufklärungstext gelesen und verstanden. Ich hatte die Möglichkeit, Fragen zu stellen, und habe die Antworten verstanden und akzeptiere diese. Mein Arzt hat mich über die mit der Teilnahme an der Studie verbundenen Risiken und den möglichen Nutzen informiert.

Ich hatte ausreichend Zeit, mich zur Teilnahme an dieser Untersuchung zu entscheiden und weiß, dass die Teilnahme freiwillig ist.

Mir ist bekannt, dass ich jederzeit und ohne Angaben von Gründen diese Zustimmung widerrufen kann, ohne dass sich dieser Entschluss nachteilig auswirkt.

Ich habe eine Kopie der Patienteninformation und dieser Einwilligungserklärung erhalten. Ich erkläre hiermit meine freiwillige Teilnahme an dieser Studie. 


\title{
7.1.3 Patientenfragebogen
}

\section{Fragebogen:}

\section{Klinische Studie zur möglichen Assoziation von rheumatoider Arthritis} und Parodontitis

\author{
Name: \\ Adresse: \\ Geburtsdatum: \\ Telefon:
}

Status:

Bitte beantworten Sie die folgenden Fragen bzw. kreuzen Sie j a oder $n$ e in an.

Die gewissenhafte Beantwortung ist eine Voraussetzung für eine erfolgreiche Behandlung!

1. Sind Sie in ständiger ärztlicher Behandlung?

ja nein

Wenn ja, weswegen?

[ ] []

2. Sind Sie Diabetiker? Insulinpflichtig? (HbA1c Wert?

3. Leiden Sie an einer Herzerkrankung? (z.B. A. pectoris, Endokarditis, Klappenfehler)

4. Leiden Sie an Bluthochdruck (Werte?

5. Müssen Sie ständig Medikamente einnehmen? Wenn ja, welche? (z.B. zur Blutzuckersenkung; gegen Herzbeschwerden, Bluthochdruck; zur Hemmung der Blutgerinnung; Rheumamittel; Beruhigungs-/Schlaftabletten)

6. Sind Sie zur Zeit in ärztlicher Behandlung? Wenn ja, weswegen?

7. Nehmen Sie zur Zeit Medikamente ein? Wenn ja, welche?

8. Haben Sie in den letzten 3 Monaten ein Antibiotikum einnehmen müssen? Wenn ja, weshalb?

9. Nehmen Sie Hormonpräparate ein? Wenn ja, welche?

10. Sind Sie je operiert worden?

11. Sind Ihnen jemals Blut oder Blutprodukte übertragen worden? Wenn ja, weswegen?

12. Sind Sie allergisch auf bestimmte Medikamente oder Substanzen? Wenn ja, welche? (z.B. Schmerzmittel, Penicillin, Sulfonamide, Jod, Latex)

13. Haben Sie einen Allergie-Pass? Wenn ja, für welche Substanzen?

Leiden/Litten Sie an folgenden Erkrankungen? (Bitte ankreuzen)

[ ] niedriger Blutdruck bzw. Kreislaufbeschwerden (Ohnmacht, kalte Hände/Füße)

[] Lungenerkrankung (Embolie, Tuberkulose)

[] Bluterkrankungen

[] Lebererkrankungen (Gelbsucht)

[] Hautkrankheiten

[] Nierenerkrankung

[] Asthma

[] Infektionskrankheiten (HIV, Hepatitis, Geschlechtskrankheiten)

[] Magenerkrankungen

[] Anfallsleiden (Epilepsie)

[] Rheuma 
14. Wann sind Sie zum letzten Mal zahnärztlich untersucht worden?

15. Sind Ihre Zähne temperaturempfindlich?

16. Biutet Ihr Zahnfleisch?

17. Bemerken Sie Stellungsveränderungen Ihrer Zähne?

18. Atmen Sie häufig durch den Mund?

19. Haben Sie manchmal einen schlechten Geschmack im Mund?

20. Haben Sie eine Zahnspange getragen?

21. Haben Sie wegen Zahnlockerung bzw. Zahnfleischbeschwerden schon einmal einen Zahnarzt aufgesucht?

Wenn ja, was wurde gemacht?

22. Haben Sie schon einmal einen Zahn verloren?

Wenn ja, was war die Ursache?

Karies ( ) Parodontose/ Zahnlockerung ( ) Trauma/Unfall ( )

23. Wurde bei Ihnen bereits eine "Parodontose"-Behandlung durchgeführt? Wenn ja, wann?

24. Rauchen Sie oder haben Sie geraucht?

25. Wie viel Zigaretten/ Schachteln pro Tag etwa? Zigaretten/ Tag, Schachteln/ Tag

26. In welchem Lebensalter haben Sie mit dem Rauchen begonnen? Mit Jahren

27. Vor wie viel Monaten/Jahren haben Sie mit dem Rauchen aufgehört? Vor Monaten/ Vor Jahren

28. Konsumieren Sie alkoholische Getränke? (Bier, Wein, Sekt, Spirituosen) nie [] gelegentlich [] täglich [ ]

29. Konsumieren Sie zuckerhaltige Genussmittel (z.B. gesüßte Getränke, Schokoriegel, Eis u. ä.) nie [] gelegentlich [] täglich [] mehrmals täglich []

30. Wie sehen Ihre Zahnputzgewohnheiten aus? Wie oft putzen Sie? 1mal täglich ( ) morgens und abends ( ) nach jeder Mahlzeit () seltener

Wie putzen Sie? Handzahnbürste ( ) elektrische Zahnbürste ( )

Benutzen Sie Zahnseide? Nie ( ) wöchentlich ( ) Gelegentlich ( ) täglich ( )

Leiden/ Litten Sie an folgenden Erkrankungen? (Bitte ankreuzen)

[ ] Haben Sie häufig Erkältungskrankheiten?

[ ] Sind Sie ständig durstig?

[] Bekommen Sie schnell blaue Flecken?

[ ] Leiden Sie an längeren Blutungen, z.B. nach Schnittverletzungen oder Zahnextraktion? Sonstige Angaben:

Göttingen, den Unterschrift: 


\subsection{Abbildungsverzeichnis}

Abb. 1: $\quad$ Ätiologie und Pathogenese der Parodontitis (nach Page \& Kornman 1997, S.11)

Abb. 2: Darstellung der parodontopathogenen Bakterien nach den Socransky-Komplexen (aus: Zahn-, Mund-, Kieferheilkunde - Konservierende Zahnheilkunde und Parodontologie, S. 262)

Abb. 3: Schematische Darstellung der Reaktionswege bei rheumatoider Arthritis. (aus: Choy und Panayi 2001, S. 908)

Abb. 4: Schematischer Querschnitt durch ein Kniegelenk (aus: Choy und Panayi 2001, S. 911)

Abb. 5: Rheumatoide Arthritis im Handskelettbereich mit Ulnardeviation und Subluxationsstellung (aus: Gross 2004, S. 1057)

Abb. 6: Schematische Darstellung der Gebissunterteilung in Sextanten (www.zahnwissen.de)

Abb. 7: Schematische Darstellung der Sondierungspunkte bei der Erhebung des PSI (Heidemann 1997, S. 103)

Abb. 8: $\quad$ Markierung der WHO-Sonde (www.zahnwissen.de)

Abb. 9: Übersicht der PSI-Werte der einzelnen Sextanten graphisch dargestellt.

Abb. 10: Verteilung des Rauchverhaltens der Patienten (Raucher/Nichtraucher) nach dem Parodontalzustand (gesund/Gingivitis, moderate Parodontitis, ausgeprägte Parodontitis)

Abb. 11: Anzahl der Patienten in den jeweiligen Genotypgruppen

Abb. 12: Verteilung der ermittelten IL-1-Polymorphismen (Risikogenotyp 1-4) nach dem Parodontalzustand

Abb. 13: Verteilung des Rauchverhaltens (Raucher/Nichtraucher) nach dem ermittelten IL-1-Polymorphismus (Risikogenotyp 1-4) 


\subsection{Tabellenverzeichnis}

Tab. 1: Postulate für Infektionserkrankungen nach Henle \& Koch und Socransky (Slots und Rams 1992)

Tab. 2: $\quad$ Parodontalphatogene Bakterien mit hoher bzw. sehr hoher klinischer Relevanz

Tab. 3: Klassifikationskriterien der rheumatoiden Arthritis (nach Arnett et al.1988)

Tab. 4: $\quad$ Larsen-Stadien der radiologischen Befunde (nach Larsen 1973, S.137)

Tab. 5: $\quad$ Einteilung der Krankheitsaktivität nach DAS28

Tab. 6: Patientencharakteristik der Teilnehmer nach Geschlecht, Alter (in Jahren), Dauer der Erkrankung nach Erstdiagnose (in Jahren) und Rauchverhalten

Tab. 7: $\quad$ Eingenommene Medikamente und Blutparameter der Studienteilnehmer

Tab. 8: $\quad$ Mittelwerte der erhobenen dentalen Befunde (DMF-T)

Tab. 9: $\quad$ Absolute Häufigkeit der PSI-Werte

Tab. 10: Verteilung der IL-1-Polymorphismen (IL-1A -889, IL-1B +3953, IL-1RN +2018) nach Genotyp (homozygot negativ, homozygot positiv und heterozygot)

Tab. 11: Verteilung des Risikogenotyps (1-4) nach dem Parodontalzustand

Tab. 12: Prävalenz der einzelnen Bakterien nach Komplexen in der Patientengruppe sowie mediane Bakterienkonzentration oberhalb der Nachweisgrenze über die gesamte Patientengruppe und für die ausschließlich positiven Befunde $(n=65)$

Tab. 13: Statistischer Vergleich ( $p$-Werte adjustiert) des Einflusses der Faktoren Rheumafaktor und Genotyp sowohl der Kovariablen (Alter, Geschlecht, Raucher und Medikation) auf die untersuchten parodontalpathogenen Bakterien.

Tab. 14: Prävalenz der einzelnen Bakterien in Abhängigkeit von Gingivitis oder Parodontitis 


\subsection{Bisherige Veröffentlichungen der Ergebnisse}

\subsubsection{Artikel}

Ziebolz D, Pabel SO, Lange K, Krohn-Grimberghe B, Hornecker E, Mausberg RF (2011):

Clinical periodontal and microbiologic parameters in patients with rheumatoid arthritis.

J Periodontol $\underline{82}, 1424-1432$

\subsubsection{Vorträge}

Ziebolz D, Pabel SO, Lange K, Mausberg RF:

Parodontalzustand und IL-1 Genotyp bei Patienten mit rheumatischen Erkrankungen.

DGP-Jahrestagung; München 2009

\subsubsection{Poster}

Mausberg RF, Pabel SO ,Hornecker E, Ziebolz D:

Periodontal situation and genetic risk for periodontitis in patients with rheumatic diseases - First results

Europerio; Stockholm 2009

Ziebolz D, Pabel SO, Lange K, Hornecker E, Mausberg RF:

Parodontalzustand und Bakterienlast von Patienten mit rheumatischen Erkrankungen.

DGZMK- / DGP-Jahrestagung; Frankfurt 2010 


\section{Literaturverzeichnis}

ACR (American College of Rheumatology Subcommittee on Rheumatoid Arthritis Guidelines) (2002):

Guidelines for the management of rheumatoid arthritis: 2002 update.

Arthritis Rheum $\underline{46}$, 328-346

Ainamo J, Barmes D, Beagrie G, Cutress T, Martin J, Sardo-Infirri J (1982): Development of the World Health Organization (WHO) community periodontal index of treatment needs (CPITN).

Int Dent J $\underline{32}, 281-291$

Alamanos Y, Drosos AA (2005):

Epidemiology of adult rheumatoid arthritis.

Autoimmun Rev $\underline{4}, 130-136$

Aletaha D, Neogi T,Silman AJ, Funovits J, Felson DT, Bingham CO, Birnbaum NS, Burmester GR, Bykerk VP, Cohen MD et al. (2010): 2010 Rheumatoid arthritis classification criteria: an American College of Rheumatology/European League Against Rheumatism collaborative initiative. Arthritis and rheumatism $\underline{62}, 2569-2581$

Arnett FC, Edworthy SM, Bloch DA, McShane DJ, Fries JF, Cooper NS, Healey LA, Kaplan SR, Liang MH, Luthra HS (1988):

The American Rheumatism Association 1987 revised criteria for the classification of rheumatoid arthritis.

Arthritis Rheum 31, 315-324

Attström R (1972):

Entzündungsmechanismen und immunologische Reaktionen in der Gingiva.

Dtsch Zahnarztl Z 28, 1166-1169

Bas S, Perneger TV, Seitz M, Tiercy J, Roux-Lombard P, Guerne PA (2002): Diagnostic tests for rheumatoid arthritis: comparison of anti-cyclic citrullinated peptide antibodies, anti-keratin antibodies and IgM rheumatoid factors.

Rheumatology (Oxford) 41, 809-814

Beck J, Garcia R, Heiss G, Vokonas PS, Offenbacher S (1996):

Periodontal disease and cardiovascular disease.

J Periodontol $\underline{67}, 1123-1137$

Berglin E, Johansson T, Sundin U, Jidell E, Wadell G, Hallmans G, RantapääDahlqvist S (2006):

Radiological outcome in rheumatoid arthritis is predicted by presence of antibodies against cyclic citrullinated peptide before and at disease onset, and by $\lg A-R F$ at disease onset.

Ann Rheum Dis $\underline{65}$, 453-458 
Birkedal-Hansen H, Taylor RE, Zambon JJ, Barwa PK, Neiders ME (1988): Characterization of collagenolytic activity from strains of Bacteroides gingivalis. J Periodont Res 23, 258-264

Bonagura VR, Artandi SE, Davidson A, Randen I, Agostino N, Thompson K, Natvig JB, Morrison SL (1993):

Mapping studies reveal unique epitopes on IgG recognized by rheumatoid arthritisderived monoclonal rheumatoid factors.

J Immunol 151, 3840-3852

Brooks PM, Day RO (1991):

Nonsteroidal antiinflammatory drugs-differences and similarities.

N Engl J Med 324, 1716-1725

Brower AC (1990):

Use of the radiograph to measure the course of rheumatoid arthritis. The gold standard versus fool's gold.

Arthritis Rheum 33, 316-324

Bukhari M, Lunt M, Harrison BJ, Scott DGI, Symmons DPM, Silman AJ (2002): Erosions in inflammatory polyarthritis are symmetrical regardless of rheumatoid factor status: results from a primary care-based inception cohort of patients.

Rheumatology (Oxford) 41, 246-252

Calgüneri M, Ureten K, Akif Oztürk M, Onat AM, Ertenli I, Kiraz S, Akdogan A (2006):

Extra-articular manifestations of rheumatoid arthritis: results of a university hospital of 526 patients in Turkey.

Clin Exp Rheumatol 24, 305-308

Campus G, Salem A, Uzzau S, Baldoni E, Tonolo G (2005):

Diabetes and periodontal disease: a case-control study.

J Periodontol $\underline{76}, 418-425$

Cardoso CR, Garlet GP, Crippa GE, Rosa AL, Júnior WM, Rossi MA, Silva JS (2009):

Evidence of the presence of T helper type 17 cells in chronic lesions of human periodontal disease. Oral Microbiol.

Immunol 24, 1-6

Carmona L, González-Alvaro I, Balsa A, Angel Belmonte M, Tena X, Sanmartí R (2003):

Rheumatoid arthritis in Spain: occurrence of extra-articular manifestations and estimates of disease severity.

Ann Rheum Dis $\underline{62}, 897-900$

Chandrasekaran AN, Radhakrishna B (1995):

Rheumatoid arthritis and connective tissue disorders: India and South-East Asia.

Bailliere Clin Rheumatol $\underline{9}, 45-57$ 
Choi YW, Kotzin B, Herron L, Callahan J, Marrack P, Kappler J (1989):

Interaction of Staphylococcus aureus toxin "superantigens" with human T cells.

Proc Natl Acad Sci U S A $\underline{86}$, 8941-8945

Choy EH, Panayi GS (2001):

Cytokine pathways and joint inflammation in rheumatoid arthritis.

$\mathrm{N}$ Engl J Med 344, 907-916

Clague RB, Firth SA, Holt PJ, Skingle J, Greenbury CL, Webley M (1983):

Serum antibodies to type II collagen in rheumatoid arthritis: comparison of 6 immunological methods and clinical features.

Ann Rheum Dis $\underline{42}, 537-544$

Costenbader KH, Feskanich D, MandI LA, Karlson EW (2006):

Smoking intensity, duration, and cessation, and the risk of rheumatoid arthritis in women.

Am J Med 119, 503, (Abstract \# e1-9)

Cuesta IA, Sud S, Song Z, Affholter JA, Karvonen RL, Fernández-Madrid F, Wooley PH (1997):

$\mathrm{T}$ cell receptor ( $\mathrm{V}$ beta) bias in the response of rheumatoid arthritis synovial fluid $\mathrm{T}$ cells to connective tissue antigens.

Scand J Rheumatol 26, 166-173

Cutler CW, Shinedling EA, Nunn M, Jotwani R, Kim BO, Nares S, lacopino AM (1999):

Association between periodontitis and hyperlipidemia: cause or effect?

J Periodontol $\underline{70}$, 1429-1434

D'Aiuto F, Graziani F, Tetè S, Gabriele M, Tonetti MS (2005):

Periodontitis: from local infection to systemic diseases.

Int J Immunopathol Pharmacol 18, 1-11

D'Aiuto F, Parkar M, Nibali L, Suvan J, Lessem J, Tonetti MS (2006):

Periodontal infections cause changes in traditional and novel cardiovascular risk factors: results from a randomized controlled clinical trial.

Am Heart J 151, 977-984

Dalla Vecchia CF, Susin C, Rösing CK, Oppermann RV, Albandar JM (2005):

Overweight and obesity as risk indicators for periodontitis in adults.

J Periodontol 트, 1721-1728

Dellabona P, Peccoud J, Kappler J, Marrack P, Benoist C, Mathis D (1990):

Superantigens interact with MHC class II molecules outside of the antigen groove.

Cell $\underline{62}, 1115-1121$

Demmer RT, Desvarieux M (2006):

Periodontal infections and cardiovascular disease: the heart of the matter.

J Am Dent Assoc 137, 14-20 
de Pablo P, Dietrich T, McAlindon TE (2008):

Association of periodontal disease and tooth loss with rheumatoid arthritis in the US population.

J Rheumatol $\underline{35}, 70-76$

de Pablo P, Chapple ILC, Buckley CD, Dietrich T (2009):

Periodontitis in systemic rheumatic diseases.

Nat Rev Rheumatol $\underline{5}, 218-224$

DeStefano F, Anda RF, Kahn HS, Williamson DF, Russell CM (1993):

Dental disease and risk of coronary heart disease and mortality.

BMJ $\underline{306}, 688-691$

Desvarieux M, Demmer RT, Rundek T, Boden-Albala B, Jacobs DR, Papapanou PN, Sacco RL (2003):

Relationship between periodontal disease, tooth loss, and carotid artery plaque: the Oral Infections and Vascular Disease Epidemiology Study (INVEST).

Stroke $\underline{34}, 2120-2125$

Detert J, Pischon N, Burmester G, Buttgereit F (2010):

Pathogenesis of parodontitis in rheumatic diseases.

Z Rheumatol $\underline{69}$, 109-12, 114-6

Deutsche Gesellschaft für Parodontologie:

Klassifikation der Parodontalerkrankungen;

Quintessenz, Berlin 2002

Diamanti-Kipioti A, Papapanou PN, Moraitaki-Tsami A, Lindhe J, Mitsis F (1993):

Comparative estimation of periodontal conditions by means of different index systems.

J Clin Periodontol $\underline{20}, 656-661$

Dissick A, Redman RS, Jones M, Rangan BV, Reimold A, Griffiths GR, Mikuls TR, Amdur RL, Richards JS, Kerr GS (2010):

Association of periodontitis with rheumatoid arthritis: a pilot study.

J Periodontol $\underline{81}$, 223-230

Doĝan B, Buduneli E, Emingil G, Atilla G, Akilli A, Antinheimo J, Lakio L, Asikainen S (2005):

Characteristics of periodontal microflora in acute myocardial infarction.

J Periodontol $\underline{76}, 740-748$

Dörtbudak O, Eberhardt R, Ulm M, Persson GR (2005):

Periodontitis, a marker of risk in pregnancy for preterm birth.

J Clin Periodontol $\underline{32}, 45-52$

Dye BA, Choudhary K, Shea S, Papapanou PN (2005):

Serum antibodies to periodontal pathogens and markers of systemic inflammation. J Clin Periodontol $\underline{\text { 32, }}$ 1189-1199 
Elter JR, Champagne CME, Offenbacher S, Beck JD (2004):

Relationship of periodontal disease and tooth loss to prevalence of coronary heart disease.

J Periodontol $\underline{75}, 782-790$

\section{Eshdat Y, Sharon N (1984):}

Recognitory bacterial surface lectins which mediate its mannose-specific adherence to eukaryotic cells.

Biol Cell 51, 259-266

Ezzo PJ, Cutler CW (2003):

Microorganisms as risk indicators for periodontal disease.

Periodontol 2000 32, 24-35

Forner L, Nielsen CH, Bendtzen K, Larsen T, Holmstrup P (2006):

Increased plasma levels of IL-6 in bacteremic periodontis patients after scaling. J Clin Periodontol $\underline{33}$, 724-729

Fransen J, van Riel PL (2005):

The Disease Activity Score and the EULAR response criteria.

Clin Exp Rheumatol 23, 93-99, (Abstract \# 39)

\section{Furst DE (1994):}

Are there differences among nonsteroidal antiinflammatory drugs? Comparing acetylated salicylates, nonacetylated salicylates, and nonacetylated nonsteroidal antiinflammatory drugs.

Arthritis Rheum 37, 1-9

\section{Gängler P, Arnold WH:}

Äthiologie und Pathogenese - Parodontalerkrankungen in Zahn-Mund-

Kieferheilkunde - Konservierende Zahnheilkunde und Parodontologie, hrsg.

Gängler P, Hoffmann T u.a.; 2. Auflage;

Georg Thieme Verlag, Stuttgart 2005, 251-298

Gascoigne NR, Ames KT (1991):

Direct binding of secreted T-cell receptor beta chain to superantigen associated with class II major histocompatibility complex protein.

Proc Natl Acad Sci U S A $\underline{88}, 613-616$

Genco RJ (1992):

Host responses in periodontal diseases: current concepts.

J Periodontol $\underline{63}, 338-355$

Genco RJ, Ho AW, Grossi SG, Dunford RG, Tedesco LA (1999):

Relationship of stress, distress and inadequate coping behaviors to periodontal disease.

J Periodontol $\underline{70}, 711-723$ 
Goekoop-Ruiterman YPM, Vries-Bouwstra JK de, Allaart CF, van Zeben D, Kerstens PJSM, Hazes JMW, Zwinderman AH, Peeters AJ, Jonge-Bok JM de, Mallée C et al. (2007):

Comparison of treatment strategies in early rheumatoid arthritis: a randomized trial. Ann Intern Med 146, 406-415

Goodson JM, Tanner AC, Haffajee AD, Sornberger GC, Socransky SS (1982): Patterns of progression and regression of advanced destructive periodontal disease. J Clin Periodontol $\underline{9}$, 472-481

Goodson N, Marks J, Lunt M, Symmons D (2005):

Cardiovascular admissions and mortality in an inception cohort of patients with rheumatoid arthritis with onset in the 1980s and 1990s.

Ann Rheum Dis $\underline{64}, 1595-1601$

Gran JT, Husby G, Thorsby E (1983):

The association between rheumatoid arthritis and the HLA antigen DR4.

Ann Rheum Dis 42, 292-296

Greenstein G, Hart TC (2002):

A critical assessment of interleukin-1 (IL-1) genotyping when used in a genetic susceptibility test for severe chronic periodontitis.

J Periodontol $\underline{73}, 231-247$

Greenstein G, Lamster IB (2000):

Parodontale Strategien im Umbruch: Konsequenzen für die Therapie.

Int J Periodontics Restorative Dent 20, 325-345

Greenwald RA, Kirkwood K (1999):

Adult periodontitis as a model for rheumatoid arthritis (with emphasis on treatment strategies).

J Rheumatol 26, 1650-1653

Gromnica-Ihle E:

Rheumatoide Arthritis; in: Harrisons Innere Medizin,hrsg. Dietel M, Suttorp N, u.a.; 16. Auflage

McGraw-Hill, Berlin 2005, 2115-2124

\section{Gross WL:}

Erkrankungen des rheumatischen Formenkreises; in: Innere Medizin, hrsg. Derdel WE, Böhm M u. a.; 5. Auflage,

Urban \& Fischer, Müchen 2004, 1049-1110

Haffajee AD, Socransky SS (2006):

Introduction to microbial aspects of periodontal biofilm communities, development and treatment.

Periodontol $2000 \underline{42}, 7-12$ 
Hall FC, Thomson K, Procter J, McMichael AJ, Wordsworth BP (1998):

TCR beta spectratyping in RA: evidence of clonal expansions in peripheral blood lymphocytes.

Ann Rheum Dis 프, 319-322

Hara Y, Kaneko T, Yoshimura A, Kato I (1996):

Serum rheumatoid factor induced by intraperitoneal administration of periodontopathic bacterial lipopolysaccharide in mice.

J Periodont Res 31, 502-507

Haraldsson G, Meurman JH, Könönen E, Holbrook WP (2005):

Properties of hemagglutination by Prevotella melaninogenica.

Anaerobe 11, 285-289

Haraszthy VI, Zambon JJ, Trevisan M, Zeid M, Genco RJ (2000):

Identification of periodontal pathogens in atheromatous plaques.

J Periodontol $\underline{71}, 1554-1560$

\section{Havemose-Poulsen A, Sørensen LK, Stoltze K, Bendtzen K, Holmstrup P} (2005):

Cytokine profiles in peripheral blood and whole blood cell cultures associated with aggressive periodontitis, juvenile idiopathic arthritis, and rheumatoid arthritis.

J Periodontol $\underline{76}$, 2276-2285

Havemose-Poulsen A, Sørensen LK, Bendtzen K, Holmstrup P (2007):

Polymorphisms within the IL-1 gene cluster: effects on cytokine profiles in peripheral blood and whole blood cell cultures of patients with aggressive periodontitis, juvenile idiopathic arthritis, and rheumatoid arthritis.

J Periodontol $\underline{78}, 475-492$

Heasman L, Stacey F, Preshaw PM, McCracken GI, Hepburn S, Heasman PA (2006):

The effect of smoking on periodontal treatment response: a review of clinical evidence.

J Clin Periodontol 33, 241-253

Heidemann D:

Praxis der Zahnheilkunde 4 Parodontologie, 3. Auflage;

Urban \& Schwarzenberg, München 1997, 101-103

Hirsch RS, Clarke NG (1989):

Differential diagnosis of severe periodontal lesions.

Aust Dent J $\underline{34}$, 548-558

Howell TH, Ridker PM, Ajani UA, Hennekens CH, Christen WG (2001):

Periodontal disease and risk of subsequent cardiovascular disease in U.S. male physicians.

J Am Coll Cardiol 37, 445-450 
Hujoel PP, Drangsholt M, Spiekerman C, DeRouen TA (2000):

Periodontal disease and coronary heart disease risk.

JAMA $\underline{284}, 1406-1410$

Hung H, Joshipura KJ, Colditz G, Manson JE, Rimm EB, Speizer FE, Willett WC (2004):

The association between tooth loss and coronary heart disease in men and women.

J Public Health Dent $\underline{64}$, 209-215

Huynh-Ba G, Lang NP, Tonetti MS, Salvi GE (2007):

The association of the composite IL-1 genotype with periodontitis progression and/or treatment outcomes: a systematic review.

$\mathrm{J}$ Clin Periodontol 34, 305-317

Inanc N, Dalkilic E, Kamali S, Kasapoglu-Günal E, Elbir Y, Direskeneli H, Inanc M (2007):

Anti-CCP antibodies in rheumatoid arthritis and psoriatic arthritis.

Clin Rheumatol $\underline{26}, 17-23$

Janket S, Baird AE, Chuang S, Jones JA (2003):

Meta-analysis of periodontal disease and risk of coronary heart disease and stroke. Oral Surg Oral Med Oral Pathol Oral Radiol Endod $\underline{95}$, 559-569

Jansson L, Lavstedt S, Frithiof L, Theobald H (2001):

Relationship between oral health and mortality in cardiovascular diseases.

J Clin Periodontol $\underline{28}, 762-768$

Johnsen AK, Plenge RM, Butty V, Campbell C, Dieguez-Gonzalez R, GomezReino JJ, Shadick N, Weinblatt M, Gonzalez A, Gregersen PK et al. (2008):

A broad analysis of IL1 polymorphism and rheumatoid arthritis.

Arthritis Rheum $\underline{58}, 1947-1957$

Joshipura KJ, Rimm EB, Douglass CW, Trichopoulos D, Ascherio A, Willett WC (1996):

Poor oral health and coronary heart disease.

J Dent Res $\underline{75}$, 1631-1636

Kaarela K (1985):

Prognostic factors and diagnostic criteria in early rheumatoid arthritis.

Scand J Rheumatol Suppl $\underline{57}, 1-54$

Kazor CE, Mitchell PM, Lee AM, Stokes LN, Loesche WJ, Dewhirst FE, Paster BJ (2003):

Diversity of bacterial populations on the tongue dorsa of patients with halitosis and healthy patients.

J Clin Microbiol 41, 558-563

Kinane DF, Hart TC (2003):

Genes and gene polymorphisms associated with periodontal disease.

Crit Rev Oral Biol Med 14, 430-449 
Kinane DF, Lappin DF (2001):

Clinical, pathological and immunological aspects of periodontal disease.

Acta Odontol Scand $\underline{59}, 154-160$

Klareskog L, van der Heijde D, Jager JP de, Gough A, Kalden J, Malaise M, Martín Mola E, Pavelka K, Sany J, Settas L et al. (2004):

Therapeutic effect of the combination of etanercept and methotrexate compared with each treatment alone in patients with rheumatoid arthritis: double-blind randomised controlled trial.

Lancet $\underline{363}, 675-681$

Klareskog L, Stolt P, Lundberg K, Källberg H, Bengtsson C, Grunewald J, Rönnelid J, Harris HE, Ulfgren A, Rantapää-Dahlqvist S et al. (2006):

A new model for an etiology of rheumatoid arthritis: smoking may trigger HLA-DR (shared epitope)-restricted immune reactions to autoantigens modified by citrullination.

Arthritis Rheum $\underline{54}, 38-46$

Kleber BM:

Parodontologie - Kompendium für Studierende und Zahnärzte;

Deutscher Ärzteverlag, Köln1998

\section{Kleber BM:}

Parodontologie - ein Leitfaden für die Praxis;

WM-Colleg, Aalen 2000

Kobayashi T, Ito S, Kuroda T, Yamamoto K, Sugita N, Narita I, Sumida T, Gejyo F, Yoshie H (2007):

The interleukin-1 and Fcgamma receptor gene polymorphisms in Japanese patients with rheumatoid arthritis and periodontitis.

J Periodontol $\underline{78}, 2311-2318$

Kohal RJ, Dennison DK (2000):

Neue Paradigmen in der Pathogenese parodontaler Erkrankungen.

Dtsch Zahnarztl Z $\underline{55}$, 660-666

Kornman KS, Crane A, Wang HY, Di Giovine FS, Newman MG, Pirk FW, Wilson TG, Higginbottom FL, Duff GW (1997):

interleukin-1 genotype as a severity factor in adult periodontal disease.

$\mathrm{J}$ Clin Periodontol 24, 72-77

Larsen A (1973):

Radiological grading of rheumatoid arthritis: an interobserver study.

Scand J Rheumatol, 2, 136-138

Lee $\mathbf{H}$, Irigoyen P, Kern M, Lee A, Batliwalla F, Khalili H, Wolfe F, Lum RF, Massarotti E, Weisman M et al. (2007):

Interaction between smoking, the shared epitope, and anti-cyclic citrullinated peptide: a mixed picture in three large North American rheumatoid arthritis cohorts.

Arthritis Rheum $\underline{56}, 1745-1753$ 
Liao F, Li Z, Wang Y, Shi B, Gong Z, Cheng X (2009):

Porphyromonas gingivalis may play an important role in the pathogenesis of periodontitis-associated rheumatoid arthritis.

Med Hypotheses $\underline{72}, 732-735$

\section{Lindhe J:}

Klinische Parodontologie;

Georg-Thieme-Verlag, Stuttgart 1986, 125-157

Listgarten MA (1986):

Pathogenesis of periodontitis.

J Clin Periodontol 13, $418-430$

Listgarten MA (1987):

Nature of periodontal diseases: pathogenic mechanisms.

J Periodont Res 22, 172-178

Lockhart PB, Brennan MT, Thornhill M, Michalowicz BS, Noll J, BahraniMougeot FK, Sasser HC (2009):

Poor oral hygiene as a risk factor for infective endocarditis-related bacteremia.

J Am Dent Assoc 140, 1238-1244

Löe, H.; Anerud, A.; Boysen, H. (1992):

The natural history of periodontal disease in man: prevalence, severity, and extent of gingival recession.

J Periodontol $\underline{63}, 489-495$

Loos BG (2005):

Systemic markers of inflammation in periodontitis.

J Periodontol $\underline{76}, 2106-2115$

López NJ, Jara L, Valenzuela CY (2005):

Association of interleukin-1 polymorphisms with periodontal disease.

J Periodontol $\underline{76}$, 234-243

\section{Lu J, Zhang W, Hao Y, Zhu Y (2009):}

Defect of cell wall construction may shield oral bacteria's survival in bloodstream and cause infective endocarditis.

Med Hypotheses $\underline{73}$, 1055-1057

Malthaner SC, Moore S, Mills M, Saad R, Sabatini R, Takacs V, McMahan AC, Oates TW (2002):

Investigation of the association between angiographically defined coronary artery disease and periodontal disease.

J Periodontol 73, 1169-1176

Maradit-Kremers H, Nicola PJ, Crowson CS, Ballman KV, Gabriel SE (2005): Cardiovascular death in rheumatoid arthritis: a population-based study.

Arthritis Rheum $\underline{52}, 722-732$ 
Marinou I, Walters K, Dickson MC, Binks MH, Bax DE, Wilson AG (2009):

Evidence of epistasis between interleukin 1 and selenoprotein-S with susceptibility to rheumatoid arthritis.

Ann Rheum Dis $\underline{68}, 1494-1497$

Martin T, Crouzier R, Weber JC, Kipps TJ, Pasquali JL (1994):

Structure-function studies on a polyreactive (natural) autoantibody. Polyreactivity is dependent on somatically generated sequences in the third complementaritydetermining region of the antibody heavy chain.

J Immonol 152, 5988-5996

Martinez-Martinez RE, Abud-Mendoza C, Patiño-Marin N, Rizo-Rodríguez JC, Little JW, Loyola-Rodríguez JP (2009):

Detection of periodontal bacterial DNA in serum and synovial fluid in refractory rheumatoid arthritis patients.

J Clin Periodontol $\underline{36}, 1004-1010$

Mathur A, Michalowicz B, Yang C, Aeppli D (1995):

Influence of periodontal bacteria and disease status on $\mathrm{V}$ beta expression in $\mathrm{T}$ cells. J Periodont Res $\underline{30}$, 369-373

Mattila KJ, Nieminen MS, Valtonen VV, Rasi VP, Kesäniemi YA, Syrjälä SL, Jungell PS, Isoluoma M, Hietaniemi K, Jokinen MJ (1989):

Association between dental health and acute myocardial infarction.

BMJ $\underline{298}, 779-781$

Mattila KJ, Valtonen VV, Nieminen M, Huttunen JK (1995):

Dental infection and the risk of new coronary events: prospective study of patients with documented coronary artery disease.

Clin Infect Dis 20, 588-592

Mattila KJ, Asikainen S, Wolf J, Jousimies-Somer H, Valtonen V, Nieminen M (2000):

Age, dental infections, and coronary heart disease.

J Dent Res $\underline{79}, 756-760$

McDevitt MJ, Wang HY, Knobelman C, Newman MG, Di Giovine FS, Timms J, Duff GW, Kornman KS (2000):

Interleukin-1 genetic association with periodontitis in clinical practice.

J Periodontol $\underline{71}, 156-163$

McGraw WT, Potempa J, Farley D, Travis J (1999):

Purification, characterization, and sequence analysis of a potential virulence factor from Porphyromonas gingivalis, peptidylarginine deiminase.

Infect Immun 67, 3248-3256

Mealey BL, Oates TW (2006):

Diabetes mellitus and periodontal diseases.

J Periodontol $\underline{77}, 1289-1303$ 
Mercado F, Marshall RI, Klestov AC, Bartold PM (2000):

Is there a relationship between rheumatoid arthritis and periodontal disease?

J Clin Periodontol 27, 267-272

Mercado FB, Marshall RI, Klestov AC, Bartold PM (2001):

Relationship between rheumatoid arthritis and periodontitis.

J Periodontol $\underline{72}, 779-787$

Mercado FB, Marshall RI, Bartold PM (2003):

Inter-relationships between rheumatoid arthritis and periodontal disease. A review. J Clin Periodontol $\underline{30}, 761-772$

Mewar D, Coote A, Moore DJ, Marinou I, Keyworth J, Dickson MC, Montgomery DS, Binks MH, Wilson AG (2006):

Independent associations of anti-cyclic citrullinated peptide antibodies and rheumatoid factor with radiographic severity of rheumatoid arthritis.

Arthritis Res Ther $\underline{8}, \mathrm{R} 128$

Micheelis W, Schiffner U:

Vierte Deutsche Mundgesundheitsstudie (DMS IV). Institut der Deutschen

Zahnärzte (Band 31);

Deutscher Ärzte-Verlag, Köln 2006

Mikuls TR, Payne JB, Reinhardt RA, Thiele GM, Maziarz E, Cannella AC, Holers VM, Kuhn KA, O'Dell JR (2009):

Antibody responses to Porphyromonas gingivalis (P. gingivalis) in subjects with rheumatoid arthritis and periodontitis.

Int Immunopharmacol $\underline{9}, 38-42$

Miller DR, Lamster IB, Chasens Al (1984):

Role of the polymorphonuclear leukocyte in periodontal health and disease.

J Clin Periodontol 11, 1-15

Moen K, Brun JG, Madland TM, Tynning T, Jonsson R (2003):

Immunoglobulin $G$ and $A$ antibody responses to Bacteroides forsythus and

Prevotella intermedia in sera and synovial fluids of arthritis patients.

Clin Diagn Lab Immunol 10, 1043-1050

Moen K, Brun JG, Valen M, Skartveit L, Eribe EK, Olsen I, Jonsson R (2006): Synovial inflammation in active rheumatoid arthritis and psoriatic arthritis facilitates trapping of a variety of oral bacterial DNAs.

Clin Exp Rheumatol 24, 656-663

Molitor JA, Alonso A, Wener MH, Michalowicz BS, Beck J, Gersuk VH, Buckner JH (2009): Moderate to severe adult periodontitis increases risk of rheumatoid arthritis in nin-smokers and is associated with elevated ACPA titers: the ARIC study. Arthritis Rheumatol $\underline{60}, 16-21$, (Abstract \#10)

Mombelli A (2003):

Periodontitis as an infectious disease: specific features and their implications.

Oral Dis $\underline{9}, 6-10$ 
Moore WE, Holdeman LV, Smibert RM, Good IJ, Burmeister JA, Palcanis KG, Ranney RR (1982):

Bacteriology of experimental gingivitis in young adult humans.

Infect Immun 38, 651-667

Müller HP (2002):

Myokardinfarkt, Schlaganfall und Parodontitis.

Der freie Zahnarzt $\underline{6}, 47-52$

Mutschelknauss R:

Lehrbuch der klinischen Parodontologie:

Quintessenz, Berlin 2000

Netuschil L :

Mikrobiologie und Biochemie der Zahnplaque und des Zahnsteins; in: Zahn-, Mund-, Kieferheilkunde - Konservierende Zahnheilkunde und Parodontologie:

Georg-Thieme-Verlag, Stuttgart 2005, 260-262

\section{Newkirk MM (2002):}

Rheumatoid factors: host resistance or autoimmunity?

Clin Immunol $\underline{104}, 1-13$

Niederman R, Brunkhorst B, Smith S, Weinreb R, Ryder MI (1990):

Ammonia as a potential mediator of adult human periodontal infection: Inhibition of neutrophil function.

Arch Oral Biol 35, 205-209

Offenbacher S, Katz V, Fertik G, Collins J, Boyd D, Maynor G, McKaig R, Beck J (1996):

Periodontal infection as a possible risk factor for preterm low birth weight.

J Periodontol $\underline{67}, 1103-1113$

Ogrendik M, Kokino S, Ozdemir F, Bird PS, Hamlet S (2005):

Serum antibodies to oral anaerobic bacteria in patients with rheumatoid arthritis. Med Gen Med 7, 2

Oliver RC, Brown LJ, Löe H (1998):

Periodontal diseases in the United States population.

J Periodontol $\underline{69}$, 269-278

Ortiz P, Bissada NF, Palomo L, Han YW, Al-Zahrani MS, Panneerselvam A, Askari A (2009):

Periodontal therapy reduces the severity of active rheumatoid arthritis in patients treated with or without tumor necrosis factor inhibitors.

J Periodontol $\underline{80}, 535-540$

Østergaard M, Ejbjerg B, Szkudlarek M (2005):

Imaging in early rheumatoid arthritis: roles of magnetic resonance imaging, ultrasonography, conventional radiography and computed tomography.

Best Pract Res Clin Rheumatol 19, 91-116 
Page RC (1991):

The role of inflammatory mediators in the pathogenesis of periodontal disease. J Periodont Res 26, 230-242

Page RC (1999):

Milestones in periodontal research and the remaining critical issues.

J Periodont Res $\underline{34}$, 331-339

\section{Page RC, Schroeder HE (1976):}

Pathogenesis of inflammatory periodontal disease. A summary of current work. Lab Invest $\underline{34}$, 235-249

Page RC, Kornman KS (1997):

The pathogenesis of human periodontitis: an introduction.

Periodontol $2000 \underline{14}, 9-11$

Persson GR, Persson RE (2008):

Cardiovascular disease and periodontitis: an update on the associations and risk. J Clin Periodontol $\underline{35}$, 362-379

Petersen PE (2003):

The World Oral Health Report 2003: continuous improvement of oral health in the 21st century--the approach of the WHO Global Oral Health Programme.

Community Dent Oral Epidemiol 31, 3-23

Petersen PE (2009):

Global policy for improvement of oral health in the 21st century--implications to oral health research of World Health Assembly 2007, World Health Organization. Community Dent Oral Epidemiol 37, 1-8

Pinson M, Hoffman WH, Garnick JJ, Litaker MS (1995):

Periodontal disease and type I diabetes mellitus in children and adolescents.

J Clin Periodontol 22, 118-123

Pischon N, Pischon T, Kröger J, Gülmez E, Kleber B, Bernimoulin J, Landau H, Brinkmann P, Schlattmann P, Zernicke J et al. (2008):

Association among rheumatoid arthritis, oral hygiene, and periodontitis.

J Periodontol $\underline{79}$, 979-986

Pischon N, Pischon T, Gülmez E, Kröger J, Purucker P, Kleber B, Landau H, Jost-Brinkmann P, Schlattmann P, Zernicke J et al. (2010):

Periodontal disease in patients with ankylosing spondylitis.

Ann Rheum Dis $\underline{69}$, 34-38

Pitiphat W, Joshipura KJ, Gillman MW, Williams PL, Douglass CW, RichEdwards JW (2008):

Maternal periodontitis and adverse pregnancy outcomes.

Community Dent Oral Epidemiol 36, 3-11 
Potempa J, Banbula A, Travis J (2000):

Role of bacterial proteinases in matrix destruction and modulation of host responses. Periodontol $2000 \underline{24}, 153-192$

Pussinen PJ, Alfthan G, Tuomilehto J, Asikainen S, Jousilahti P (2004):

High serum antibody levels to Porphyromonas gingivalis predict myocardial infarction.

Eur J Cardiovasc Prev Rehabil 11, 408-411

Rantapää-Dahlqvist S, Jong BAW de, Berglin E, Hallmans G, Wadell G, Stenlund H, Sundin U, van Venrooij WJ (2003):

Antibodies against cyclic citrullinated peptide and $\lg A$ rheumatoid factor predict the development of rheumatoid arthritis.

Arthritis Rheum $\underline{48}$, 2741-2749

Rateitschak KH, Rateitschak EM, Wolf HF:

Farbatlanten der Zahnmedizin - Parodontologie (Band 1), 2. Auflage

Georg-Thieme-Verlag, Stuttgart 1989

Renggli HH (1977):

Crevicular leukocytes and immunology.

Rev Odontostomatol (Paris) $\underline{6}$, 349-351

Riede U:

Allgemeine und spezielle Pathologie. 2 Auflage.

Georg-Thieme-Verlag, Stuttgart: 1989

Rönnelid J, Lysholm J, Engström-Laurent A, Klareskog L, Heyman B (1994): Local anti-type II collagen antibody production in rheumatoid arthritis synovial fluid. Evidence for an HLA-DR4-restricted IgG response.

Arthritis Rheum 37, 1023-1029

Rosenstein ED, Greenwald RA, Kushner LJ, Weissmann G (2004):

Hypothesis: the humoral immune response to oral bacteria provides a stimulus for the development of rheumatoid arthritis.

Inflammation 28, 311-318

Ruddle NH (1992):

Tumor necrosis factor (TNF-alpha) and lymphotoxin (TNF-beta).

Curr Opin Immunol 4, 327-332

Saglie FR, Marfany A, Camargo P (1988):

Intragingival occurrence of Actinobacillus actinomycetemcomitans and

Bacteroides gingivalis in active destructive periodontal lesions.

J Periodontol $\underline{59}, 259-265$

Salvi GE, Lawrence HP, Offenbacher S, Beck JD (1997):

Influence of risk factors on the pathogenesis of periodontitis.

Periodontol 2000 14, 173-201 
Sanderink RB, Bernhardt H, Knoke M, Meyer J, Weber C, Weiger R:

Curriculum Orale Mikrobiologie und Immunologie;

Quintessenz, Berlin 2004

Saraux A, Berthelot JM, Chalès G, Le Henaff C, Mary JY, Thorel JB, Hoang S, Dueymes M, Allain J, Devauchelle V et al. (2002):

Value of laboratory tests in early prediction of rheumatoid arthritis.

Arthritis Rheum 47, 155-165

Scannapieco FA (1998):

Position paper of The American Academy of Periodontology: periodontal disease as a potential risk factor for systemic diseases.

J Periodontol $\underline{69}$, 841-850

Schätzle M, Löe H, Bürgin W, Anerud A, Boysen H, Lang NP (2003):

Clinical course of chronic periodontitis. I. Role of gingivitis.

J Clin Periodontol $\underline{30}$, 887-901

Schellekens GA, Jong BA de, van den Hoogen FH, van de Putte LB, van Venrooij WJ (1998):

Citrulline is an essential constituent of antigenic determinants recognized by rheumatoid arthritis-specific autoantibodies.

J Clin Invest 101, 273-281

Schellekens GA, Visser H, Jong BA de, van den Hoogen FH, Hazes JM, Breedveld FC, van Venrooij WJ (2000):

The diagnostic properties of rheumatoid arthritis antibodies recognizing a cyclic citrullinated peptide.

Arthritis Rheum $\underline{43}, 155-163$

Schroeder HE:

Pathobiologie oraler Strukturen: Zähne, Pulpa, Parodont; 3. Auflage;

Karger-Verlag, Basel 1997

\section{Schroeder HE:}

Orale Strukturbiologie; 5. Auflage;

Georg-Thieme-Verlag, Stuttgart 2000

\section{Schroeder HE, Attström R:}

Pocket formation: An Hypothestis; in: The borderland between caries and periodontal disease, hrsg. Lehner T, Cimasoni G u.a.;

Brune \& Stratton Press, London 1980, 99-123

Seymour GJ (1991):

Importance of the host response in the periodontium.

J Clin Periodontol $\underline{18}, 421-426$

Seymour GJ, Ford PJ, Cullinan MP, Leishman S, Yamazaki K (2007):

Relationship between periodontal infections and systemic disease.

Clin Microbiol Infect 13 Suppl 4, 3-10 
Slots J (1986):

Bacterial specificity in adult periodontitis. A summary of recent work.

J Clin Periodontol 13, 912-917

Slots J (2003):

Update on general health risk of periodontal disease.

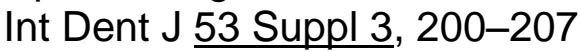

\section{Slots J, Genco RJ (1984):}

Mircrobial pathogenity. Black pigmented bacteroides species, capnocytophaga species, andactinobacillus actinomycetemcomitans in human periodontal disease: Virulence factors in colonization, survival, and tissue destruction.

J Dent Res $\underline{63}, 412-421$

Slots J, Rams TE:

Microbiology of periodontal disease. In: Slots J und Taubmann M: Contemporary Oral Microbiology and Immunology,

Mosby-Year Book, St. Louis: 1992, 428-430

\section{Socransky SS (1979):}

Criteria for the infectious agents in dental caries and periodontal disease.

J Clin Periodontol $\underline{6}, 16-21$

Socransky SS, Haffajee AD (1992):

The bacterial etiology of destructive periodontal disease: current concepts.

J Periodontol $\underline{63}, 322-331$

Socransky SS, Haffajee AD (2002):

Dental biofilms: difficult therapeutic targets.

Periodontol $2000 \underline{28}, 12-55$

Socransky SS, Haffajee AD, Cugini MA, Smith C, Kent RL (1998):

Microbial complexes in subgingival plaque.

J Clin Periodontol 25, 134-144

Socransky SS, Smith C, Haffajee AD (2002):

Subgingival microbial profiles in refractory periodontal disease.

J Clin Periodontol 29, 260-268

\section{Strunk J, Lange U, Müller-Ladner U (2005):}

Rheumatoid arthritis.

Dtsch Med Wochenschr 풍, 1761-1768

Syrjänen J, Peltola J, Valtonen V, livanainen M, Kaste M, Huttunen JK (1989): Dental infections in association with cerebral infarction in young and middle-aged men.

J Intern Med 225, 179-184 
Tabrizi F, Buhlin K, Gustafsson A, Klinge B (2007):

Oral health of monozygotic twins with and without coronary heart disease: a pilot study.

J Clin Periodontol 34, 220-225

Tesmer LA, Lundy SK, Sarkar S, Fox DA (2008):

Th17 cells in human disease.

Immunol Rev $\underline{223}$, 87-113

Thé J, Ebersole JL (1996):

Rheumatoid factor from periodontitis patients cross-reacts with epitopes on oral bacteria.

Oral Dis $\underline{2}, 253-262$

Theilade E (1986):

The non-specific theory in microbial etiology of inflammatory periodontal diseases.

J Clin Periodontol $\underline{13}$, 905-911

\section{Thomas L, Abdelhamid S:}

Labor und Diagnose. Indikation und Bewertung von Laborbefunden für die medizinische Diagnostik; 3. Auflage;

Medizinische Verlagsgesellschaft, Marburg Lahn 1988

Tonetti MS (2009):

Periodontitis and risk for atherosclerosis: an update on intervention trials.

J Clin Periodontol $\underline{36}, 15-19$

Tonetti MS, Claffey N (2005):

Advances in the progression of periodontitis and proposal of definitions of a periodontitis case and disease progression for use in risk factor research. Group C consensus report of the 5th European Workshop in Periodontology.

J Clin Periodontol, $\underline{32}, 210-213$

Tonetti MS, D'Aiuto F, Nibali L, Donald A, Storry C, Parkar M, Suvan J, Hingorani AD, Vallance P, Deanfield J (2007):

Treatment of periodontitis and endothelial function.

N Engl J Med 356, 911-920

Tuominen R, Reunanen A, Paunio M, Paunio I, Aromaa A (2003):

Oral health indicators poorly predict coronary heart disease deaths.

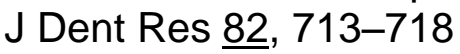

Turesson C, Jacobsson LTH (2004):

Epidemiology of extra-articular manifestations in rheumatoid arthritis.

Scand J Rheumatol $\underline{33}$, 65-72 
Turesson C, Schaid DJ, Weyand CM, Jacobsson LTH, Goronzy JJ, Petersson IF, Sturfelt G, Nyhäll-Wåhlin B, Truedsson L, Dechant SA et al. (2005):

The impact of HLA-DRB1 genes on extra-articular disease manifestations in rheumatoid arthritis.

Arthritis Res Ther $\underline{7}, 1386-93$

van den Berg WB (2000):

Arguments for interleukin 1 as a target in chronic arthritis.

Ann Rheum Dis $\underline{59}, 81-84$

van der Heijde D, Landewé R, Klareskog L, Rodríguez-Valverde V, Settas L, Pedersen R, Fatenejad S (2005):

Presentation and analysis of data on radiographic outcome in clinical trials: experience from the TEMPO study.

Arthritis Rheum $\underline{52}, 49-60$

van der Helm-van Mil AHM, Verpoort KN, Breedveld FC, Toes REM, Huizinga TWJ (2005):

Antibodies to citrullinated proteins and differences in clinical progression of rheumatoid arthritis.

Arthritis Res Ther $\underline{7}$, R949-58

van der Helm-van Mil AHM, Verpoort KN, Le Cessie S, Huizinga TWJ, Vries RRP de, Toes REM (2007):

The HLA-DRB1 shared epitope alleles differ in the interaction with smoking and predisposition to antibodies to cyclic citrullinated peptide.

Arthritis Rheum $\underline{56}$, 425-432

van Dyke TE (1984):

Role of the neutrophil in oral disease: receptor deficiency in leukocytes from patients with juvenile periodontitis.

Rev Infect Dis $\underline{7}, 419-425$

van Palenstein Helderman WH (1981):

Microbial etiology of periodontal disease.

$\mathrm{J}$ Clin Periodontol $\underline{8}, 261-280$

van Snick J (1990):

Interleukin-6: an overview.

Annu Rev Immunol $\underline{8}$, 253-278

van Winkelhoff AJ, van Steenbergen TJ, Graaff J de (1988):

The role of black-pigmented Bacteroides in human oral infections.

J Clin Periodontol 15, 145-155 
Verpoort KN, Papendrecht-van der Voort EAM, van der Helm-van Mil AHM, Jol-van der Zijde CM, van Tol MJD, Drijfhout JW, Breedveld FC, Vries RRP de, Huizinga TWJ, Toes REM (2007):

Association of smoking with the constitution of the anti-cyclic citrullinated peptide response in the absence of HLA-DRB1 shared epitope alleles.

Arthritis Rheum $\underline{56}$, 2913-2918

Vilcek J, Lee TH (1991):

Tumor necrosis factor. New insights into the molecular mechanisms of its multiple actions.

J Biol Chem 266, 7313-7316

\section{Villiger PM, BrühImann P:}

Rheumatoide Arthritis; in: Innere Medizin; hrsg. Alexander K, Daniel WG u. a.;

Georg-Thieme-Verlag, Stuttgart 1999, 1622-1631

Weissmann G (2004):

Pathogenesis of rheumatoid arthritis.

J Clin Rheumatol 10, S26-31

WHO (World Health Organization):

Oral health surveys. Basic methods.

World Health Organization, Genf 1997

Ximénez-Fyvie LA, Haffajee AD, Socransky SS (2000):

Microbial composition of supra- and subgingival plaque in subjects with adult periodontitis.

J Clin Periodontol 27, 722-732

Yamamoto K, Yamada R (2007):

Lessons from a genomewide association study of rheumatoid arthritis.

N Engl J Med 357, 1250-1251

Yang HW, Asikainen S, Doğan B, Suda R, Lai CH (2004):

Relationship of Actinobacillus actinomycetemcomitans serotype $b$ to aggressive periodontitis: frequency in pure cultured isolates.

J Periodontol $\underline{75}, 592-599$

Yoshida A, Nakano Y, Yamashita Y, Oho T, Ito H, Kondo M, Ohishi M, Koga T (2001):

Immunodominant region of Actinobacillus actinomycetemcomitans 40-kilodalton heat shock protein in patients with rheumatoid arthritis.

J Dent Res 80, 346-350 


\section{Danksagung}

An dieser Stelle möchte ich Allen, die mich bei der Erstellung dieser Arbeit unterstützt haben, nochmals herzlich danken.

Mein besonderer Dank gilt:

Prof. Dr. R. F. Mausberg für die freundliche Überlassung und die gute Betreuung dieser Arbeit

Dr. D. Ziebolz für unermüdliche Tatkraft bei der Betreuung und der Durchsicht der Arbeit

Dr. B. Krohn-Grimberghe für die freundliche Unterstützung im Rahmen der Patientenuntersuchung und die fachliche Beratung

Dr. K. Lange aus der Abteilung Medizinische Statistik der Universitätsmedizin Göttingen für die Unterstützung bei der statistischen Auswertung der Daten

den Patienten der Rheumaklinik Bad Wildungen für ihre freiwillige Teilnahme an der Untersuchung. 